\title{
LANDFILL OPERATION FOR CARBON SEQUESTRATION AND MAXIMUM METHANE EMISSION CONTROL
}

Cost-effectiveness and potential: Controlled landfilling for greenhouse gas abatement.

\author{
Phase II Topical Report (Draft)
}

Reporting Period: July 15, 1998 to January 15, 1999

$$
\text { Prepared by }
$$

Institute for Environmental Management 4277 Pomona Avenue

Palo Alto, CA 94306

Don Augenstein, Principal Author

Contract DE-AC26-98FT40422

Date of Issue: January 11, 1999 


\section{Disclaimer}

This report was prepared as an account of work sponsored by an agency of the US Government. Neither the United States Government, nor any agency thereof, nor any of their employees, makes any warranty, express or implied, or assumes any legal liability or responsibility for the accuracy, completeness, or usefulness of any information, apparatus, product or process disclosed, or represents that its use would not infringe privately owned rights. Reference herein to any specific commercial product, process, or service by trade name, trademark, manufacturer or otherwise does not necessarily constitute or imply its endorsement, recommendation or favoring by the United States Government or any agency thereof. The views and opinions of authors expressed herein do not necessarily state or reflect the views of the United States Government or any agency thereof.

This report is available to the public from the National Technical Information Service, U.S. Department of Commerce, 5285 Port Royal Road, Springfield, VA 22161; phone orders accepted at (703) 487-4650. 


\section{DISCLAIMER}

Portions of this document may be illegible in electronic image products. Images are produced from the best available original document. 


\section{ABSTRACT}

"Conventional" waste landfills emit methane, a potent greenhouse gas, in quantities such that landfill methane is a major factor in global climate change. Controlled landfilling is a novel approach to manage landfills for rapid completion of total gas generation, maximizing gas capture and minimizing emissions of methane to the atmosphere. With controlled landfilling, methane generation is accelerated and brought to much earlier completion by improving conditions for biological processes (principally moisture levels) in the landfill. Gas recovery efficiency approaches $100 \%$ through use of surface membrane cover over porous gas recovery layers operated at slight vacuum. A field demonstration project's results at the Yolo County Central Landfill near Davis, California are, to date, highly encouraging. Two major controlled landfilling benefits would be the reduction of landfill methane emissions to minuscule levels, and the recovery of greater amounts of landfill methane energy in much shorter times than with conventional landfill practice. With the large amount of US landfill methane generated, and greenhouse potency of methane, better landfill methane control can play a substantial role in reduction of US greenhouse gas emissions.

This work, part of an ongoing project to advance this technology, has analyzed "greenhouse cost effectiveness" for a controlled landfill of size (1000TPD waste inflow) representative of typical modern landfill sizes in the US. A controlled landfill module was compared to (1) a landfill module with no controls and (2) a landfill module whose gas is extracted by conventional technology as presently applied under New Source Performance Standards. Marginal costs per marginal unit $\mathrm{CO}_{2}$ abatement and marginal costs per marginal unit methane recovery were calculated using discounted cash flow analysis at $0 \% 7 \%$ and $15 \%$. Design assumptions and performance were based on standard Subtitle $\mathrm{D}$ landfill design specifications and approaches used in the successful demonstration now ongoing in Yolo County, California. $\mathrm{CO}_{2}$ abatement costs of $\$ 1-\$ 5 /$ tonne were obtained for the range of discount rates for both bases of comparison. Raw methane costs ranged from $\$ 0.41$ to $\$ 0.74 / \mathrm{MCF}$. Both the calculated $\mathrm{CO}_{2}$ abatement costs and landfill methane energy costs are attractive by extant standards.

Federal and state policies are in general developing positively, toward acceptance of "bioreactor" and this controlled landfill technology. A present lack of incentives for greenhouse gas abatement, combined with low energy prices limit implementation of the technology. However there are several initiatives toward realizing such incentives.

The potential for methane abatement for the US as a whole has been estimated at $\approx 80$ million tonnes/year. Given uncertainties inherent in any such estimates, the likely greenhouse gas reduction potential is 50-100 million tonnes/ year, amounting to about 1$2 \%$ of total fossil $\mathrm{CO}_{2}$ emission for the United States. Altogether, it appears that controlled landfilling offers one attractive future option for the United States to meet a significant portion of its greenhouse gas reduction targets. 


\section{ACKNOWLEDGMENTS}

IEM and the author acknowledge the considerable help and support of the following, and their contributions:

Sean Plasynski, of the Federal Energy Technology Center (FETC) for guidance and consultation during preparation of this report.

Vicky Shears, of the Federal Energy Technology Center (FETC) for guidance and consultation on contract issues throughout the preparation of this report.

Ramin Yazdani, Director of the Yolo County, California Department of Solid Waste and Planning. For all his work critical to success of this project, since his beginning as a new Yolo County employee. His work has included contributions in instrumentation, construction management, and other areas--too many to mention here. He is thanked for his recent expert review of this report.

To Karina Dahl, Civil Engineer for Yolo County for her contribution to success of this project in managing the demonstration field operations for the last three years and her recent expert review of the report.

To Rick Moore, formerly of Yolo County who contributed in ways too numerous to mention to all phases of the demonstration

To W. Greg Vogt, Vice President, SCS Engineers for his contributions beginning with discussions of controlled landfilling as greenhouse gas mitigation technology, and most recently with his help as part of SCS Engineers' review of the report. 


\section{CONTENTS}

\section{PAGE}

DISCLAIMER

i

ABSTRACT ii

ACKNOWLEDGMENTS iii

LIST OF FIGURES $\quad$ vi

LIST OF TABLES vii

EXECUTIVE SUMMARY 1

INTRODUCTION AND BACKGROUND $\quad 5$

COST ANALYSIS: PURPOSE AND APPROACH $\quad \cdot \quad 17$

$\begin{array}{ll}\text { BASE CASE COST EVALUATION } & 19\end{array}$

Controlled landfill operational and other factors $\quad 20$

$\begin{array}{ll}\text { Timing of liquids addition } & 20\end{array}$

Landfill design and landfill geometry 23

CAPITAL AND OPERATING COSTS 26

$\begin{array}{ll}\text { CAPITAL COSTS } & 26\end{array}$

Surface geomembrane lining $\quad 28$

$\begin{array}{ll}\text { Porous gas collection layer } & 28\end{array}$

$\begin{array}{ll}\text { System for liquid delivery } & 29\end{array}$

Overview of liquid addition $\quad 29$

$\begin{array}{ll}\text { Other equipment } & 36\end{array}$

GRENHOUSE GAS ABATEMENT COSTS 43

-Greenhouse emission comparisons: conventional, controlled, and uncontrolled "base cases" $\quad 46$

-Economic analyses: greenhouse cost effectiveness 46 
-Greenhouse gas abatement cost vs. inflow and waste depth

-Controlled landfilling of decomposable organics only

-Effect of increased containment costs

EVALUATION OF METHANE COST: $\quad 57$

-Controlled landfilling versus absence of controls

-Incremental gas cost: controlled landfilling versus same landfill with NSPS controls

-METHANE COST SENSITIVITY ANALYSES

61

-Methane cost vs. inflow and waste depth

61

-Controlled landfilling of decomposable organics only

62

-Cost of other pretreatments --shredding and breaking bags

63

-Cost effects of "double" base liner

SUMMARY AND CONCLUSIONS:

CO2 ABATEMENT AND METHANE COSTS

CURRENT REGULATIONS AND POLICY RELATING

TO CONTROLLED LANDFILLS

POTENTIAL MAGNITUDE OF GREENHOUSE GAS

ABATEMENT BENEFITS FROM CONTROLLED

LANDFILLING FOR THE UNITED STATES

CONCLUSIONS

REFERENCES

APPENDICES 


\section{List of Figures}

Figure

Title

Page

1

Methane production rate versus moisture content

10

2

Arrhenius Plot Showing dependence of rate on temperature

for methane fermentations of solid substrates

3. Oblique (Isometric) view of enhanced and control cells

14

4.

Cumulative landfill gas for the enhanced and control cells

Schematic of gas withdrawal from base layer

6.

Vertical cross section of typical cut-and-fill landfill 


\section{LIST OF TABLES}

Table number

Title

Page

1

Summary of Incremental 1000 TPD Controlled

42

Landfill Component Costs per Module: Comparison

Bases, no Controls and NSPS Controls

2

Calculation of total equivalent fossil $\mathrm{CO} 2$ abatement

and cost: base case 1000TPD controlled landfill

3

Incremental Capital Costs of Controlled Landfilling

53

with Size Doubled vs. "Base Case"

Total equivalent fossil $\mathrm{CO} 2$ abatement and cost:

Calculation for 2000 TPD controlled landfill module and comparison with 1000 TPD module

Comparative costs of $\mathrm{CO} 2$ abatement for base case 1000 ton/day landfill: Single vs. double base liner.

Calculated gas costs for controlled landfilling: Base case, 1000 TPD

Calculated gas costs for controlled landfilling with double base geomembrane (see text) 


\section{EXECUTIVE SUMMARY}

"Conventional" sanitary landfills emit substantial quantities of methane to the atmosphere. Such methane emission ("fugitive" methane) is substantial even though landfills may be equipped with gas controls mandated under regulations. The fugitive landfill methane emissions are in part due to inefficiency of conventional collection systems, and partly due to the several-decades-long term of methane generation. Methane generated at long terms is often not easily controlled in conventional landfill operation Methane is a very potent greenhouse gas, and emitted landfill methane is documented in many studies as highly significant to climate change.

An approach to give more complete control of landfill methane emissions, ("controlled landfilling"), is under intensive investigation at the Yolo County Central Landfill near Davis, CA. This approach combines (a) improved biological conditions to speed methane generation to rapid completion and maximum potential yield with (b) complete collection of generated gas, through use of membrane cover over a permeable surface gas collection layer. This approach can both reduce methane emissions to near-negligible levels, and also provide fossil fuel offsets through energy use of additional captured methane. The field demonstration, progressing well to date, indicates these objectives can be met.

The purpose of this report, supported by the Federal Energy Technology Center (FETC) is to carry out additional work to assess controlled landfilling. The overall objectives include (a) more detailed economic analysis of the controlled landfilling approach from standpoints of greenhouse gas mitigation and energy and (b) maintaining field demonstration operations and measurements to an endpoint that allows process projections as accurately as possible, and design for larger scale operation. This report comprises (a), the Phase I effort to develop a more thorough economic analysis, with outside input and review from experts experienced in landfill operations and costs.

In this work, greenhouse gas mitigation costs were estimated for a "base case" controlled landfill with specifications representative of a "typical" landfill in the US. This base case landfill receives 1000 TPD waste and is filled to final depth averaging 60 feet, with other specifications herein. Fractional mitigation of generated greenhouse gas, and marginal methane mitigation cost, were estimated for two cases, both common: The case where no controls would be required, and the case where the landfill's controls would be required under the present New Source Performance Standards ("NSPS landfill"). Incremental capital equipment and operating costs were estimated for implementing controlled landfilling for each case. Costs of equivalent $\mathrm{CO} 2$ abatement were estimated for discount rates of $0 \%, 7 \%$ APR and 15\% APR. The resultant costs are summarized in table ES-1 
Table ES-1

Costs of $\mathrm{CO} 2$ abatement for base case 1000 ton/day landfill at various discount rates.

Comparison bases: No controls and "conventional" NSPS controls

Incremental $\mathrm{CO} 2$

abatement cost vs.

no controls, \$/tonne

$d=0 \% \quad d=7 \% \quad d=15 \%$ APR

Costs for

"base case $\begin{array}{lll}1.09 & 2.08 & 3.37\end{array}$
Incremental $\mathrm{CO} 2$

abatement cost

vs. NSPS \$/tonne

$\mathrm{d}=0 \quad \mathrm{~d}=.07 \quad \mathrm{~d}=.15$

$\begin{array}{lll}1.77 & 3.08 & 5.01\end{array}$

Depending on whether conventional gas controls are otherwise required, the base case $\mathrm{CO} 2$ equivalent mitigation cost is $\$ 1-5 /$ tonne $\mathrm{CO} 2$. Such cost is very attractively low by standards of cost for other approaches to greenhouse gas mitigation. Furthermore, the calculation is conservative in assigning all controlled landfilling costs to the greenhouse gas abatement

Assuming no controls are otherwise required, the costs are sensitive to a variety of other factors. Doubling of landfill size (both inflow and depth) approximately halves cost as shown in table ES-2. On the other hand, regulators may require additional base lining which imposes very substantial capital costs in turn manifested in the increased cost shown in table ES-2. Other changes--such as removing easily separable inert material from the waste have only minor effects (not shown) on the costs.

Altogether, throughout a considerable number of possible variations in parameters, the cost of greenhouse gas abatement by controlled landfilling appears very low by extant standards and the process merits further work

It is also instructive to determine methane energy costs. If the marginal cost to implement controlled landfilling are instead assigned to recovered methane, the methane costs were found to be as shown in Table ES-3

Although landfill gas is not a perfect fuel, it is widely usable providing its characteristics are taken into account and adequate revenue obtained for the energy product. A favorable renewable energy sale price for extra energy obtained can offset part or all of controlled landfilling's costs. 


\section{Table ES-2}

Costs of $\mathrm{CO} 2$ abatement for base case 1000 ton/day landfill at discount rates. and other options (a) doubled size (b) added base lining requirement imposed

Incremental $\mathrm{CO} 2$

abatement cost vs.

no controls, \$/tonne

$d=0 \% \quad d=7 \% \quad d=15 \%$ APR

$\begin{array}{lll}1.09 & 2.08 & 3.37\end{array}$

0.603

1.163

1.910

doubled size

2000 TPD

Costs with

double liner
Incremental $\mathrm{CO} 2$

abatement cost

vs. NSPS \$/tonne

$d=0 \quad d=.07 \quad d=.15$

$\begin{array}{lll}1.77 & 3.08 & 5.01\end{array}$

$0.994 \quad 1.727 \quad 2.81$

$4.40 \quad 7.63 \quad 12.43$

Table ES-3

Calculated methane costs for controlled landfilling

Methane cost

vs. no controls,

$\$ /(\mathrm{MCF}=\mathrm{mmBtu} \cong \mathrm{Gj})$

$d=0 \quad d=7 \%$ APR $d=15 \%$ APR
Methane cost

vs. NSPS

\$MCF
$=\$ 0.413 \quad 0.533 \quad .742 / \mathrm{MCF}$
$\$ 0.458 \quad 0.419 / \mathrm{MCF} \quad .578 / \mathrm{MCF}$

$d=0$

$d=7 \%$ APR

$d=15 \%$ APR

Topical Report: Greenhouse Cost-effectiveness of Controlled Landfilling Contract DE-AC26 98FT40422 Page 3 
Regulatory and Policy Considerations

A rapidly evolving regulatory and policy situation relates importantly to controlled landfilling in several ways. Although there are variations from state to state, a Solid Waste Association of North America (SWANA) survey shows that state regulators are coming to accept bioreactor and hence controlled landfills as viable waste management options. Necessary liquids additions to landfills, previously opposed, are now interpreted as allowed as amendments under governing Federal code (40 CFR 258.28). Federal policy in the 1993 Climate Change Action Plan calls for use of bioreactor landfills as one tool to address climate change. Additional constraints, principally additional base lining, that will pose additional costs, are being required in some states.

Policy and regulatory developments that could facilitate controlled landfilling include the support of "green" renewable landfill-gas-fueled electricity with various incentives including the recently federally proposed renewables portfolio standard, and crediting of greenhouse gas abatement under any of several revenue-providing mechanisms. The controlled landfill and variations on it are being discussed with regulators by a SWANA committee that includes the present author, and it is expected that further effort along such lines will also facilitate application of the technology.

Example calculations were carried out to evaluate possible magnitude of greenhouse gas abatement benefits if controlled landfilling were widely applied in the US. It is estimated that application of controlled landfilling to a majority of US wastes could lead to $\mathrm{CO}_{2}$ equivalent greenhouse gas reductions of about 80 million tonnes/year (implying a likely range of 50-100 million tonnes/year), at costs in ranges above. Calculations are presented in the report which follows.

Continuing investigation and testing of controlled landfill appears warranted, as one promising avenue to future low-cost greenhouse gas abatement. 


\section{INTRODUCTION AND BACKGROUND}

\section{Landfill methane: Generation and collection}

Sanitary landfilling is the dominant municipal solid waste disposal avenue within the U.S With present practice, wastes received at landfills are spread, compacted, and covered with thin soil or other cover on a daily basis until a planned depth is reached. Wastes are then covered with permanent cover, most frequently clay. This practice, while satisfying all present and anticipated regulations, still has several associated environmental impacts. In particular, though there is ordinarily no attempt to control landfill biological conditions, waste does generate and emit gas ("landfill gas" or "LFG", or "landfill methane") comprised of methane $\left(\mathrm{CH}_{4}\right)$, carbon dioxide $\left(\mathrm{CO}_{2}\right)$ and low levels of air pollutants. The methane is generated, generally very slowly, as microorganisms decompose landfilled wastes' organic constituents over decades. For cellulose, the principal decomposable component, of most municipal wastes, the overall conversion reaction, to methane, (simplified) is:

$$
\begin{aligned}
& \left(\mathrm{C}_{6} \mathrm{H}_{10} \mathrm{O}_{5}\right)_{\mathrm{n}}+\mathrm{nH}_{2} \mathrm{O} \longrightarrow 3 \mathrm{nCH}_{4}+3 \mathrm{n} \mathrm{CO}_{2} \\
& \text { cellulose monomer water bacteria methane and } \mathrm{CO}_{2} \text { (gas exits) }
\end{aligned}
$$

Methane generation from decomposing waste is very significant from climate perspectives, simply because of huge amounts of landfilled decomposable waste. The US alone landfills about 160 million tons/year. Worldwide roughly a half billion US tons yearly are placed in landfills (or dumps wherein wastes may also decompose to methane). Methane generation estimates are being refined, based on studies such as the major 19-landfill study sponsored by the Department of energy [DOE]/Solid Waste Association of North America [SWANA] study (Vogt and Augenstein, 1997) A default yield of $2800 \mathrm{ft3} / \mathrm{ton}$ (87 $\mathrm{M} 3 / \mathrm{kg}$ ) and a US landfilling rate estimated at 160 million tons/year (145 million tonnes/year) leads to US landfills' estimated methane generation at 6-10 million US tons or 5.5-9 metric tons (tonnes) per year. At accepted methane potency 21 -fold greater by weight than $\mathrm{CO}_{2}, 5.5-9$ million tonnes per year (for example) of methane would be "greenhouse-equivalent" to 115-190 million tonnes of $\mathrm{CO}_{2}$ per year for the US alone. Worldwide, it can be estimated that $\mathbf{3 0}$ million tonnes--or more--of landfill methane emissions add about $3-5 \%$ to the annual increase in radiative forcing due to buildup of all greenhouse gases in earth's atmosphere (using data adapted from Augenstein, 1992, Bingemer and Crutzen, 1987). As discussed later, a major fraction of the generated methane is emitted even when all mandated control strategies are applied. Better control, the overall objective of this project, can have substantial climate benefit. 


\section{Comment: Quantities and units}

Before further discussion, comments are necessary here about units to be used below. U. S. units will be used primarily, inasmuch as these (US tons, cubic feet of gas, thousands of cubic feet of gas or MCF, and pounds) are traditional measures in both the waste management and energy fields. Metric equivalents will also be stated for the important parameters

\section{Landfill gas collection, and fugitive emissions}

Much of the design of landfills is governed under recent federal regulation ("Subtitle D" below). In turn, at the federal level, the collection of gas from landfills is governed by recently-finalized New Source Performance Standards (NSPS) which are part of the revised Clean Air Act (CAA). For a few states or districts within states (i. e. Los Angeles basin), air pollutant control standards are stricter than the basis federal NSPS/CAA ("NSPS") standards. However for the great majority of US waste, NSPS rules are applied. The NSPS rules mandate landfill methane collection when two conditions are met (a) landfill design capacity is over 2.75 million US tons ( 2.5 Teragrams, $\mathrm{Tg}$ or 2.5 million metric tons), and also (b) testing by prescribed methods establishes that emissions of volatile organic compounds (VOC's, local air pollutants) exceeds 50 Metric (55 US tons) per year.

Discussion to follow must be somewhat qualitative in view of partial statistics and continuing changes. However it is clear that much waste in the US is exempted from gas control. This is partly because much US waste is in landfills under size thresholds (above) necessitating controls. Additionally important is that landfill gas VOC's (air pollutants) have fallen (because of improving exclusion of volatile hydrocarbon and similar wastes from landfills) to about $10 \%$ of EPA default assumptions. These VOC's, by law, not methane, provide the only statutory basis for gas controls under the NSPS/CAA. It is readily established using validated predictive methods (Peer et. al., 1992, Vogt and Augenstein, 1997, Walsh, 1997) that landfills well above the 2.75 million ton/year limit, up to 5-10 million tons can "test out" of gas controls at low VOC emission levels now routinely encountered. A judgment (on partial statistics in the changing situation) is that $25-45 \%$ of generated US landfill methane could escape controls completely--that is, continue to be emitted from landfills that will have no controls at all--given expected control criteria and practice. This large amount of methane provides opportunity for substantial greenhouse gas abatement with proper incentives (such as renewable energy revenue and emission reduction credits) that should lead to control. Further example calculations are presented later in this report.

When gas controls are required, control is generally by vertical wells connected to a vacuum manifold system (see EMCON, 1982). Even when controls are installed at given

Topical Report: Greenhouse Cost-effectiveness of Controlled Landfilling Contract DE-AC26 98FT40422 Page 6 
landfills, methane capture is inefficient and fugitive emissions are significant for several reasons:

1. Vertical wells are generally $60-90 \%$ efficient--when they are operating (Augenstein and Pacey, 1991) $75 \%$ is a widely used efficiency figure (Peer et. al., 1992, California Air Resources Board, 1990). Waste is porous, and even the "best" of conventional (clay) covers are demonstrably porous. Extraction rates and efficiency are limited by air entrainment.

2. Well installation is often not required for several years after waste placement (law allows up to 5 years before wells are installed), for operational reasons. During this several year interval before well placement, a large fraction, frequently approaching all methane, is emitted to the atmosphere

3. Numerous studies show waste in "conventional" landfills generates gas for extremely long periods of time, many decades (Augenstein and Pacey, 1991). Gas control is normally mandated for 30 years following landfill closure. However significant quantities of gas may be generated well beyond 30 years. For an example, the EPA first order model using $\mathrm{k}+0.04$ years-1 (as determined for landfills in Los Angeles County) suggests that over $30 \%$ of the gas total might be generated more than 30 years after waste placement. Collection of gas generated long-term at low rates is quite expensive. This is because of high fixed annual costs per unit gas recovered at low rate. For various reasons recovery is often not attempted long-term. Nonetheless, continuing emission from landfills, though at low rates, adds up to long-term methane emission totals that are high (for example the $30 \%$ cited above).

In summary, Subtitle D landfills, even equipped with gas controls, can still emit substantial quantities of methane because of (a) emissions prior to installation of controls (b) inefficiencies while controls operate, and (c) long-term emissions that may occur after control (gas extraction) ceases. Thus, it is judged that landfills with gas controls conforming to all regulations would for the most part appear to collect only $50-75 \%$ of the gas they generate (supporting estimates will be presented for example cases). In addition, for reasons noted (size limits--and because regulations require only VOC control above high VOC thresholds--there is no authority to control methane) a large fraction of US waste, perhaps 25 to $45 \%$, will be exempted from gas control under regulations. Better control of landfill methane offers an avenue to substantial greenhouse gas abatement benefit.

\section{Landfill gas energy}

In addition to environmental impacts, landfill methane emitted rather than captured represents substantial energy potential lost. For example if electricity were the energy product, estimates by both EPA (EPA, 1993) and the Electric Power Research Institute 
(Gauntlett, 1992) suggest that sufficient landfill gas could be recovered to generate between 5000-7000 MWe. This would meet over $1 \%$ of current US electric need, sufficient to supply total electrical requirements associated with all activities of 2 million or more US citizens. Landfill gas is in fact used for energy at about 150 sites in the US (Thorneloe et. al.; 1997 Augenstein and Pacey, 1991). However attractive sites (over 1 million tons waste in place) number several times this figure (by EPA's estimate over 700). Present generation of about $500 \mathrm{MW}$, [includes electric equivalent of thermal at appropriate conversion efficiencies], is only about $10 \%$ of potential as estimated in several independent studies (EPRI, USEPA 1993, Augenstein et. al. 1994). The low energy realization relates to factors including incomplete decomposition of waste to gas, inefficient recovery, and inability to accurately predict gas availability over time at landfills which are operated conventionally.

Greater energy use of landfill gas can accrue greenhouse benefit from fossil offsets as well as the emission prevention. Controlled landfilling is expected to facilitate energy use by greater recovery (and in turn economies of energy equipment scale) and greater predictability and controllability of methane recovery. With better predictability and controllability, energy equipment can be sized properly to make full use of the greater quantity of recovered fuel gas.

\section{Surface membranes and gas capture augmentation}

Simply covering landfills with plastic sheet ("geomembrane", or "membrane") can allow recovery of nearly all gas that is generated under the membrane. Membranes may be a post-closure requirement for many landfills (Federal Register, June 26, 1992). Installed over surface gas-permeable layers (such as shredded tires), membranes can capture close to $100 \%$ of generated methane. However membrane does not, alone by itself, "work" inasmuch as it results in another problem. Plastic prevents moisture (precipitation) infiltration and greatly slows decomposition. (Kraemer et. al., 1993, Leszkiewicz 1995). This results in what is widely called the "dry tomb" (For example see article by Lee, 1995). Decomposition is slowed, to the point where it can require a century or more of continuing effort to control slowly generated gas (as opposed to 2-5 decades, already a substantial problem with current practice). Further, if surface containment breaks down, decomposition occurs in uncontrolled fashion. This results in releases at long times after filling when management (which requires preparation and in-place equipment) is very unlikely to be available and resultant methane is instead emitted to the atmosphere.

Dry tomb disadvantages include (a) economics become very poor for gas that will be very slowly recovered over very long terms, (b) Waste fractions that stay dry are being found with no apparent long-term decomposition at all and (c) Membrane containment integrity must be maintained long-term as "entombed" waste remains un-decomposed or continues to decompose very slowly. Alternately, failure of the containment system allowing 
moisture to infiltrate a very long time after waste placement, would accelerate gas emission when careful control of the landfill is no longer occurring.

To avoid long-term "entombing" difficulties with membrane coverage it is highly desirable to also manage and speed waste decomposition, to enhance methane generation to completion within a short time span, ideally 5 to 10 years. The methane enhancement combined with membrane coverage is referred to here as "controlled landfilling".

\section{Process approach and demonstration}

Controlled landfilling combines two key elements: (a) enhancement of methane generation to complete waste decomposition rapidly to maximum possible yield, with (b) membranecovered surface gas permeable layer to allow collection of all gas that is generated. Much-faster completion of methane generation avoids dealing with gas generation at long terms; a membrane-covered surface permeable layer at slight vacuum reduces emissions to nil. Methane generation enhancement, central to the approach, will be discussed next.

Although other factors can be important, effects of moisture (Halvadakis et. al, 1983) are paramount in accelerating methane decomposition. Elevated moisture (by conventional landfill standards) is essential for accelerating biological activity and methane generation. Figure 1 shows pronounced effects of moisture typical of studies on moisture enhancement of methane generation. Temperature is quite important even though it has received rather little attention as a variable (Ashare et, al, 1978, Hartz and Ham, 1982). Figure 2 shows, as an Arrhenius plot, the effect of temperature. Rate has a temperature dependence with an apparent $\mathrm{Ea}$ of about $15 \mathrm{kcal}$, and an over 30-fold increase in rate constant is seen in figure 2 as temperature rises from 15 to $60 \mathrm{C}$. Moisture and temperature are, from regulatory and other (particularly cost) standpoints the easiest parameters to manipulate in landfills and to enhance methane in controlled landfilling.

The goal of controlled landfilling is to accomplish the necessary methane enhancement and other operations in a manner that integrates most readily with present landfill practice. Conventional practice would be followed as much as possible. Some important aspects of design and operation, and the necessary variations from conventional practice, are listed for reference in box 1 .

\section{Yolo County Controlled Landfill Demonstration}

A Controlled Landfill demonstration has been initiated (enhancement start, 1996) at the Yolo County Central Landfill (YCCL), near Davis, California. The Yolo Central landfill that hosts this demonstration is a fullscale (500-700 ton/day) operation conforming to all California environmental standards, among strictest in the US. The demonstration consists of two test cells operated within the much larger "conventionally" operated landfill.

Topical Report: Greenhouse Cost-effectiveness of Controlled Landfilling Contract DE-AC26 98FT40422 Page 9 


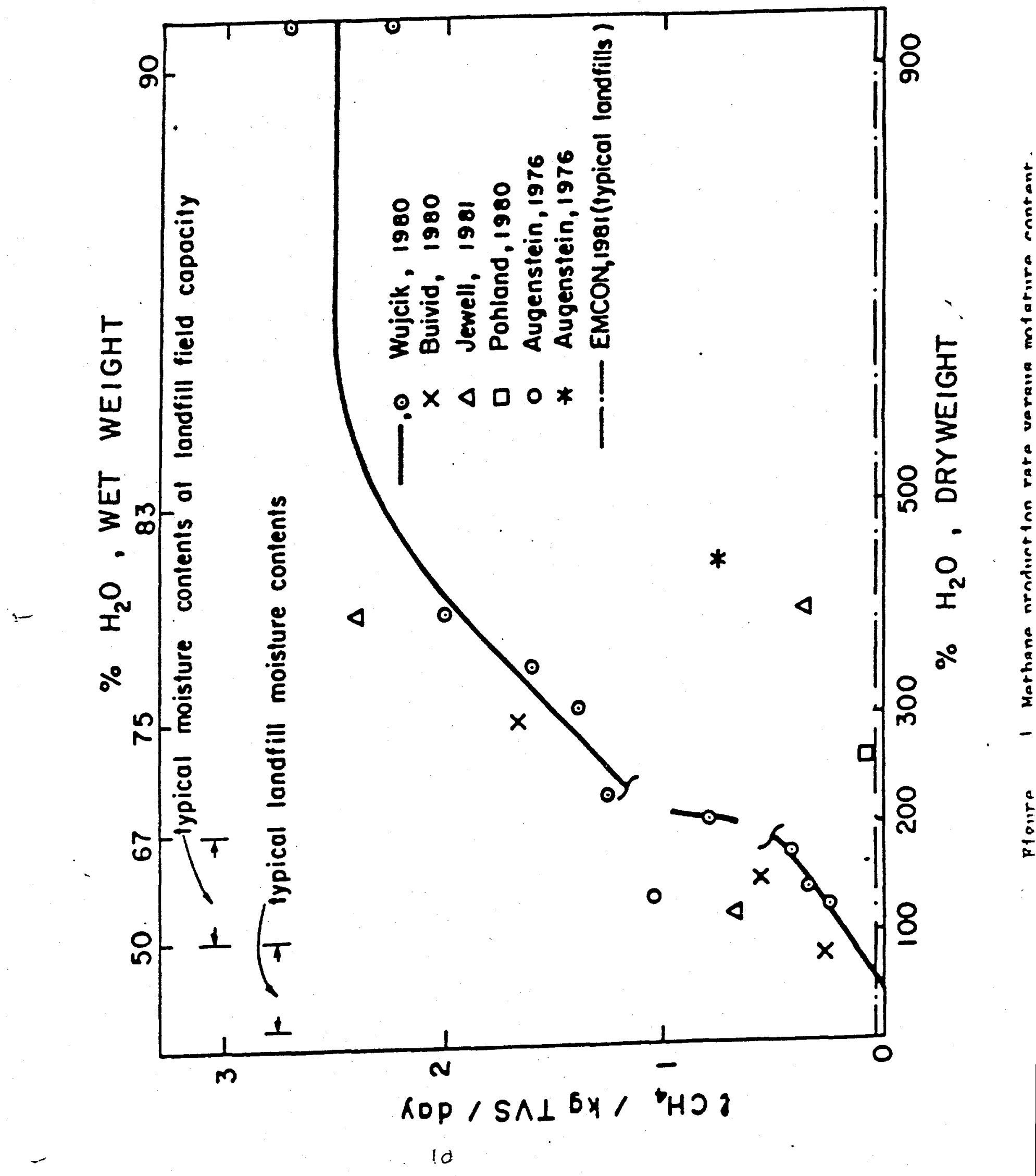




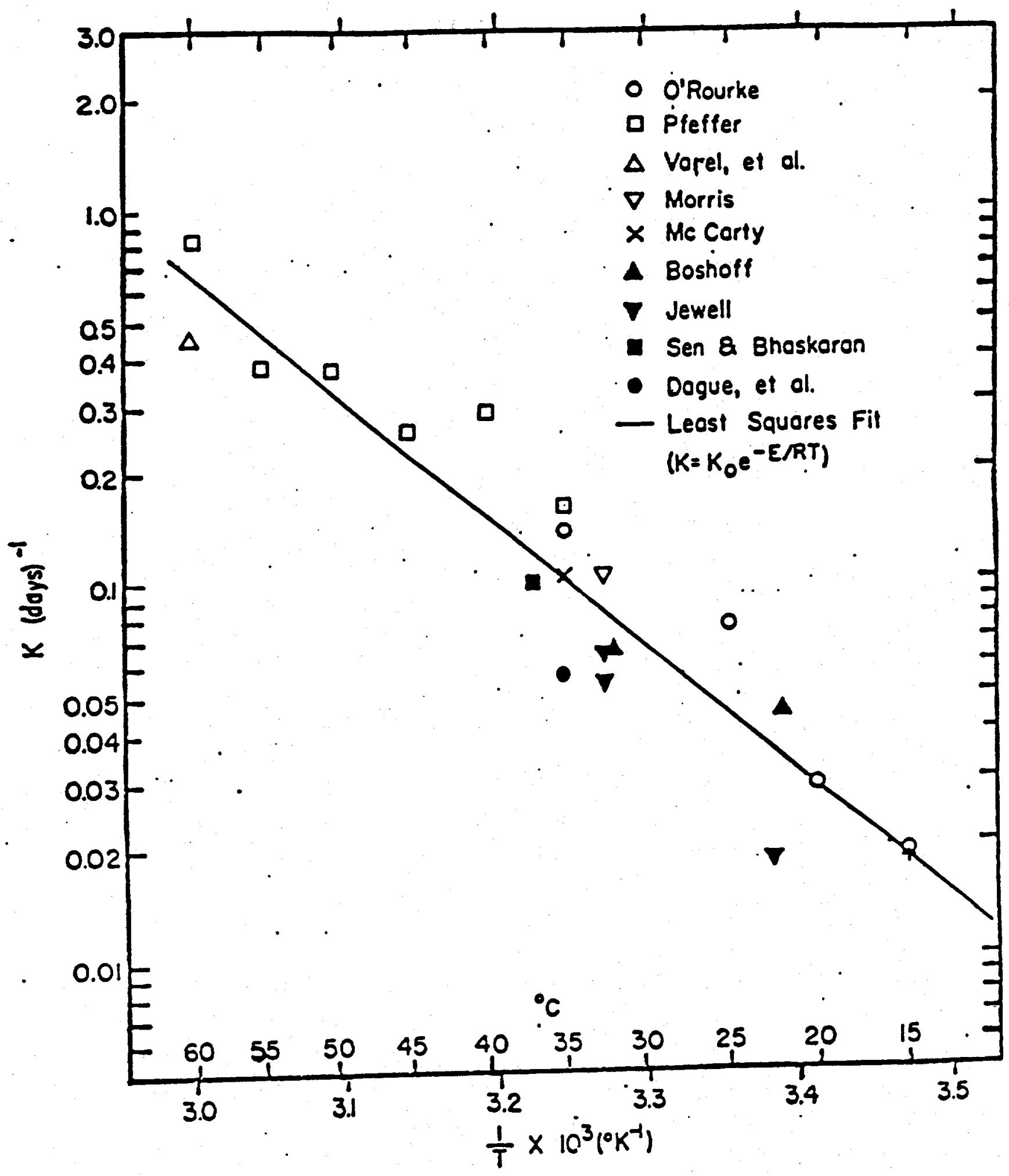

Figure 2

Arrhenius Plot Showing Dependence of Rate on Temperature for Methane Fermentations of Solid Substrates (Ashare et. al.) 


\section{Box 1}

\section{Controlled landfill design and operational features}

1. Design with appropriate highly permeable bottom layer drainage to preclude static head. (clogging as discussed by Koerner, 1993 can be avoided (Koerner et. al. 1993).

2. Place waste largely following standard landfill practice except freely permeable daily cover (chopped yardwaste, soluble foam etc.) serves the daily cover function, rather than soil. This allows permeation of moisture at maximum possible rates and also limits lateral moisture diversion.

3. Surface the top of waste with sufficient permeable porous material (waste tire chips or other) for a highly conductive gas collection layer to capture and conduct gas to collection point. Provide for uniform liquid addition through multiple injection points at the surface of the waste. (Control by manifold of hoses with orifices)

4. Cover landfilled waste with impermeable membrane and other necessary structural components.

5. Add liquid amendment (generally, leachate and water; possibly treated gray waters.). Addition and waste moisture content can be managed as needed to preclude base hydrostatic head. Safety factors can be afforded in at least two respects : (a) elementary hydraulic analysis indicates liquid would not exit waste faster than it enters, and addition is planned slowly over several months. (b) Base leachate collection layer can easily be, and would be, conservatively designed so it could handle severalfold the anticipated flow while still avoiding any significant hydrostatic head (federal limits $30 \mathrm{~cm}=1 \mathrm{ft}$.).

6. Collect all gas as it is generated. Size collection lines and other equipment to allow for greater gas recovery. Preferably abate methane by energy use.

Discussion below will give only a brief overview of the Yolo County demonstration. For readers interested in more information, abundant further detail is available in a SWANA symposium paper (Augenstein et. al., 1997) Additional design features will also be presented as the cost analysis is conducted.

The Yolo demonstration operates two test cells, each containing about $8700 \mathrm{U}$. S. tons (7900 tonnes $=$ metric tons) of waste. Cells are thoroughly instrumented to gain maximum information as the demonstration proceeds. Instrumentation includes 24 temperature sensors and 56 moisture sensors (total for both cells) distributed throughout the waste. Parameters such as gas pressure at points within the cell, and base hydrostatic 
head are monitored. All liquid inflows and outflows of concern, and gas outflows and compositions, are accurately measured. One cell has had no additions and serves as control. Methane in the other cell (the "enhanced" cell) was enhanced by carefully controlled addition of well water at a rate (10GPM) estimated sufficient to raise the moisture to maximum levels compatible with federal standards in about 4 months. A schematic (oblique view) is shown in figure 3. Readers may refer to Augenstein et. al., 1997 (op cit.) for more information.

After 2 years for construction and setup, the demonstration has been in full operation since midsummer of 1996 when cell filling was completed and the permeable layer and membrane were placed over the top of waste. Moisture additions to enhance methane generation began in October 1996. The "bottom line" is that performance has been excellent.

The cell gas recovery data are shown in Figure 4. Among the several lines of figure 4, the most important is the top line showing the total of gas generated from the enhanced cell. For reference, the expected gas production from a "conventional" landfill is also sketched on the graph (based on findings from the 19-landfill study of Vogt and Augenstein, 1997). One noteworthy result is the averaged productivity of 0.57 cubic feet of methane per pound of waste per year through the entirety of calendar 1997. During calendar 1997 the enhanced cell produced gas at close to ten times the rate of conventional landfills. This represents the highest normalized methane recovery documented from such a large mass of waste anywhere, worldwide.

The observed high productivity is attributed in part to moisture, for the enhanced cell, but also to temperature. Normal landfill practice, with daily coverage by impermeable soil, leaves waste placed in conventional landfills near ambient temperatures. The controlled landfilling approach (greenwaste daily cover allowing waste exposure to air) apparently allowed initial aerobic composting of the waste to the extent that the waste temperature in both cells, instead of being near ambient, was the order of $50 \mathrm{C}$, on completion of filling (Augenstein et. al., 1998) This substantially warmer temperature, would of itself be expected to accelerate methanogenesis severalfold. This beneficial effect of temperature is supported by initial rapid methane generation of the control cell. (owever the control cell methane generation has now fallen to less than $20 \%$ of the level of the enhanced. showing the importance of elevated initial moisture in maintaining methanogenesis.)

The rapid rate of methane generation, continuing in the enhanced cell, suggests the goal of rapid completion of methane generation to approach $(95+\%$ of $)$ maximum yield within a few years--likely under 5 --should be possible. Other important findings to date include:

-Liquid addition to multiple points distributed over the waste surface is readily accomplished and inexpensive (automated irrigation valving of liquid through simple

Topical Report: Greenhouse Cost-effectiveness of Controlled Landfilling Contract DE-AC26 98FT40422 Page 13 


\section{METHANE ENHANCEMENT BY ACCELERATED ANAEROBIC COMPOSTING DEMONSTRATION PROJECT AT THE YOLO COUNTY CENTRAL LANDFILL}

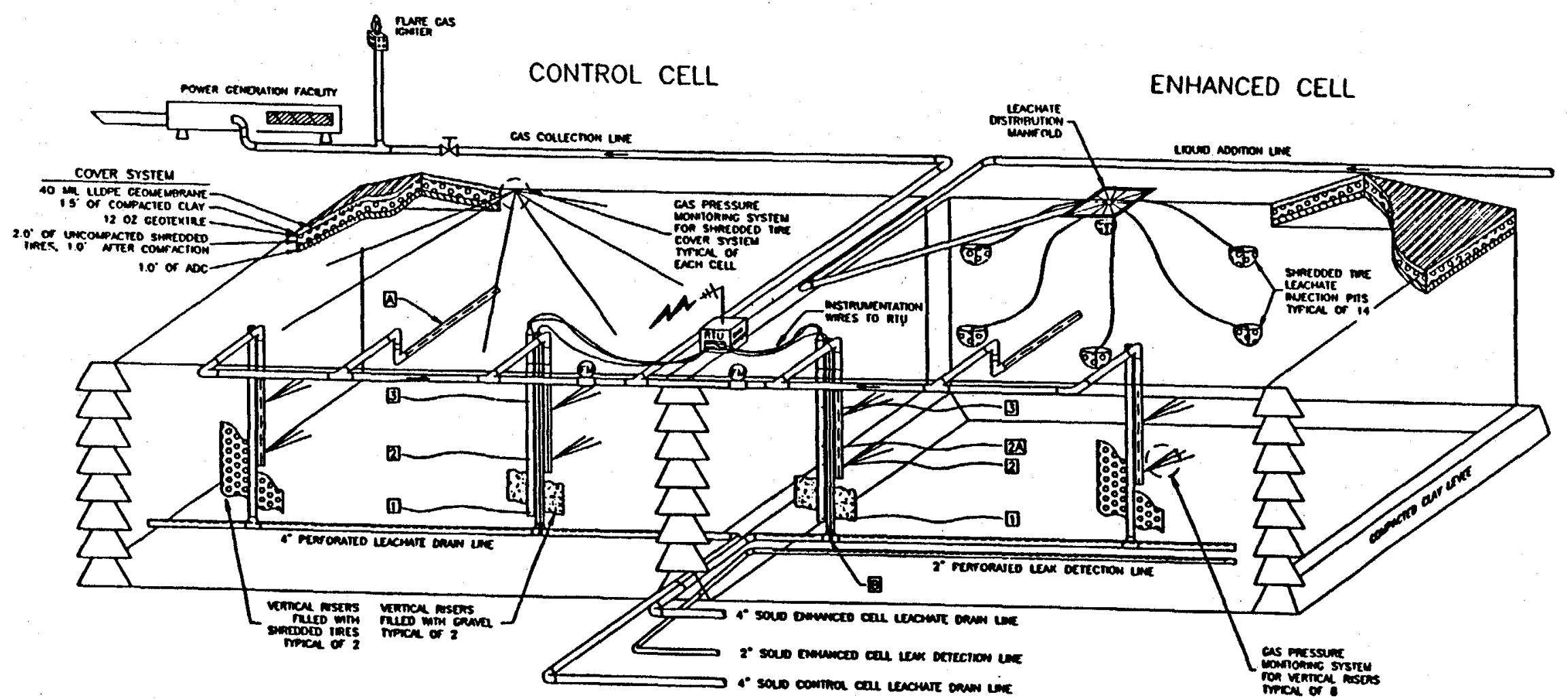

FEATURE KEY

(1) IEVR I WSTRLMENTATION (MOSTIRE NND TEMPERATURE)

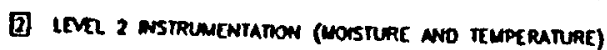

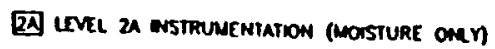

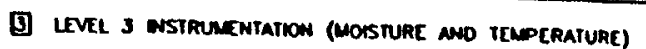

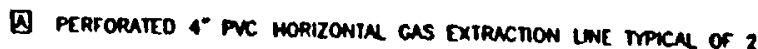

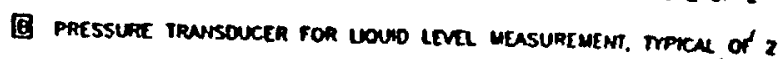

mo court amper womat PRINCIPAL SYSTCM COMPONENIS CUtawaY view LOOKING NORIH 


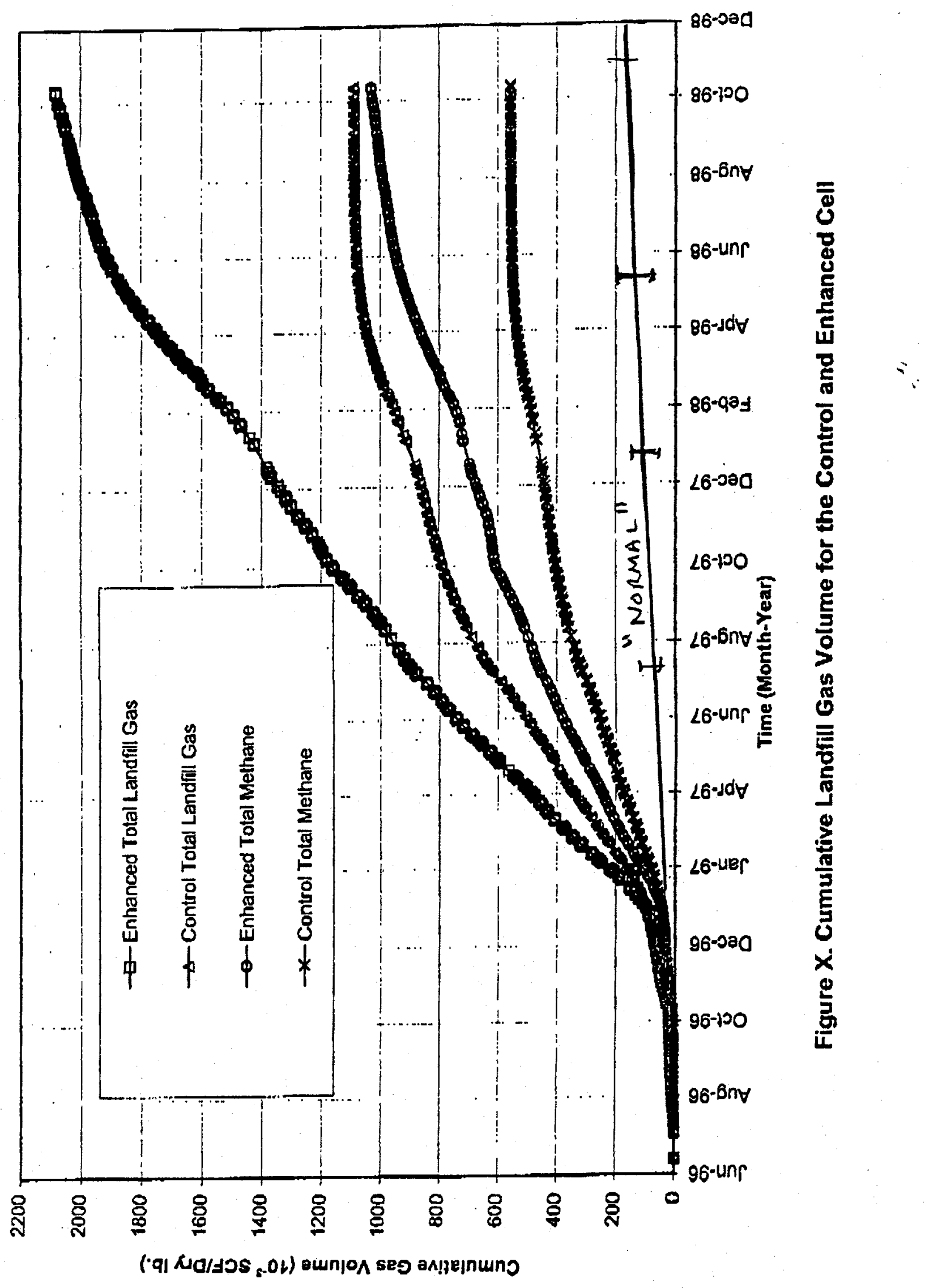


hoses equivalent to "garden hoses" to tire-chip-filled "pits" at the waste surface). It results in thorough wetting of the waste to desired moisture levels ("field capacity"), as confirmed by liquid sensors. Liquid addition timing with this controlled approach can in turn allow timing of the onset of rapid methane generation.

-With porous greenwaste daily cover, waste permeability to liquid is more than adequate $(>2 \times 10-4 \mathrm{~cm} / \mathrm{sec}$ ) to allow moistening in reasonable times of a few months (under a year even for deep, ca. 100' depth, landfills)

-Capture of gas by the permeable layer beneath membrane is essentially $100 \%$. The permeable layer is maintained at slight vacuum. Permeability of the layer is extremely high so pressure is uniform through the permeable layer, over all waste surface from which gas may exit. So long as even slight permeable layer vacuum is maintained, the only leaks possible are of air in. Methane emissions through membrane to atmosphere are zero.

-The demonstration was in compliance with federal regulations. More discussion of regulatory and policy issues is presented later.

As a background note, there has been work elsewhere on what are variously termed "bioreactor" or "enhanced" landfills. These resemble the present Yolo project in improvement of biological conditions. However other projects at earlier times have not conformed to changed federal regulations. Methane control has also not been a focus of other projects. Despite extensive literature, measurements for other projects have been limited and material balance closures incomplete. It is important to emphasize that the ongoing Yolo demonstration project is only the second, and the most successful, of projects that combine methane generation completion to full potential yield with full capture of the generated gas.. The first such project (which the present author helped initiate) was in Mountain View, CA. The Yolo and earlier Mountain View projects have been unique among all projects--worldwide--in combining methane enhancement with full capture to minimize greenhouse emissions ${ }^{1}$. It is also the most fully instrumented. Other views on this project may be obtained from staff of the Geosynthetic Institute at Drexel University, Philadelphia, which has followed this project closely.

With successful operation at Yolo, the next step and object of this Phase I work, is to refine and verify the initial economic analysis. The overall purpose is to determine relative

1 A comprehensive survey of methane-enhanced landfilling was carried out by Hans Oonk of TNO. the Dutch Research Institute in Apeldoorn, Netherlands (Tel. 0113155549 3416). The Dutch concluded the Yolo project is unique (among over 200 projects examined worldwide) in its provisions for full methane capture. The Dutch are initiating a demonstration to carry out controlled landfilling closely following the Yolo project.

Topical Report: Greenhouse Cost-effectiveness of Controlled Landfilling Contract DE-AC26 98FT40422 Page 16 
economic merit and potential of this process for greenhouse gas abatement. At the outset (in the initial proposal leading to this project in 1991) the assignment of all costs to incremental captured gas was estimated to result in a gas cost ranging from $\$ 0.40$ to $2.00 / \mathrm{mmBtu}$ (within the precision of such estimates, about the same per GJ). Below is discussed the approach to be taken to the cost analysis, whose ultimate purpose (for this work for FETC) is to determine the greenhouse cost effectiveness of the approach

\section{PHASE I COST ANALYSIS: PURPOSE AND APPROACH}

Purpose and approach

The purpose of the cost analyses to follow is to determine probable values for "greenhouse cost effectiveness" of controlled landfilling as well as costs of methane fuel product. A further objective is to estimate potential for US greenhouse gas abatement. Greenhouse cost effectiveness will be expressed in terms of dollars/(metric ton $=$ tonne) $\mathrm{CO}_{2}$ equivalent. Potential for US greenhouse gas abatement will be expressed as annual tonnes of equivalent $\mathrm{CO}_{2}$ abated for the US.

\section{Accounting}

To start, it must be noted that there can be many "accounting" variations in calculating greenhouse gas mitigation costs and gas costs as sought here. As an example of such accounting choices, incremental controlled landfill costs might be apportioned to (a) energy (b) greenhouse gas abatement and/or (c) other waste management benefits which might also be credited so as to reduce cost apportioned to energy and greenhouse gas abatement. Valuations of potential credits can vary widely. In addition some of the gas may be collected in any case under regulations, and accounting can consider this gas as "given" (It is being termed "anyhow" gas in the waste management sector and by some regulators).

Accounting is fortunately simplified in respects, insofar as some choices are fixed under internationally accepted standards. For example, the $\mathrm{CO}_{2}$ equivalence of methane will be that accepted by the IPCC and DOE (21-fold greater potency of methane by weight compared to carbon dioxide). With respect to landfills, subtitle $D$ specifications can be assumed to apply. Least-cost modifications (but where possible with history of use in states such as California, under standards providing high levels of environmental protection) will be selected.

This analysis will attempt to be as conservative as possible, in assigning full possible cost to the benefit of interest. In estimating gas cost the full cost of controlled landfilling will be assigned to the incremental gas. Greenhouse cost-effectiveness estimates will--instead- 
- assign the full incremental cost to greenhouse gas abatement. Assumptions will be stated as the analysis proceeds.

General approach

The general approach begins by postulating a "base case" design, applying conventional landfill practice to the maximum extent possible, but adapted to controlled landfill operation based on experience with the successful Yolo demonstration. The base case is intended to represent as closely as possible a typical or median US landfill, except modified as stated. Incremental capital and operating costs of controlled landfilling versus conventional practice will be then be evaluated. This base case evaluation will first develop costs for greenhouse gas abatement, the desired end result of this Phase I report. The greenhouse gas abatement itself has two components (a) incremental gas emission prevention, and (b) fossil fuel reductions (hereafter "offsets") from energy use of resultant methane recovery. Representative discount rates (implied cost of funds or return needs), will be used in calculating the $\mathrm{CO}_{2}$ equivalent abatement cost in dollars per ton $\mathrm{CO}_{2}$. The base case analysis will then develop costs for methane energy.

Each base case evaluation--both of greenhouse cost effectiveness and energy--will be followed by analysis of variations on the base case. Even though Subtitle D prescribes many features, a host of landfill design aspects can still vary by site. There is, simply, no standard" landfill. The significant variations or factors that will influence cost compared to the base case, include:

1. Landfill size, in terms of tonnage inflow rate of waste, and depth

2. The option of controlled landfilling only that fraction of incoming wastes that are readily decomposable

3. The situation where (as is possible) regulations mandate features such as double base lining, which increase costs.

4. The effects of other waste pretreatments, and incentives.

Controlled landfill costs will be evaluated in comparison to two reference cases in which (a) controls would be mandated, or alternatively (b) a situation where controls would not be required. Situation (a) is more common with larger landfills, (b) with smaller--but (a) and (b) both occur over a wide range of landfill sizes.

Finally, this analysis will examine approximate GHG abatement potential presuming wide application of controlled landfilling to a large fraction of US landfilled waste. 


\section{Data issues: Quality and variability}

A comment is necessary here about uncertainties. Significant uncertainties are recognized in waste management data and related areas such as emissions predictions in both waste management and atmospheric science communities. Data quality issues have been described elsewhere (SRI, 1991) and will not be reiterated here. There will also be the noted variation in landfill-to landfill cost on the basis of local circumstances. Analyses below will as far as possible discuss the uncertainties and ranges attending various calculations.

\section{$\underline{\text { Regulatory and policy issues }}$}

In addition to technical and accounting issues, a number of regulations, and governmental policies and initiatives are relevant to controlled landfilling. At the outset, it can be noted that controlled landfilling as envisioned in this report can be carried out in compliance with all federal statutes. In fact federal policy statements and research support have favored controlled landfilling (for climate benefit, the Phase I objective) as discussed later. Regulations are still evolving state-by-state. Cost analyses below will be followed by a discussion of evolving regulations and policy relating to controlled landfilling.

\section{BASE CASE COST EVALUATION}

The "base case" evaluation is for a landfill following Subtitle D regulations and conventional practice to the maximum extent practical. Important features of this base case landfill are listed in Box 2. The intent is that any modifications to conventional practice be easy to implement in any location across the US. Features of this base case, essential for controlled landfilling, which would not necessarily be found in conventional landfill designs, are marked with asterisks ${ }^{2}$. The 1000TPD landfill placement rate was chosen as representative for waste inflow, in that over half of US waste flows into landfills receiving 1000TPD or more, with the rest of US waste entering smaller landfills at lower rates. (It should be noted that for reasons including siting difficulties and economies of scale the US tendency is toward fewer, larger, landfills, so a 1000TPD landfill may be considered relatively "small" in a few years.)

The landfill design is the generic "cut and fill". A description, more design features, and sensitivities to features, will be presented later. The base case depth (averaged) of 60 feet was judged typical for a present-day large landfill.

\section{Controlled landfilling operational and other features}

In operation the landfill would be filled lift-by-lift (i. e., a new waste layer daily, continuing layer by layer) until waste reaches design depth and surface profile. Waste would be

2 They are also features that can be reasonably expected. or have already been demonstrated. workable.

Topical Report: Greenhouse Cost-effectiveness of Controlled Landfilling Contract DE-AC26 98FT40422 Page 19 
covered daily with material (chipped vegetative compost or other similar matter) which has high permeability to liquid. It is assumed that average waste depth for the base case is 60 feet at assumed density of 38 pounds per cubic foot (measured compacted density of $38 \mathrm{lb} / \mathrm{ft} 3$ in the Yolo demonstration is assumed here.) An average area of 0.12 acre would be filled 10 feet deep daily for the example. A projected inflow of 1000 TPD amounts to about 1.2 acre-foot/day of "normal" compacted waste. Thus the filling of the base case 10-acre module would require 500 days (calculated: 496.6 days $/ 496.600$ tons; this is rounded to 500 days and 500,000 tons for simplicity). Module size could range widely in practice, but controlled landfilling technology would begin with modules of modest size.

There could be fairly significant amounts $(\approx 3-10 \%$ of the waste's total methane potential) generated during this filling process, which from start of filling to completion of cover and capture system occupies over a year's time for the base case evaluated below. It is desirable to capture as much as possible of such "early" methane to limit fugitive methane emissions as the waste is placed. Prevention of a large fraction of early methane emission (that could otherwise occur) can be accomplished by extracting methane from the base of the waste through the porous drainage layer. A perforated "tap" line or well (s) may be installed for this purpose when filling begins. Such early (pre-geomembrane-coverage) gas control need only operate during the filling process, since cover will enable capture of all gas once in place on the filled module. A schematic is shown in figure 5 "Schematic of gas withdrawal from base layer" The tap can be simply connected to the preceding controlled landfill module gas collection system by means such as 6" agricultural drainage line (vehicle-load resistant Hancor AHPL104 M252 Highway grade or equivalent). Alternatively, it could be connected in conventional fashion (as with vertical gas wells) directly to the extraction system. Simple gas flow analysis suggests half or more of the gas generated before coverage will be collectible from the bottom of the waste--rather than fugitive. Withdrawal control would be along standard lines used to control extraction by gas wells (see Appendix B in Augenstein and Pacey, 1992) The tap pipe that allows gas extraction from the bottom permeable layer is discussed further below.

Here it can be noted that there is an option of filling smaller modules more rapidly. This will not be discussed further except to note it as another way to minimize early fugitive emissions (it may sacrifice some economies of scale).

\section{Timing of liquids addition}

Although it may be convenient to add liquid to waste as it is filled, the Yolo County demonstration results strongly suggest this strategy will lead to rapid methane evolution before the full methane capture capability (particularly the necessary cover) can be readied. Thus for best greenhouse methane control this analysis assumes that liquid addition occurs only after waste is filled and covered, rather than as it is filled. This permits maximum control of the onset of methane generation through timing of liquid 


\section{FIGURE 5}

SCHE MATIC: SYSTEM FOR LIMITING FUGITIVE EMISSION OF CELLS UNDER CONSTRUCTION

GAS WITHDRAWAL FROM BASE LAYER

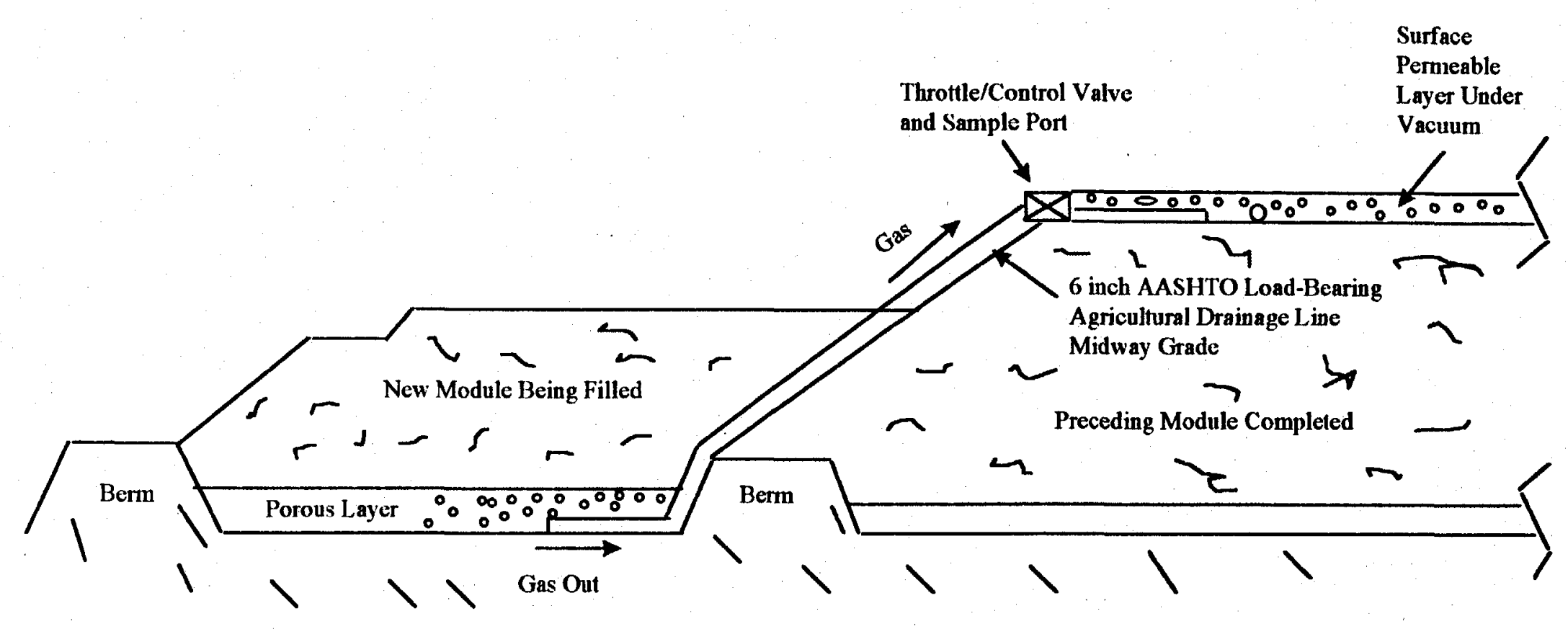

Notes:

1. LOAD-RESISTANT FLEXIBLE POLYETHYLENE AGRICULTURAL DRAINAGE LINE (SEE TEXT) CONNECTS POROUS BASE LAYER OF CELL UNDER CONSTRUCTION TO POROUS SURFACE EXTRACTION LAYER OF PRECEDING CELL.

2. PIPE RUNS WITHIN POROUS LAYERS ARE PERFORATED. 


\section{Box 2}

\section{Characteristics of "Base Case" Controlled Landfill.}

Waste inflow: $1000 \mathrm{U}$. S. Tons/day time-average (907 Mg/Day)

Waste depth: Average 60 feet (18 Meters) + one meter (Appx.) for cover layers

Waste lift depth 10 feet

Module size: Ten acres (Subdivided as four x 2.5 acre [ 1 Hectare] sections; see text) 25 modules constructed over landfill lifetime of 34 years

** Intermediate cover that is sufficiently porous. Assumed "greenwaste" (chopped up yard waste or similar material). This is readily available nationwide

** Waste surface coverage by porous gas-collecting layer (assumed chipped or shredded tires), overlain by geotextile, soil (for weight) and Linear Low Density (high-stretch) Polyethylene (LLDPE). Thorough cover sealing.

** Provision for moisture addition by metered addition through surface "irrigation system" to surface "pits" (see text) at $50+$ pits/acre. See text.

** Flowmeters to measure cumulated moisture inflow (by each section) and outflow (total for module)

** Sensors in waste to measure moisture and temperature

Manhole or similar leachate surge reservoir (depends on chosen liquid handling approach)

** Gas collection: Pipe to withdraw gas from permeable surface tire chip layer.

** Pressure regulation system to control pressure of gas within tire chip layer to very slightly sub-atmospheric (ca. -0.1 to $-0.5 \mathrm{~cm}$ water head)

Base drainage layer. Capacity to handle maximum leachate outflow (see text).

(Optional, likely) "Tapline" gas extraction for control while filling progresses and waste surface is open. Extraction assumed via porous layer. See text for discussion.

Other landfilling practice-as much as possible conventional, following subtitle D regulations.

addition. High-rate methane generation occurs only after the cover capture system is in place, assuring capture of greatest possible fraction of greenhouse methane gas, and energy.

The sequence of operations is shown in Box 3. All capital expenditure is assumed to occur in a "lump sum" one year before completion of filling. Although expenditures

Topical Report: Greenhouse Cost-effectiveness of Controlled Landfilling

Contract DE-AC26 98FT40422 Page 22 
would actually be spread out over time, this assumption introduces little error and is conservative, in that most of the necessary expenditure would actually occur later. The timing of operations is assumed as follows:

Complete module base including liner and operations layer ${ }^{3}$ : Start filling: Time, $t=$ -0.37 years

Capital expended: $t=0$

Complete filling: $t=1$ year

Complete liquid distribution system (see later), surface membrane coverage, and begin liquid addition: $t=1.5$ years. Note that the liquid is likely to be added to sections or sub-areas of module (described below) sequentially.

Begin high-rate enhanced methane generation. Generation starts $t==+2$ years

Value of first full years' enhanced methane generation realized at $t=+3$ years

For the conventional landfill, the approximation is that after controls are in place for recovery, the first years' methane generation value is also realized at $t=+3$. years

Note that times are estimates based on judgment and experience from the demonstration project. Times can be affected by procedural variations. (As one example, timing of liquid addition could vary depending on needs for gas in energy uses downstream.) However for purposes of analysis these times above are considered representative for a fullscale operation.

\section{$\underline{\text { Landfill design and landfill geometry }}$}

Differing landfill designs are possible (Tchobanoglous et al 1993); the chosen design here is the "cut and fill". This design is nearly universally usable in that it can be placed on most earth topography that is not too steeply sloped. It can be used almost anywhere waste disposal is required in the US-or worldwide. A generic "cut and fill" design at any nominal design depth maximizes waste filling by some variant of "nesting" waste cells and sections against one another. A cross section of such a landfill is shown in figure 6. Vertical cross section of typical cut-and-fill landfill"

This generic discussion of geometry and figure 6 is for reference as controlled landfill design is discussed below. Controlled landfilling will be practiced with new landfills, or

3 The base layer construction is always needed, thus it is not an incremental cost assignable to controlled landfilling.

Topical Report: Greenhouse Cost-effectiveness of Controlled Landfilling Contract DE-AC26 98FT40422 Page 23 


\begin{tabular}{|l}
\multicolumn{1}{c|}{ Box 3} \\
Sequence of Module Construction Steps in Controlled Landfilling \\
Construct landfill cell base by standard techniques \\
Place base permeable layers (shredded tires) and gas tapline (see text) \\
Fill cell lift-by-lift with MSW using greenwaste temporary cover \\
Place permeable shredded tire layer and soil over waste. As this is done, install liquid \\
addition lines and equipment \\
Cover permeable layer with membrane or other sufficiently gas-impermeable cover; \\
surface landfill normally. \\
Add liquid at rates shown feasible in demonstration to enhance generation \\
Collect gas as it is generated and combust (preferably via use for energy)
\end{tabular}

new landfill lateral expansions. The footprint of a 25 -module landfill can be any reasonable configuration having 250 acres, such as a square 3300 feet on a side. For reasons including the large up-front costs, one primary objective of most new landfills, cut-and-fill or other design, is to place as much waste as possible over given areas. There will, typically, be a maximum permitted design depth. Average waste depth is slightly lower (by $2-10 \%$ ) than peak permitted depth for several reasons including (a) need for surface sloping and drainage channels to handle runoff, (b) loss of volume to side slopes, which are typically sloped about $3 / 1$ ( 3 horizontal to 1 vertical). The central purpose here is to identify the incremental costs associated with controlled landfilling. For this purpose assumption of an average height serves well, without the need to fix other design details.

\section{Design: other issues}

To determine cost, the critical result desired in this Phase I work, a substantial number of design and operational issues must resolved to some extent. Many of these details have not been previously addressed. Analysis below develops preliminary design approaches, and assumptions to extents necessary to allow cost estimates and make clear the basis for estimates. Designs do not have the degree of completeness needed for implementing an actual project. It is, however, the intent to provide design assumptions with sufficient 
FIGURE 6

SCHEMATIC CROSS SECTION OF "NESTED" MODULES IN FULLSCALE LANDFILL

$1 j$

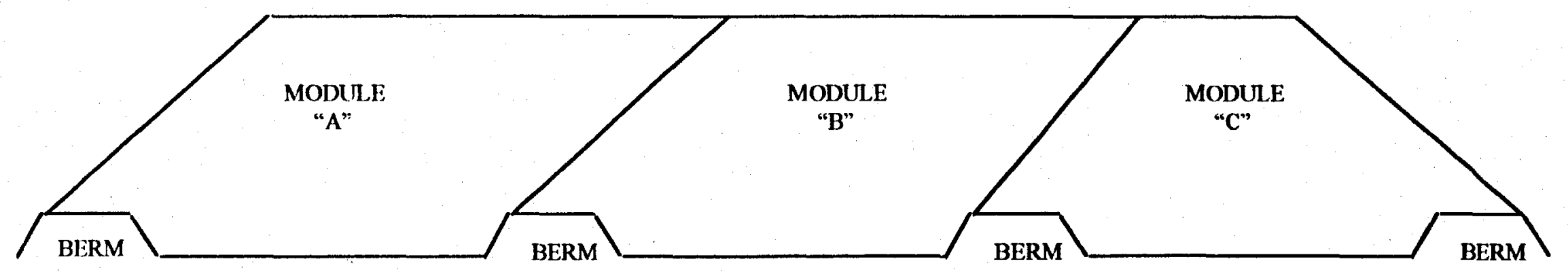


clarity so translation into a detailed design for a specific landfill should be possible with further work by qualified experts. Model numbers and specifications of suitable equipment, investigated as part of this work, are presented where possible.

\section{Landfill cost analyses: general}

For purposes of costing modern landfills it must be recognized that the great majority of expenses are inevitably incurred as part of basic waste handling and environmental protection. Thus, most costs are independent of whether methane recovery or methane enhancement/capture (controlled landfilling) is practiced. For examples: (a) leachate, the liquid that percolates from the base of waste will be present in any case. It must be addressed by an adequate leachate handling/recovery system, needed and in fact mandated in all landfills to prevent groundwater contamination (b) Waste surface coverage will be required in any event to standards that assure continuing coverage with time, as well as rodent, bird protection, etc. (c) All normal operation and maintenance work will be required in any case. With normal design and environmental protection standards the capital and operating cost bases are only those incremental costs incurred when methane enhancement with complete recovery is practiced, compared to when it is not practiced. These incremental costs are addressed next.

\section{CAPITAL AND OPERATING COSTS}

\section{CAPITAL COSTS}

The incremental capital and other costs for features necessary for controlled landfilling are discussed next. These features' costs in turn will be applied later to determine greenhouse cost-effectiveness as well as product gas cost.

In costing below, all cost figures will be reduced to a per-module (10x per-acre) basis Costs of equipment are estimated as installed, i. e. fully burdened and incorporating engineering and design as well as installation costs. Note that engineering/design costs are expected low since they will be spread over the large number (assumed 25) modules that are very similar. Some items have relatively greater cost uncertainties, because of limited available information or other reasons discussed below.

In estimating costs, several basic questions and issues must be addressed including

(a) What cost to assign to capital equipment which serves several modules--or serves for the total life of the landfill. Examples include

-the main water line which must deliver water to the landfill for several decades, (below) and

Topical Report: Greenhouse Cost-effectiveness of Controlled Landfilling Contract DE-AC26 98FT40422 Page 26 
-dataloggers which can serve several modules in succession.

Flares, reservoirs, etc that serve the entirety of the landfill

Clearly, a single module should not be assigned the entire cost of any item which serves several modules. The choice here for items that will serve the entire landfill is to assign to each module an estimated $20 \%$ of the total capital cost of any item shared by all modules (if the item can be expected to serve all 25 modules). This estimate considers financing, amortization and maintenance charges. Other cost estimates will be discussed as made below.

(b) The scale-dependence of items' cost. For one example increasing gas recovery rate increases size of necessary gas flares and blowers. In this report, the costs are assumed to rise at a standard scale exponent, (scale) 0.7

(c) Cost variability. Examples of this are the main water supply line which could easily vary severalfold depending on length--possibly anywhere from a few hundred feet to miles; Similarly the cost of water for enhancement (assumed irrigation water) can vary severalfold per acre foot. Numerous factors like permitting tend to vary widely depending on state rules. The overall cost variability will be discussed as part of the analysis.

(d) Level of design detail: This project's scope does not allow detailed design and costing for the host of needed "small" items. Some example items in this category are

Filters--costs for wire mesh filters are based on experienced costs for other inline filters

Other items estimated similarly include: (1) Installed line costs per foot (2) Hose fittings (3) Valves, (4) Pressure gauges (5) Orifices (6) other items presented below

Many items below are costed "generically" based on experience, including experience with similar items.

(e) Bases for cost comparison: There exist two bases against which controlled landfilling may appropriately be compared. These are (a) the situation where controls would not otherwise be necessary and where controlled landfilling is applied (b) situation where controls under NSPS standards would be required in any case. As noted earlier both situations do in fact apply to large quantities of waste in the US. Thus both will be examined below.

With this preface, the intent here is to develop "base case" costs which represent as well as possible a typical operation with approach that could be widely applied. The purpose is to 
develop a reasonable design that incorporates all likely costs as well as they can be estimated.

A discussion of costs is presented next. Costs are estimated for both a "grass roots" project and also a project where controlled landfilling substitutes for conventional "NSPS" gas recovery.

\section{Surface geomembrane lining}

It is assumed that surface geomembrane lining will be required in any event whether the landfill may be operated "conventionally" or "controlled". For purposes of controlled landfilling the maintenance of cover integrity (i.e. assuring cover does not leak) is extremely important. This surface lining is assumed to be "high stretch" linear low density polyethylene (LLDPE). This geomembrane has demonstrated excellent ability to stretch with settlement. It appears from experience to be leak-resistant as it stretches. As this is becoming a frequent cover choice at landfills it is assumed to pose no incremental cost

\section{Porous gas collection layer}

A porous layer that is freely gas-permeable is required beneath the surface geomembrane for gas recovery. Gas exiting the surface of the waste passes through this porous layer to a recovery line. Originally, this layer was envisioned to be gravel or sand, usually imported at significant cost. However shredded or chip tires are becoming widely available nationwide. Landfills will nearly always be paid to dispose of such tire material. Shredded tires have already performed quite well throughout the Yolo Demonstration project. Consequently, tire material is very attractive for use in any porous layer, either gas collection or base layer drainage. The porous layer will be assumed to be made of shredded or chip tires (there is little cost/performance difference).

Per-ton disposal fees for chip/shredded tires are similar to waste. (around \$20-30/ton now typical in California). Considering this, net cost for a two foot thick tire layer, (in the case where "extra" tire volume is not permitted and tires must substitute for waste) is assumed near zero. It is even possible that extra height due to the porous tire layer will be permitted--porous tire layers could even provide profit (though an uncertain profit, so such profit is not assumed).

Beneath the porous layer would be layers of soil (enough to bed liquid delivery system piping [described below] under maximum loads from vehicles, etc.) and "greenwaste" in ratios and layer thicknesses decided appropriate. Greenwaste is chopped up/shredded yard waste and/or other vegetative material (wood chips, etc) which landfills are paid to dispose. This soil and greenwaste material is that necessary in any case and assumed to pose no extra incremental cost over conventional practice.

Topical Report: Greenhouse Cost-effectiveness of Controlled Landfilling Contract DE-AC26 98FT40422 Page 28 


\section{Surface liquid addition points (pits).}

Pit cost: $\$ 4000$ per acre or $\$ 40,000$ per module

With the chosen design, chip tire filled "pits" in the waste surface receive liquid addition of water and recycled leachate. All measurements have indicated such pits to work quite well without problems in the demonstration. A simplified view of "pits" is seen in figure 7, "Simplified schematic of surface pits for liquid addition" Pits receive added liquid at the pits' location on the waste surface, from which it percolates down (i. e., added liquid will fill pits' void volume ${ }^{4}$ rather than possibly flow uncontrolled over the surface of the waste from the addition point). Void volume of the pits provides "surge" capacity. The spacing of these pits will be close to that used successfully in the demonstration project to give desired uniform wetting of the waste (near 40 pits per acre). For each pit, there is assumed to be a liner penetration or boot (or, alternatives to boots are possible as discussed below). Based on demonstration project experience pits are assumed easily excavated with pit and boot together costing $\$ 100$. As far as lost volume (which sacrifices waste gate fees) is concerned, pits hold chip tires so volume cost is nil.

\section{System for liquid delivery}

Liquid must be delivered to the surface pits in to enhance methane generation ${ }^{5}$. A manifolded conduit system--essentially a specialized irrigation system--will be required for controlled water distribution and delivery to the pits in the waste surface. The estimated installed cost of all components of the liquid delivery system is shown in Box 4. This cost total of $\$ 148,800$ represents an average cost of about $\$ 15,000$ per acre. Because of the importance and rather unique nature of this system a discussion of its design and basis follows.

\section{Overview of liquid addition}

The system for liquid addition consists of the following major components:

(a) A main delivery line capable of delivering liquid rapidly enough to achieve field capacity in 500,000 US tons (454,000 tonnes) over a period of 6 months. This liquid is delivered to the reservoir described later.

\footnotetext{
4 With chip tire filling pits, void vloume will be about $75 \%$.

5 The liquid might. depending on availability and permits, consist of any of (a) water, such as well water. (b) "gray" water, such as treated wastewaters often used to irrigate non-food vegetation (c) leachate and (d) condensate.
}

Topical Report: Greenhouse Cost-effectiveness of Controlled Landfilling Contract DE-AC26 98FT40422 Page 29 
FIG. 7

SINIPLIFIED SCHEMATIC (CROSS SECTION) OF SURFACE "PITS" FOR LIQUID INJECTION TO ENHANCED LANDFILL

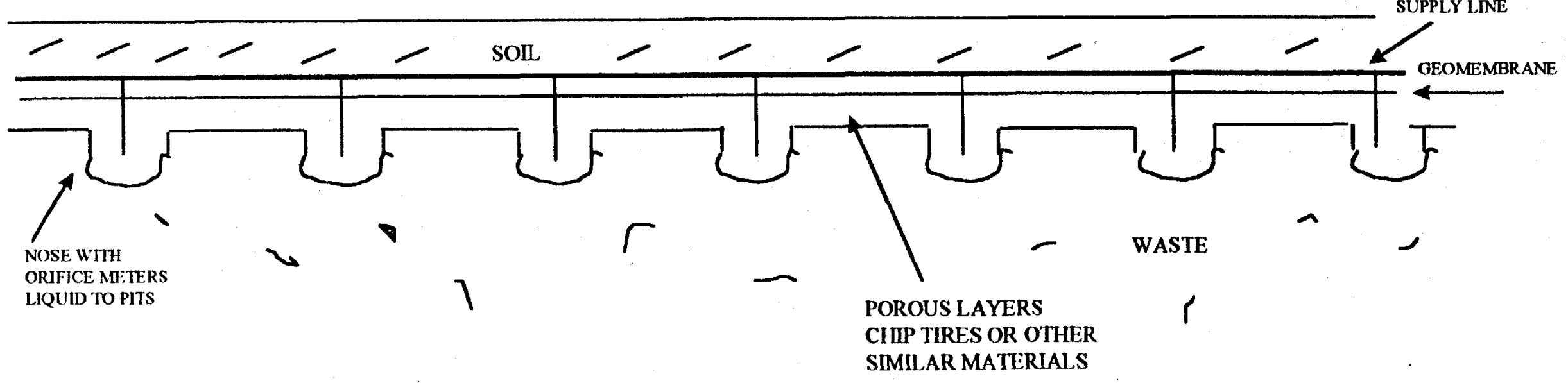


(b) A conduit system enabling water/leachate to be delivered independently on desired schedule to four sections of the landfill module. Schedule can be based on factors including desired control of the generation rate as detailed below. (The overall goal is expected to be best possible control of methane generation to match generation to energy equipment needs.) This liquid conduit system arrangement also allows for detecting and dealing with problem sections where line breaks, etc. may have occurred (below).

\section{Liquid delivery network for modules and sections within module.}

A schematic of key portions of the landfill module's overall liquid distribution system is shown in figure 8 "Schematic of conduit network: 10 acre module". The module is divided into four sections; this allows liquid addition to be "staged" with desired timing-sequential liquid addition to module sections-- as needed for maximum control of methane generation timing once the module is filled and covered. (The alternative, addition of liquid to all four sections simultaneously could lead to peaking production of gas, to extents that could be unmanageable or wasteful.) Only one section's liquid delivery manifold is represented for clarity though all four modules are manifolded. The module inlet line is equipped with inlet wire-mesh filter with mesh size sufficiently small $(0.02$ " = $0.5 \mathrm{~mm}$ ) to remove particles that could otherwise clog the orifices which control delivery. Each section is also equipped with a flowmeter (Box 4) to measure cumulated flow to that section. Simple valving determines which of the sections receives liquid through its distribution manifold. The assumed manifold design minimizes line lengths under the geomembrane cover to reduce likelihood of repairs under the cover, which would be difficult. The surface membrane is covered with soil 6 . Line can be bedded about $1 / 3$ way up in the soil above geomembrane to limit freezing problems; With this approach it is expected that elevated waste temperature, routinely seen, will help prevent any freezing in colder climates. A significant line leak in soil overlying the cover should be detectable by erosion (clearly evident at more than a few $\mathrm{gpm}$ ) or by pressure measurements with system design as described below. For line above the membrane repairs can be accomplished readily.

The liquid supply line from outside the landfill (above) is estimated to cost $\$ 100,000$. (Buried 4-inch line, estimated length $1 \mathrm{~km}$ (3370 feet) and estimated cost 30/foot = $\$ 100,000$. However length, thus cost, can vary widely). At $20 \%$ of total capital assigned per module, the per-module shared cost is $\$ 20,000$ From this water line, the liquid supply for the entire landfill simply arrives at a reservoir (described later). The reservoir delivers all received liquid as described below to conduit networks serving individual modules.

6 Note here that soil above the membrane has high value in reducing rates of leaks--by orders of magnitude for any membrane perforation area-compared to the leak rates which would occur in the absence of soil. In this respect soil and membrane are synergistic in the same way as clay and geomembrane are synergistic for bottom lining of landfills.

Topical Report: Greenhouse Cost-effectiveness of Controlled Landfilling Contract DE-AC26 98FT40422 Page 31 
Important features of the liquid supply network include

-600 PSI burst strength (standard burst strength and providing large safety factor) and stated ability of all hose to take at least 100 cycles from 0-100 PSI

-Line sizing so inline frictional pressure losses at anticipated flows (140 GPM if moisture is added at full rate over the entire module) are tolerable. Aside from pressure drops across flow control orifices, pressure drops for the conduit network below are calculated at under $\mathbf{8}$ psi from the main delivery point to liquid addition pits. Thus liquid gauge pressure is close to constant over the waste surface and to each liquid addition pit despite any elevation variations.

-Shielding of 3" line by wrapping in 4-inch diameter load-resistant polyethylene drainage line (Hancor AHPL104 AASHTO M252 Highway grade or equivalent)

-Ability to detect and localize line leaks through measurement of pressure drops across strategically placed orifices and pressure drops at ends of lines (see below)

Ability to adjust and sequence liquid additions as desired to sectors of module (below)

-Cost of $\$ 10,000$ per module for supply lines connecting the liquid/leachate storage reservoir to individual modules.

Basis: Several approaches are possible to bring liquid from the reservoir to the modules. However the least-cost approach appears to connect main liquid supply reservoir "firehose" fashion to each module as its enhancement by liquid is needed. Hose passes over the waste (as do gas collection lines at many landfills). Hose flexibility accommodates expected settlement. With this arrangement any leaks in the hose can be readily seen and fixed.

Although portable hose length (from the main water line outlet to liquid inlet of the module liquid addition manifold) differs module by module, geometry dictates this "fire hose" length increment will average about 800 feet $(=250 \mathrm{M})$. Flow can be obtained with acceptable pressure drop using a standard fire hose (if liquid addition to sections is sequenced) or two hoses in parallel with standard fire equipment (NST) fittings. List purchase price of 50' $\times 21 / 2 \mathrm{ID}$ model DJ $250 \mathrm{NST}$ is $\$ 265 / 50$ feet. Two hoses in parallel are estimated at $\$ 10,000$ per module.

-3 inch line for headers of the distribution system in individual modules (with line properly bedded for service in ground traveled by tractors ). One suitable line is Goodyear 
FIGURE 8

SIMPLIFIED SCHEMATIC OF LIQUID CONDUIT NETWORK AND PITS FOR LIQUID INTRODUCTION (10 ACRE MODULE)

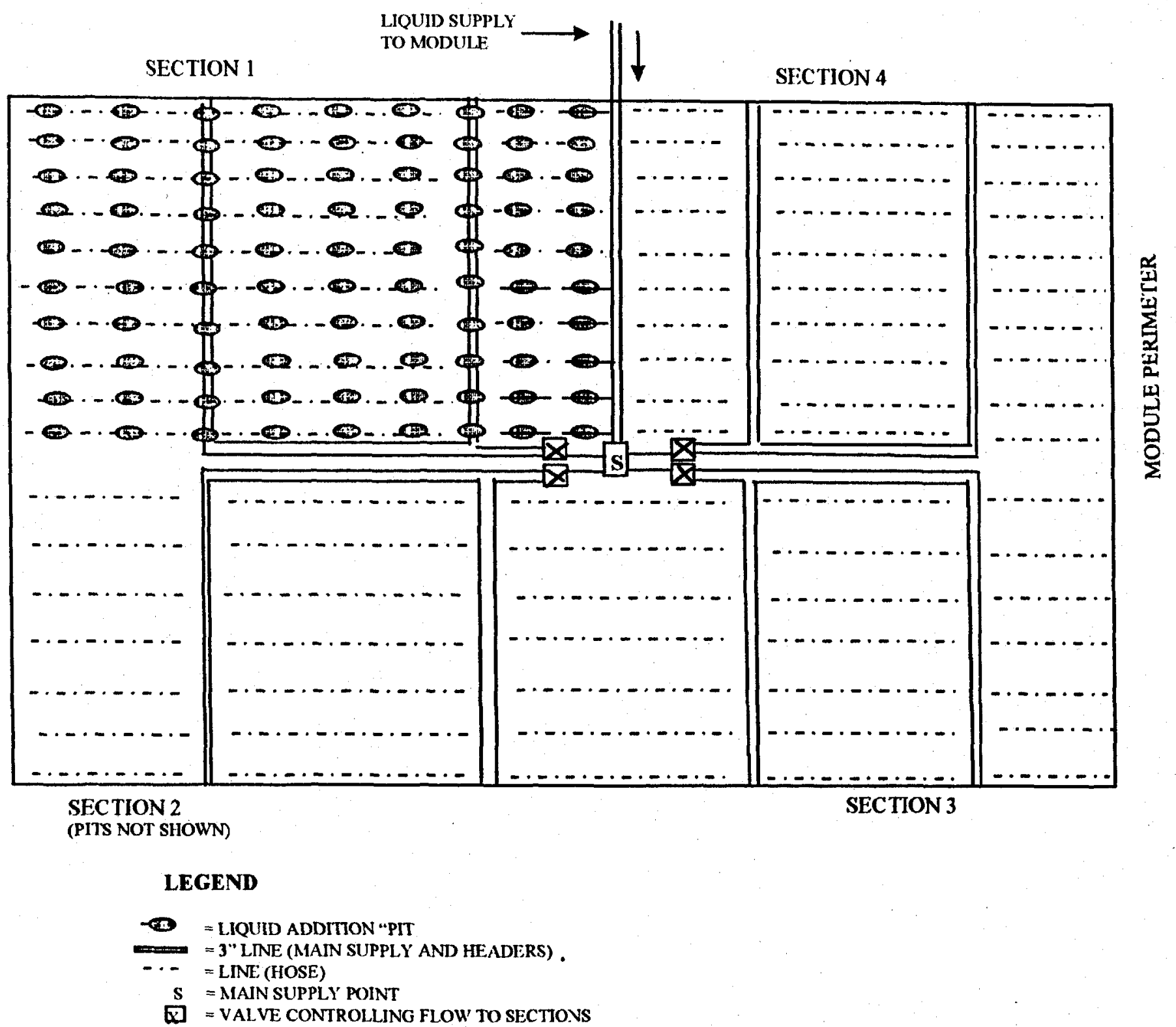


Pilicord ${ }^{\circledR}$ 542-158-107, list $\$ 7.10$ /foot with significant discounts at lengths over 1000 feet. Each line (eight per module) has simple orifice and differential pressure gauge (0$4 \mathrm{psi}$ ) for leak/burst detection at inlet point. Per module, a total of 2800 feet at $\$ 10 /$ foot installed is $\$ 28,000$. To protect this hose from breakage (from either surface load pressure or tension) it is "sleeved" in low-cost 4-inch ID load-resistant agricultural drainage line (Hancor Highway grade or equivalent, see above: List $\$ 0.35 /$ foot)

--Flowmeters to module sections (section $=2.5$ acre $=1 \mathrm{Ha}$ ). These can be simple circular stainless orifice plates with differential pressure gauges (an example gauge is the Omega PX26-005GV). Alternately, pulsing flowmeters such as Omega FTB6120-PT One per 3-inch header or 8 per module at $\$ 1000$ each $=\$ 8000$.

Pressure gauges, $0-150 \mathrm{psi}, 8 /$ module at $\$ 100=800$. Omega cat. PGS-35L series or equivalent. For leak detection at hose ends (below)

-Low-cost garden or garden-style hose (installed cost about $\$ 1 / \mathrm{ft}$ ) is the final conduit from the 3-inch header hose to each "pit". Sears Roebuck and other vendors sell suitable hose (rated at a surprising 600 PSI burst strength) at about 50 cents/foot. This cost is comparable to the 43 cents per foot paid for line in the demonstration. 14,000 feet at $\$ 1 /$ foot $=\$ 14,000$

(Note possible alternatives to this design such as discussed in the box, next)

Note design alternative: Geomembrane surface liner penetrations may be simpler or avoidable. Individual boot penetrations allowing "garden hose" access to each pit were assumed above. The "assembly line" installation of 400 of these per module has been assumed to lessen cost so that the total cost of pits with boots was $\$ 100$. However: if needed penetrations are too costly or undesirable there are also other options (a) running more of the smaller "garden-style" hose under the geomembrane cover. For example one penetration could serve (say) five pits. Variation on this which could allow dealing with undercover leaks would be to make this line redundant--two hose lines either of which could serve the same several liquid addition pits. (b) Simpler penetration than boots may also work well. Darcy flow conductivity of the tire-chip or other permeable layer, $4+$ orders of magnitude or more higher than the tire-chip permeable layer should allow satisfactory extraction with membrane coverage which will cover $99+\%$ of waste area in any event.

These are but examples of many design alternatives which can be examined in more detail in progressing to a large-scale operation 
-Marking/protecting and valving above-ground "garden" hose terminals above; 80 terminals $\mathrm{x} \$ 100=\$ 8000$

Basis: The end of this "garden" hose--the termination point, farthest from the 3-inch header and beyond the last "pit"-- is left protruding slightly above ground. The end is valved (Drum brass hose shutoff, 73010-0 C-300, local retail cost $\$ 15$ in hardware store). The valve is left closed except when pressure check is desired. The hose terminus is also surrounded by simple wire cage (such as protects newly planted trees) and flagged (durable yellow tape) for visibility. Leak detection and leak location is possible by attaching pressure gauges as needed to the hose ends in vicinity of suspected leaks. Any serious leak (such as open hose coupling or aggregated perforation area more than fivefold the individual pit orifice opening) can be seen from reduced pressure at the hose end and localized by these pressure measurements.

-For each connection of the 3 -inch header to 0.6 inch hose, possibly within adjacent hoseto-hose coupling: An orifice giving a pressure drop of $10 \mathrm{psi}\left(6.9 \times 10^{5} \mathrm{dyne} / \mathrm{cm}\right)$ when flow to the adjacent pits is at design rate of $0.35 \mathrm{GPM}$ or 0.0225 liters per second to each pit. This orifice is simply an inline perforated circular plate (i. e. stainless disc "sandwiched" in a standard hose-to-hose coupling). This orifice will (a) limit maximum flow should there be a break in line serving a group of pits, to about 3 times the design flow. Three times the design flow would be a tolerable level. (b) it will also enable leak detection with leaks past the orifice, through increased pressure loss downstream. Orifice cost included in "fittings" below.

-In individual line leading from the 0.6 inch hose to each pit: a single orifice to control flow. This orifice is simply an another inline perforated circular plate "sandwiched" in a standard hose-to-hose coupling. The orifice is sized at 0.041 in. diameter or $0.0105 \mathrm{~cm} 2$ to deliver liquid to each pit at the design flow rate to each pit of 0.35 GPM (.0225 liters $/ \mathrm{sec}$ at the $90 \mathrm{psi}$ pressure drop). The orifice would be sandwiched in the branch tee coupling above the membrane for easiest accessibility in repairs. Size of orifices would be reduced to appropriately reduce flow (flow proportional to depth) over shallower portions of the landfill such as side slopes.

Costs of this orifice also included in "fittings" below.

\section{Fittings--total}

-Per module, fittings as described in text, total cost est. $\$ 10,000$. Fittings include $403 " \mathrm{x}$ 1/2" (nominal) plastic cross tees at \$5.00,4001/2" branch tees (hose "Y's" @ 1.00 and 400 orifices (above). Hose clamped to larger 3 " x 1/2" fittings by "radiator hose" clamps. 
Basis: Many of these are standard irrigation/garden supply or otherwise simple items. The hose branch tees (standard hose thread fittings) are available for standard hoses in garden supply stores. Hose tee fittings can easily incorporate orifices described above. These orifices are simply circular stainless discs that sandwich into hose couplings. The orifice has an 0.04 inch $(0.11 \mathrm{~cm})$ diameter hole. Even if custom made they should cost under $\$ 2.00$ each. Although the item acquisition cost total less than $\$ 2000$, it is considered likely that installation per item could run to about \$3-\$6 each.

As noted, the 3 inch line and garden hose would be located and bedded about $1 / 3$ of the way up within surface soil, except for that vertical (garden) hose which would run down into each pit. The 3-inch hose would be sheathed in low-cost 4-inch load-bearing agricultural drainage line (described above). About 10-20\% extra line length over "straight run" is allowed for all lines to minimize chances of accidental line breakage in tension. All subsurface line, properly bedded in soil or greenwaste, should withstand any expected surface loading such as from vehicles without breakage.

Regarding experience and workability, it can be noted that this design is based on one that has functioned well without any problems for over two years in the Yolo demonstration.

-Simple stainless wire mesh filter on inlet hose and additionally 4 similar filters, one for each section, on central distribution system. Five with housing at $\$ 1000$ ea.: total $\$ 5000$

-Valve on main supply line (200GPM maximum flow) +4 valves, one per section (50 GPM maximum flow) $\$ 1000$ each Total $\$ 5000$

Inlet liquid flowmeters: One on main supply line and one to each section: 5 Signet 2535 (or 5 Sparling Tigermag FM 625) as have performed well in the demonstration, or equivalents. These connect to the central datalogger so that cumulated flow to sections can be readily referenced. (These could in fact substitute for the 8 large orifices on the inlet header. However both orifices and inlet flowmeters will be included in the design) $\$ 1500$ each $=\$ 7500$

QA/QC: Test water pressure/flow relationships during manifold construction: 100 hours at $\$ 75 / \mathrm{hr}=7500$

Total costs of the liquid distribution system are summarized in box 4 .

The above has detailed the liquid distribution manifold, the "irrigation system" ducting for providing liquid to the waste. Other equipment is described next

Other equipment

Sensors: $4 /$ acre at 1000 each.

Topical Report: Greenhouse Cost-effectiveness of Controlled Landfilling

Contract DE-AC26 98FT40422 Page 36 
Basis: Waste is filled normally and there is no incremental cost for filling. However 4 moisture sensors per acre (40/module) are placed to give reasonable indication that waste moisture reaches sufficient levels in the module and each of its sections. These sensors (demonstration versions were custom made by the Yolo County Chief Engineer, and consisted simply of a capacitance element in a plaster of Paris block;) are estimated, installed with leads, to cost $\$ 1000$ each for a total of $\$ 4000 /$ acre.

Water is supplied to the main supply line at an assumed $\$ 50-200 /$ acre-foot for a cost of $\$ 2500-10,000$. (Water cost could vary widely either way in different localities).

A liquid storage reservoir is required at estimated cost of zero to $\$ 10,000 /$ module

Basis: This reservoir would be similar to that described in Augenstein, Yazdani, Moore and Dahl 1997 for the field demonstration project, only larger to accommodate management of greater amounts of liquids. The reservoir receives input liquid from the external source at flows that depend on needs, and leachate at rates exiting waste (mostly from the enhanced cell). Reservoir outlets (valved, with automatic controls governing flows) can recirculate received leachate to the landfill section/ module, or to any new module that needs liquid as it is implemented, or alternatively, disposal.

An important consideration is that a leachate storage reservoir is needed in any case for conventional landfilling. Reservoir cost for controlled landfilling is incremental and depends on chosen configuration and size, and is estimated at $\$ 0-50,000$ over what would be required conventionally. (The minimum--zero cost--could result in various ways, paticularly if recirculation to extant landfill cells is always available as an option, which is deemed likely.) Note that controlled landfilling will generate no liquid for external disposal [based on field tests and experience] or be a net consumer of liquid. This will be the case so long as waste placement continues for the assumed $30+$ years.) The reservoir will be shared by all modules, giving the per-module cost of $\$ 0-10,000$.

$\$ 5000$ for 100PSU/150GPM corrosion resistant liquid supply pump (from reservoir).

Basis: The reservoir will require a pump in any event. This is only incremental cost and estimated at $\$ 25,000$ for the higher capacity higher pressure pump.

Base of landfill: A gas extraction "tap" line for early recovery as each module is filled but before cover is in place (as mentioned above this is a load-resistant ribbed polyethylene agricultural drainage line with suitable modifications). With valve and pressure gauge, est. $\$ 5000$. 


\section{Box 4}

\section{Liquid delivery system components and costs per module.}

Basis: 10 Acre (4 Hectare, Ha) Module; (Subdivided into 4 sections, 2.5 acres each.) See text and figure 8

\section{ITEM AND INSTALLED COST}

Main water supply: Assume $1 \mathrm{~km}$, (3370 feet) 6-inch buried line from source, $20 \%$ of total line cost

$\$ 20,000$

Flexible liquid delivery hose (see text) 3 to 4-inch line (aboveground) $\$ 10,000$

Section headers. (See figure 8 and text) 2800 feet 3 inch $(6.3 \mathrm{~cm})$ ID line at $\$ 10 /$ foot installed

$\$ 28,000$

Orifices and pressure gauges on section header inlets

$\$ 8000$

Pressure gauges

$\$ 800$

0.6 inch garden hose

$\$ 14000$

Protecting/flagging exposed 0.6 inch hose ends

$\$ 8000$

Fittings (see text)

$\$ 10,000$

Filters: Housed stainless wire mesh (total 5)

$\$ 5000$

Valves: Main supply and header (total 5)

$\$ 5000$

Inlet flowmeters (5/section)

$\$ 7500$

QA/QC

$\$ 7500$

Miscellaneous

$\$ 10,000$

SUBTOTAL

$\$ 124800$

contingencies at $10 \%$

$\$ \underline{12500}$

TOTAL

$\$ 148,800$

Datalogger and transponder, cost estimated from demonstration at $\$ 15,000(20 \%$ of $\$ 75,000$.)

-Permitting: If "cookbook" design and permitting approaches can be practiced (as with other landfill aspects such as gas recovery) incremental cost could be quite small. On the 
other hand permitting review may be needed. Incremental permitting cost (over normal) is estimated as ranging between $\$ 1000-10,000$.

-Gas recovery monitoring: Corrosion resistant gas meter, 0-5000 CFM, per module. Output provides electronic signal which cumulates recovery. Gas recovery measurement from an individual module provides real-time information on the progress of enhancement and allows "fine tuning" of liquid addition for enhancement. This would be a fairly simple instrument, $\$ 15,000$ to 20,000 based on demonstration costs and discussion with staff of the Roots meter division of Dresser Industries, Houston, TX.

-Monitoring of undercover gas pressure. With surface membrane coverage it is necessary to keep pressure within limits that are negative--at least marginally-- by adjusting valving. Manual adjustment (practiced in the demonstration) is one option. However a proportional controller capable of maintaining -0.5 to -6 in $\mathrm{H} 2 \mathrm{O}$ head is sold by Omega. Omega Model PX-750-06DI and large orifice $(300 \mathrm{~cm} 2$ maximum open area) proportional control valve, with installation, estimated at $\$ 5,000$.

Gas line from module:

For landfill with no gas system otherwise: 700 feet per module at $\$ 50 /$ foot $=\$ 35,000$

Basis: Incremental length of gas pipe needed per module is estimated at 700 feet. Ten inch $(25 \mathrm{~cm})$ line, installed, with condensate traps is estimated at $\$ 50 /$ foot. Although PVC pipe is often used, lower-cost agricultural drainage line can also be used (Hancor, Patterson CA is one vendor).

Compared with conventional controls: Assume doubled diameter, for 700 feet at $\$ 10$ extra/foot $=\$ 7,000$

Basis: Although this gas pipe may need to handle up to tenfold more gas flow than conventional practice from the same tonnage of waste in a given cell, capacity increases for turbulent flow as the cube of diameter. Furthermore, straight-run line, with perforated section withdrawing from the permeable layer, can run to preexisting gas collection line. This shorter straight-run line substitutes for the complex manifolding ordinarily associated with multiple gas wells that would ordinarily extract gas from the module. (The option of light movable air duct hose should also be investigated.)

(Note that actual gas recovery line length can vary, by a factor of two or more, depending on landfill configuration)

Flare and Blower:

Topical Report: Greenhouse Cost-effectiveness of Controlled Landfilling

Contract DE-AC26 98FT40422 Page 39 
A flare will be required as backup to energy equipment to dispose of gas when energy equipment is not working. The expected maximum gas flow is $5000 \mathrm{cfm}$

When compared to the absence of any control the total cost of the flare is estimated at $\$ 220,000$ installed. This value is obtained by scaling up experienced Yolo costs $(\$ 115,750$ for a flare meeting stringent California standards. Ziegler Inc. Yolo County Purchase order Y-372) by a factor of 2.5, using a scale exponent of 0.7 (i.e. the Yolo $\left.\operatorname{cost} x 2.5^{0.7}\right)$. The shared per-module cost $(0.2$ of total flare capital) will be $\$ 44,000$.

When compared to the situation of conventional control, the incremental flare cost is estimated by the same approach at $\$ 20850[(220,000-115750) \times 0.2]$

Gas recovery blower: A gas recovery blower will be necessary to recover landfill gas for energy equipment and for the backup flare. The reference blower in this case is actually a skid including HDPE piping, valves, condensate collection tank, two $1000 \mathrm{scfm}$ blowers (actual cost experienced for Yolo County flare as bid/installed, adjusted for scale)

When compared to the absence of any control the total cost of the blower skid (shared among modules) will be $\$ 175,000$. Per-module cost is $175,000 \times 0.2$ or $\$ 35,000$

When compared to the situation of conventional control, the incremental blower cost determined as above is $\$ 16,000$.

Incremental labor costs in construction (over and above normally incurred): assumed $\$ 100 /$ day for 300 days during setup and implementation of each module or $\$ 30,000$; This is based on demonstration project experience.

Base layer drainage: It is assumed that the leachate recovery and control system is identical to that required by conventional landfills. Note that percolation rates, i.e. superficial liquid velocities of $24^{\prime \prime}$ [60 $\mathrm{cm}$ ] per year are experienced at desired waste moisture in the Yolo demonstration, easily managed with conventional design. Thus it poses no extra cost.

When controlled landfilling is substituted for NSPS gas recovery, there is a credit for gas well costs avoided. Estimated at $\$ 4000 /$ acre $=\$ 40,000 /$ module.

The total incremental cost has been compiled by the author using assumptions above, and with help and expert judgment of staff of the Department of Solid Waste and Planning, Yolo County, CA. This total incremental cost is shown in Table 1.

All the above are capital costs. In addition to these capital costs there will be operating costs. The operating costs can be estimated based on the demonstration project experience. Experience has been that (aside from gathering up voluminous data which are 
experimental in nature) the system would ordinarily function with limited attention of one person, about $20 \%$ of a fully burdened cost of a person-year or 20,000 , and about $5 \%$ of capital or another $20,000 /$ year for maintenance, for a total of $40,000 /$ year. This is for a comparison of a controlled landfilling system with no controls. For highly automated operation (valving of gas extraction) and the amount of equipment repair which has characterized the demonstration so far, a controlled landfill operation could actually cost less than a conventional gas system's operation (which requires weekly well adjustments and ongoing repairs). The extraction period for controlled landfill operation should be under 10 years as opposed to at least 30 for conventional NSPS operation. It can be noted that the controlled landfill and conventional operation are carried out in parallel at the Yolo site. 


\section{Table 1}

Summary of Incremental 1000 TPD Controlled Landfill Component Costs per Module: Comparison Bases, no Controls and NSPS Controls

\section{Item}

Pits in waste surface

Liquid delivery system (see text)

Sensors at \$ 4000/acre

Water supply

Leachate/liquid reservoir (shared among modules)

Liquid supply pump on reservoir

Base layer gas "tap" line (see text)

Datalogger and transponder (shared among modules)

Permitting

Gas flowmeter

Proportional valve. porous layer pressure control

from module

Flare as backup to energy equipment (shared)

Gas recovery blower (shared)

Incremental labor during construction

Credit for vertical well cost avoided

Subtotal (thousands)

Contingency at $10 \%$

TOTAL CAPITAL COST
Incremental

"Grass roots"

Cost vs. no Control

$\$ 40,000$

$\$ 148.800$

$\$ 40,000$

$\$ 2500-10,000$

$\$ 0-10,000$

$\$ 5,000$

$\$ 5000$

$\$ 15,000$

$\$ 1,000$ to 10,000

$\$ 15,000-20,000$

$\$ 5,000$

$\$ 35,000$

$\$ 44,000$

$\$ 35,000$

$\$ 30,000$

-0 --

421.3 to 452.8

42 to 45

463,000 to 498,000
Incremental

Cost vs. NSPS

Controls

same

same

same

same

same

same

same

same

same

same

sameGas line

7,000

21,000

16,000

10,000

$(40,000)$

291.3 to 322.8

29 to 32

320,000 to 355,000

Topical Report: Greenhouse Cost-effectiveness of Controlled Landfilling

Contract DE-AC26 98FT40422 Page 42 


\section{CONTROLLED LANDFILLING COST COMPARISONS WITH ALTERNATIVES}

\section{GREENHOUSE GAS ABATEMENT COSTS}

Analyses below compare three landfill modules, with sizes of 500,000 tons each. One module is operated as a controlled landfill, one comparison module has no gas controls, and one is operated conventionally with controls specified under the New Source Performance Standards ("NSPS landfill"). The factors evaluated for the comparison landfill cases are (a) absolute and relative greenhouse emissions over time (b) fossil fuel offsets over time and (c) methane recoveries over time. Both (a) and (b) are expressed as $\mathrm{CO}_{2}$ equivalents. Costs to attain abatement in dollars per tonne $\mathrm{CO}_{2}$ equivalent are then calculated for the relevant cases followed by costs of methane energy.

Before proceeding with performance estimates and discounted cash flow cost analyses, important assumptions and approximations used in analyses are noted as follows:

1. All capital costs are incurred in a lump sum, one year before cell filling is completed.

Basis: Actually, capital costs begin to be incurred 1.37 years before filling is completed. Nearly all major capital cost (through cover completion) would accrue within 6 months after module filling is complete. Costs would actually be experienced later, on average. This conservative assumption introduces little error.

2. Methane generation kinetics:

Generation by waste in the "base case" conventional NSPS landfill with conventional controls, and landfill without controls, is assumed to follow the "first-order" model (also Scholl Canyon model or "EPA model", the standard model used by the US EPA. This model was also found to be the "best fit" in the 19-landfill model study by Vogt and Augenstein, 1997). The first order model expression for methane generation at time $t$ years from waste placement in the landfill is

$$
\mathrm{Gm}=\mathrm{MkLoe}-\mathrm{kt}
$$

Where

$\mathrm{Gm}=$ methane generation

$\mathrm{M}=$ mass of waste, tons

$\mathrm{k}=$ first order rate constant, 0.07 year -1

Lo $=$ methane yield 1.4 cubic feet per pound $(2800 \mathrm{ft} 3=2.8 \mathrm{MCF} / \mathrm{US}$ ton $)$

$\mathrm{e}=$ base of natural logarithm

The values of $\mathrm{k}=0.07$ and Lo $=2.8 \mathrm{MCF} /$ ton are parameters giving "best fit" in the SCS Engineers/LEM study. 
3. Fugitive methane emissions before full controls start: It is necessary to account for inevitable emission of some methane which will be emitted during placement, from start to completion of filling, and, thereafter, for the interval (brief) while the waste surface is open before control starts. For both controlled landfill and conventional NSPS control cases, total generation (to be distinguished from emission--see below) is the integral of the expression above evaluated from start of filling to finish of either membrane coverage or the installation of vertical gas wells. Over short intervals (say such that $k t<0.2$ ) a simple, close approximation to this generation for a constant fill rate is: $(k / 2) t_{f}+k t_{c}$ as a fraction of the total generation potential of the waste where

$-t_{f}$ is fill time (linear fill rate of 1000 TPD) and

$-t_{c}$ is the interval from completion of filling to gas capture by either membrane (controlled landfill) or vertical wells (conventional landfill with controls under NSPS)

To make comparisons as close as possible, and also presuming "best case" control, it is assumed that emissions are halved via "tapline" extraction of methane from the base porous layer of both the controlled and NSPS (conventionally controlled) landfills. Assuming $t_{f}=500$ days and one year thereafter to attainment of full control, the generation will be about $8 \%$ and fugitive emissions will be about $4 \%$ of the "conventional" gas potential $\mathrm{Lo}^{7}$. (Without bottom layer "tapline" extraction fugitive emissions would be $\approx 8 \%$ of the total generation potential) The balance of gas (92\% for the NSPS landfill) is generated after controls start, and is then subject to control at efficiencies specified below.

3. For the controlled landfill capture is $100 \%$ after coverage (a slight porous layer vacuum can assure total recovery). Timing is assumed as follows: remaining methane is generated at constant rate with generation completed in five years, (Zero order model; see Vogt and Augenstein, 1997) Ultimate yield ( $\cong 20 \%$ higher because of optimized conditions ${ }^{8}$ ) is 1.8 cubic feet of methane per pound of waste, less the 0.11 cubic feet generated before full controls start. Thus methane is generated at 0.3376 cubic feet $/ \mathrm{lb}$. year from start of enhancement, to its completion five years later. (As a comment on this recovery assumption, it is less than recovery from the Yolo County demonstration so far: Methane recovery was 0.57 cubic feet per pound for the first full calendar year.)

For the entire controlled landfill module, gas is generated at a rate of 337.6 million cubic feet, or 337,600 MCF (MCF or thousand cubic feet being the standard gas and petroleum industry unit) in years three through 7.

4. For both the controlled and NSPS landfills, as noted above, the abatement or energy value of tapline gas is accrued at the end of year 2 ( 1 year after completion of filling). The value of remaining gas is accrued at the endpoints of year 3 and onward and continues according to the respective kinetics and assumed recovery efficiencies.

\footnotetext{
7 This is the product of fractional recovery $=0.5 \times(4.7 \%$ of Lo during filling $+3.3 \%$ of Lo during a six month period before capture can be maximized)

8 This is an estimate based on a number of discussions with knowledgable parties
}

Topical Report: Greenhouse Cost-effectiveness of Controlled Landfilling

Contract DE-AC26 98FT40422 Page 44 
5. For the NSPS landfill, and reference landfill module without controls, the expression for methane generation $\mathrm{Gm}$ within any given year becomes, slightly modified from (3) above:

$\mathrm{Gm}=0.92 \mathrm{MLo}(0.932394)^{(\mathrm{t}-3)}$

or rearranging and substituting actual parameters

$\mathrm{Gm}, \mathrm{MCF}=1,589,000(0.932394)^{t}$

Where symbols are as in 2 . above

6. The greenhouse potency of methane relative to $\mathrm{CO}_{2}$ is the Intergovernmental Panel on Climate Change value of $21 / 1$ by weight. After appropriate conversions, this equates the standard U. S. Petroleum industry unit, 1000 cubic feet, or $1 \mathrm{MCF}$ emission, to emission of 0.4 metric tons (tonnes) of methane.

7. Energy use and fossil $\mathrm{CO}_{2}$ offsets from recovered methane: It is also assumed for purposes of estimation that $80 \%$ of recovered methane, whether from controlled or NSPS landfills, will be used for energy. Use is in fueling electric power generation at heat rate of $10,000 \mathrm{Btu} / \mathrm{kWh}$. (about $70 \%$ of landfill gas use is in electricity generation) Each $\mathrm{MWh}$ of electric power generated by renewable methane abates 1 US ton ( 0.9 tonnes) of fossil $\mathrm{CO}_{2}$. The basis for these assumptions is discussed in more detail later (fossil fuel displacement, page 76). With these assumptions, each MCF of recovered methane reduces (offsets) emissions of 0.072 tonnes of $\mathrm{CO}_{2}$.

For the NSPS landfill it is further assumed that recovery is of methane is $75 \%$ and fugitive emissions $25 \%$ while controls operate. It is assumed for purposes of calculation that the first full years' recovery is realized at the end of year 3 and ends 30 years after postclosure recovery begins, or, at the end of year 32 . After this interval all generated methane is emitted to the atmosphere.

8. In comparing controlled landfilling with the absence of controls, the controlled landfilling incremental operating and maintenance (O\&M) costs (above) accrue at the endpoints of year 2 to year 7 , that is, operating costs continue for 6 years. Thereafter they are zero, that is O\&M costs equal those of landfills with no controls. In comparing controlled landfilling with conventional landfill gas recovery (the NSPS landfill) the operating costs are, for purposes of comparison, assumed equal ${ }^{9}$.

9 In fact, because of longer term, the conventional operating costs would be greater so this is judged conservative.

Topical Report: Greenhouse Cost-effectiveness of Controlled Landfilling Contract DE-AC26 98FT40422 Page 45 
Greenhouse emission comparisons: conventional, controlled and uncontrolled "base cases"

The greenhouse cost effectiveness evaluations compare three landfill modules of 500.000 tons each. One landfill has no controls, one is operated conventionally and the other operated as a controlled landfill. Factors evaluated for the comparisons are (a) comparative greenhouse methane emissions over time and (b) fossil fuel offsets. Both (a) and (b) are expressed as $\mathrm{CO}_{2}$ equivalents. Costs per unit greenhouse gas abatement are then calculated.

\section{Economic analyses: greenhouse cost effectiveness}

The economic analyses of "greenhouse cost effectiveness" of landfill gas control apply a variant of "discounted cash flow" (DCF) or "discounted value" analysis applied to prevention of emissions as they would occur over time.

It can be commented that "discounted cash flow" does not seem ideal terminology here, since results are emissions abatements and their "worth" in those units (abatement discounted into the future). However discounted cash flow (or other value) analysis is very widely accepted and will be used below.

A range of discount rates, $d=0 \% 7 \%$ and $15 \%$ (APR, Annual Percentage Rate) are used. For the case where the discount rate is zero, a case can be made for taking "full early credit" for prevented landfill (greenhouse) gas emission. Argument for a zero discount rate $(d=0)$ is that an environmental technology by definition must protect and value the future, and the future ought not be discounted to the extent usual in the investment sense $^{10}$. A low discount rate is also supported on the basis that methane capture, once assured, is future environmental benefit "in the bank". From policy standpoints, there is significant advocacy for dealing with future atmospheric greenhouse methane rises through early actions. Greenhouse gas reduction is, whatever the time of the reduction, not instant in effect but always reduction in subsequent radiative forcing of climate. It is interesting that, in policymaking, or assessing climate effects, future reduction in radiative forcing as the consequence of any incremental greenhouse gas abatement is almost never discounted over time.

For purposes of this base case analysis discount rates of zero (explained above) $7 \%$ (representative of municipal financing) $15 \%$ (representative of private financing) are used.

10. The problem with discounting future values and benefits can be illustrated by a reductio ad absurdum: At discount rate of $12 \%$, present worth. in 300 years of the total current value of all goods and services created annually by all of the world's people (total world product) will be about one dollar. By DCF criteria it would not appear worth spending more than a dollar to insure continuation of a year of human activity 300 years in the future.

Topical Report: Greenhouse Cost-effectiveness of Controlled Landfilling

Contract DE-AC26 98FT40422 Page 46 
Pollution abatement and other environmental benefit projects are characterized by low costs of funds These values are also used in calculating methane cost later.

In analyses below, energy is most convenient to express in terms used in the US gas industry (one $\mathrm{MCF}=1000$ cubic feet of methane $=10^{6} \mathrm{Btu} \approx 1.06 \mathrm{Gj}$ ). Energy recovered will have units of MCF. Emissions will have units of $\mathrm{CO}_{2}$ equivalents abated and the units are tonnes $\mathrm{CO}_{2}$. Energy, or abatement of methane emission or (to equivalent effect) offset of $\mathrm{CO}_{2}$ emissions at some future time will have a value or "worth" (As an example abatement could be "worth" \$10/tonne $\mathrm{CO}_{2}$ equivalent at implied carbon tax ca. \$27 US per tonne). The discount rate, though applied to energy or emissions, also has monetary meaning in being equivalent to the cost of capital, interest cost on funds, or in some cases, necessary gross return to compete with alternatives.

Additional assumptions other than the above used in greenhouse gas and "greenhouse cost effectiveness" calculations are:

1. Using the IPCC $\mathrm{CO}_{2}$ equivalent of methane, where $1 \mathrm{MCF}=0.40$ tonnes, both the uncontrolled and conventional NSPS landfills generate a total of 620,200 US tons (560,000 tonnes) of $\mathrm{CO} 2$ equivalents.

2. For controlled and NSPS landfills; with $92 \%$ of generation occurring after year 3 , the methane generation in tonnes equivalent $\mathrm{CO}_{2}$ is given by

$\mathrm{G}_{\mathrm{CO} 2}=34830.7(.932394)^{\mathrm{t}-3}$ or, rearranged, $\mathrm{G}_{\mathrm{CO} 2}=42970(0.932394)^{\mathrm{t}}$

where $.932394=e^{-.07}$

The $\mathrm{CO}_{2}$ equivalent emission of the landfill without controls is 44800 tonnes at year 2 and thereafter given by the expression above. The $\mathrm{CO}_{2}$ equivalent emissions of the NSPS and controlled landfills are 22400 tonnes at year 2 and then as discussed below.

3 For the NSPS landfill the $\mathrm{CO}_{2}$ equivalent emission $\mathrm{E}_{\mathrm{CO}}$ is given by $25 \%$ of the expression above from year 3 to year 32 , or

$\mathrm{E}_{\mathrm{CO} 2}=10742.5(0.932394)^{\mathrm{t}}$

Thereafter, after year 32, all generated methane (equivalent $\mathrm{CO}_{2}$ ) is emitted.

(As a background note: Higher fractional capture of generated gas is possible if there are surface geomembranes used on "dry NSPS landfills. However this results in dry waste entombment. Resultant entombment and associated problems are considered unlikely, in the long term, to be allowable or acceptable for waste management--see

Topical Report: Greenhouse Cost-effectiveness of Controlled Landfilling Contract DE-AC26 98FT40422 Page 47 
earlier. When there are no controls it is assumed that all ${ }^{11}$ generated gas reaches the atmosphere as fugitive. emissions. )

4. For the NSPS and controlled landfills, it is assumed that $80 \%$ of methane is used in an energy application. This energy application is assumed to be electricity generation (70\% of landfill methane used for energy generates electricity in the US). Electricity generation by methane is at efficiency of $0.1 \mathrm{MWh} / \mathrm{MCF}$ (these numbers are representative but can vary) and methane used displaces "swing" fuel which emits 0.9 tonnes $\mathrm{CO}_{2} / \mathrm{MCF}$. Thus the captured methane provides a further $\mathrm{CO}_{2}$ offset (at $80 \%$ use) of 0.072 tonnes $\mathrm{CO}_{2} / \mathrm{MCF}$

A comment is needed here on $\mathrm{CO}_{2}$ contained in landfill gas: This $\mathrm{CO}_{2}$ cannot be considered net greenhouse gas addition since it represents atmospheric $\mathrm{CO}_{2}$ captured in the first place (in fact all petrochemical and much photosynthetic $\mathrm{CO}_{2}$ remains unconverted. Landfills on net are sequester much carbon. This is discussed later)

From the foregoing, and substituting values, the equation allowing calculation of the greenhouse cost effectiveness for the controlled landfill in comparison with no controls is

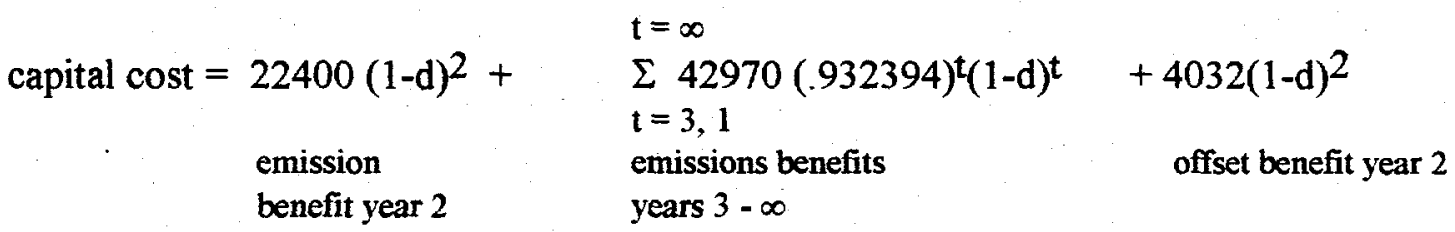

$$
\begin{array}{ll}
t=7 & t=7 \\
+\sum 24307.2(1-d) t & -\sum 40,000(1-d)^{t} \\
t=3 & t=2,1 \\
& \text { discounted operating } \\
\text { offset benefits } & \text { costs (years 2-7) } \\
\text { years 3-7 } &
\end{array}
$$

The cost per tonne $\mathrm{CO}_{2}$ is the (capital cost + discounted operating cost), divided by total net benefit in tonnes $\mathrm{CO}_{2}$ from both offset and emissions benefits on the right-hand side of the equation.

11 Some generated methane, a few percent, may be oxidized in certain landfill soil covers 
The equation for greenhouse cost effectiveness for the controlled landfill in comparison with the NSPS landfill is

capital cost $=$ (net discounted emissions NSPS landfill, tonnes $\mathrm{CO}_{2}$ ) - (net discounted offsets of controlled landfill, tonnes $\mathrm{CO}_{2}$ )

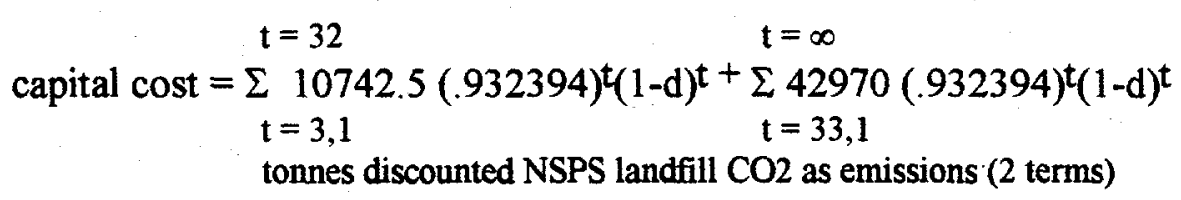

$\begin{array}{ll}\mathrm{t}=7 & \mathrm{t}=32 \\ +\sum 24307.2(1-\mathrm{d})^{\mathrm{t}} & -5800.8 \Sigma(.932394)^{\mathrm{t}}(1-\mathrm{d})^{\mathrm{t}} \\ \mathrm{t}=3,1 & \mathrm{t}=3,1 \\ \text { tonnes controlled } & \text { tonnes NSPS } \\ \text { landfill CO2 offsets } & \text { landfill CO2 offsets }\end{array}$

(note that there is no operating cost differential for the NSPS vs. controlled landfill)

The cost/tonne $\mathrm{CO}_{2}$ for the NSPS-controlled landfill comparison is simply capital cost (for example from table 1) divided by the total net tonnes $\mathrm{CO}_{2}$ from both offsets and emissions on the right-hand side of the equation above.

Appendix 1 details the discounted cash flow (value) analysis for tonnes $\mathrm{CO}_{2}$ equivalent emissions for the uncontrolled, NSPS and controlled landfills at various discount rates. (This is actually a "debit" analysis since emissions have a negative value). Present value is the discounted $\mathrm{CO}_{2}$ emission, and the benefit is in tonnes lessened emissions.

Appendix 2 details the discounted cash flow (value) analysis for $\mathrm{CO}_{2}$ offsets for the controlled landfill module, and NSPS landfill module of the same size. "Present" value is the discounted annual offset, in units of tonnes $\mathrm{CO}_{2}$.

Appendix 3 details the discounted operating costs in equation (cont. vs. no control) above

With the values of Appendices 1-3 and capital cost from Table 1 it is possible to calculate the $\mathrm{CO}_{2}$ equivalent abatement cost for the "base case". This calculation is performed in table 2. In essence, table 2 calculates cost/tonne $\mathrm{CO}_{2}$ compared to no control and NSPS control, at the various discount rates as

Topical Report: Greenhouse Cost-effectiveness of Controlled Landfilling Contract DE-AC26 98FT40422 Page 49 
cost $/$ tonne $\mathrm{CO}_{2}=\quad$ capital cost + net operating cost (if $>$ zero) total $\mathrm{CO} 2$ abated (discounted net offsets + disc. emission reduction)

It is important to recognize that this table 2 calculation is as conservative as possible in that it assigns all incremental costs to greenhouse gas reduction. No credit or revenue is taken for methane energy recovery or any other waste management benefit. Any such credit assigned to other benefits could significantly reduce net cost of greenhouse gas abatement, which, in fact, is only one benefit among several.

The calculated greenhouse gas abatement cost ${ }^{12}$ could range widely because, among other things, components contributing to costs could range widely. The limited range of capital costs in Table 1 above simply results from choices made for individual cost items. Example costs that could vary by twofold or more include the water supply pipe, water supply, and permitting. In addition to the obvious uncertainties in these areas, there are (without getting into detail) other cost unknowns. There are uncertainties in generation kinetics and yields of gas, as well as presumed recovery efficiency. Best available information and hopefully best judgment has been used, but remaining unknowns add to uncertainties.

At this point it is judged that uncertainties can be (as reasonably as possible) reflected by expressing cost as a mean. It is realistic to expect that, with variables and unknowns, actual costs may range approximately twofold $(-30 \%$ to $+50 \%)$ about the projected mean.

\section{GREENHOUSE GAS ABATEMENT SENSITIVITY ANALYSES}

The incremental costs per incremental unit gas were obtained above for controlled landfilling for a single "base case" landfill, at selected discount rates and against two reference standards. Analyses below examine cost sensitivity of $\mathrm{CO}_{2}$ abatement to important factors which can vary widely from landfill to landfill, including waste depth, inflow, and preprocessing.

12 Or landfill methane cost presented later

Topical Report: Greenhouse Cost-effectiveness of Controlled Landfilling Contract DE-AC26 98FT40422 Page 50 


\section{Table 2}

Calculation of total equivalent fossil $\mathrm{CO} 2$ abatement and cost:

base case 1000TPD controlled landfill

Controlled landfill vs. no controls

$d=0 \quad d=7 \% \quad d=15 \%$

Fossil CO2

offsets

$\mathrm{CO} 2$ equiv.

emission

abatement

Total $\mathrm{CO} 2$

equivalent

greenhouse

benefit/module,

tonnes

capital cost

differential to

attain benefit:

operating

expense

(discounted)

total

Cost per

tonne $\mathrm{CO} 2$ $\begin{array}{lll}125568 & 88482 & 58275\end{array}$

537600227268119756

$\overline{663168} \overline{315750} \overline{178031}$

$481,000 \quad 481,000 \quad 481,000$

$\$ 240,000 \$ 174,467$

$\$ 120,002$

$\overline{\$ 721000}$

655467

601002

$\$ 1.087$

$\$ 2.08$

$\$ 3.37$
Controlled landfill vs.

NSPS controls

$$
\begin{array}{lll}
d=0 & d=7 \% & d=15 \% \\
60502 & 56926 & 41456
\end{array}
$$

$13003952794 \quad 25971$

$\overline{190541} \overline{109720} \overline{67427}$
$338,000 \quad 338000 \quad 338000$

$-0-\quad-0-\quad-0-$

$-0-$

$\overline{338,000} \overline{338000} \overline{338000}$

$\begin{array}{lll}1.77 & 3.08 & 5.01\end{array}$

\section{Greenhouse gas abatement cost vs. inflow and waste depth}

It would be desirable to know the dependence of cost of controlled landfilling on landfilling scale/size. Size depends on both inflow rates and ultimate capacity. However relevant databases are at best "noisy". One similar and widely-applied process, aerobic composting, should (in principle) provide some indication of cost-size dependence of controlled landfilling. Essentially, for the aerobic composting parallels, cost per unit waste did not seem to depend on size in the study by SRI International. (SRI, 1991) This result 
appears counterintuitive since there is almost always significant economy of scale (a major reason why landfills are getting larger). It is not appear worth dwelling on this here since the scale issue can be approached analytically as detailed below. On balance increased depth improves cost-effectiveness, i.e. it can reduce costs in close proportion to the inverse of depth.

At constant inflow, an increase depth could pose some emission problem. Waste open to the atmosphere for longer'times could emit more methane to the atmosphere during the longer fill intervals. However longer fill time can be completely offset if depth and inflow rate increase proportionally, i e depth doubles from 60 to 120 feet and inflow rate doubles from 1000 to 2000 tons/day. This is the assumption for analysis of $\mathrm{CO}_{2}$ abatement (as with analysis of methane costs presented elsewhere in this document) This results in analysis of two changes simultaneously, but this combination of changes is realistic. It makes possible straightforward analysis of the two factors together.

With these assumptions, the gas generated is doubled. The cost modifications are assumed to comprise:

1. The liquid inflow rate is the same. Thus liquid delivery line, reservoir and liquidassociated costs such as flowmeters and filters are assumed unaffected.

2. Costs of construction layers essentially unaffected. Standard base layers of even deeper landfills have large safety factors in load bearing capacities

3. Charges which increase greatly with depth, or approximately double for the doubling of depth, are few: water costs double from $\$ 5600$ to $\$ 11,200 /$ acre. Costs of any capital equipment such as a gas blower or flare at scale exponent of 0.7 would increase by $62 \%$ The blower and flare are in this category.

With these minor changes, the incremental capital costs associated with controlled landfilling at module waste depth averaging 120 feet change from those in Table 1 to those in Table 3. Operating costs are for practical purposes unchanged. With the doubled inflow (from 1000 U. S. TPD to 2000 TPD) and depth (from 60 to 120 feet) the cost per tonne $\mathrm{CO}_{2}$ abated changes as shown in Table 4 . Increasing depth clearly decreases cost, and the decrease can be at a ratio very close to the inverse of depth.

\section{Controlled landfilling of decomposable organics only}

Many landfills fill waste "as received". Waste generally includes material such as construction debris, and such material as ash etc, which is from biological standpoints inert. 


\section{Table 3}

Incremental Capital Costs of Controlled Landfilling with Size Doubled vs. "Base Case": Item-by-item Cost Increment for 2000 TPD time-average inflow vs. 1000 TPD inflow--see text

\section{Refer to Table 1 for original costs}

Item

Pits in waste surface

Liquid delivery system (see text)

Sensors at \$4000/acre

Water supply (added cost)

Leachate/liquid reservoir (shared among modules)

Liquid supply pump on reservoir

Base layer gas "tap" line (see text)

Datalogger and transponder (shared among modules)

Permitting

Gas flowmeter

Proportional valve. porous layer pressure control

Gas line from module

Incremental labor during construction

Flare as backup to energy equipment (shared)

Gas recovery blower (shared)

Credit for vertical well cost avoided

Subtotal of cost increases

Contingency at $10 \%$

SUBTOTAL INCREASED CAPITAL COST

TOTAL CAPITAL COST

TOTAL 2000 TPD CAPITAL COST

OPERATING COST: UNCHANGED

2000 vs. $1000 T P D$
cost: increase
over smaller
"Grass roots"
module

unchanged

unchanged

unchanged

$\$ 2500-10,000$

unchanged

unchanged

unchanged

unchanged

unchanged

$+6.000$

unchanged

$+10,000$

$\$$ unchanged

$\$ 28,000$

$\$ 22,000$

$-0-0$

2000-1000TPD

cost: increase

for comparison

vs. NSPS

Controls

$$
\begin{aligned}
& \text { unchanged } \\
& \text { unchanged } \\
& \text { unchanged } \\
& 2500-10,000 \\
& \text { unchanged } \\
& \text { unchanged } \\
& \text { unchanged } \\
& \text { unchanged } \\
& \text { unchanged } \\
& +6,000 \\
& \text { unchanged } \\
& +2000 \\
& \text { unchanged } \\
& \$ 13,000 \\
& \$ 10,000 \\
& \text { unchanged }
\end{aligned}
$$

$\$ 68,500-76,000 \$ 33500-41000$

$6900-7600$

$3400-4100$

75000-84000

$\underline{37000-45000}$

463,000 to 498,000

320,000 to 355,000

538000 to 582000

$357000-400000$ 


\section{Table 4}

Total equivalent fossil CO2 abatement and cost: Calculation for 2000 TPD controlled landfill module and comparison with 1000 TPD module

Controlled landfill vs. no controls

$d=0 \quad d=7 \% \quad d=15 \%$

Fossil $\mathrm{CO} 2$

offsets, tonnes

$\mathrm{CO} 2$ equiv.

emission

abatement,

tonnes

Total $\mathrm{CO} 2$

equivalent

greenhouse

benefit/module,

tonnes

capital cost

differential to

attain benefit:

$560,000560,000560,000$

$\overline{1,326,336631,500} \overline{356,062}$

$1,075,200454,536239,512$

Controlled landfill vs.

NSPS controls

$$
d=0 \quad d=7 \% \quad d=15 \%
$$

$121,004 \quad 113,58282,912$

$260,078 \quad 105,58851,942$

$\overline{381,082} \quad \overline{219,440} \overline{134,854}$

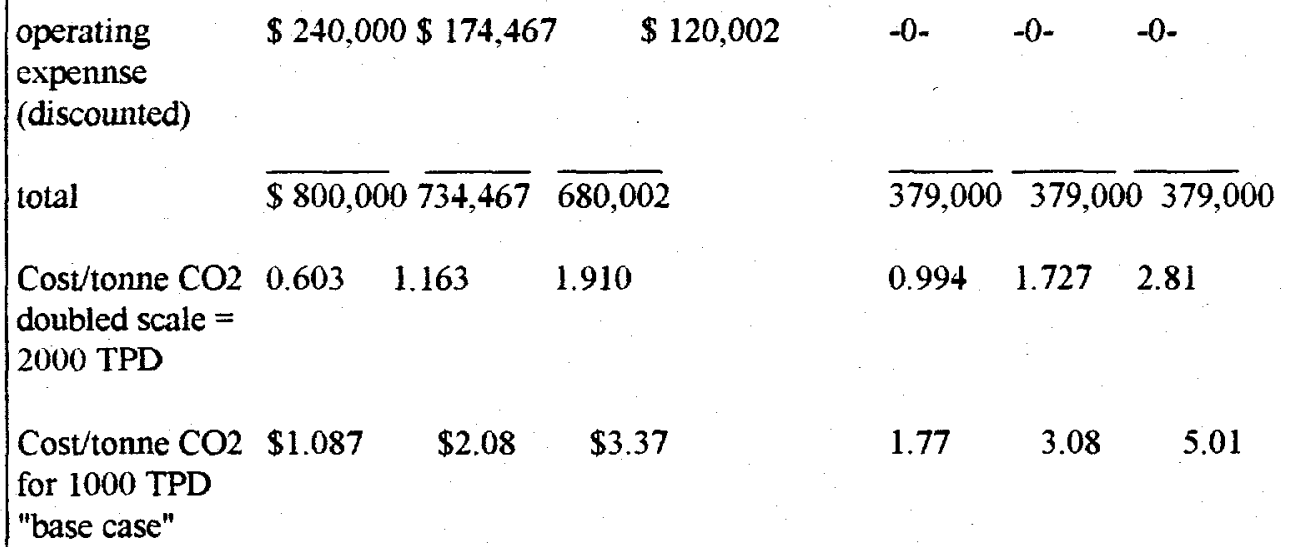


One controlled landfilling option is to landfill the decomposable fraction only, insofar as this can be separated out within practical constraints. Many landfills in fact separate out material that is for practical purposes biologically inert, for convenience. The sole purpose in many cases is to avoid installation and future operating costs of gas control for inorganic components which do not generate gas. The inorganic constituents are then landfilled in a separate area.

Some inert materials should be economically and conveniently separable from waste. Applying the classifications of Tchobanoglous et. al. (1993, chapter 3) these are

(a) construction and demolition debris-- concrete, and like material

(b) Wood residues such as tree limbs and branches (non-decomposable) and objects like discarded furniture that are largely

(c) Materials often termed "special" wastes--large bulky appliances and tires

One available guide to percentages of inerts that might be landfilled separately from decomposable fractions in waste streams is in table 3-3 in Tchobanoglous et. al. (1993). These percentages are shown in Box 5.

\section{Box 5}

Percentages of biologically inert materials that might be landfilled separately from decomposable wastes (Adapted from Tchobanoglous, 1993)

showing

Component Range, Typical percent

$\begin{array}{lll}\text { Special wastes } & 3-12 & 5\end{array}$

Construction/demolition $\quad 8-20 \quad 14$

Tree and trimming waste $2-5 \quad 3$

(est. from table 3-3 in Tchobanoglous reference) 
On the basis of experience ${ }^{13}$ nearly all of this material can be managed, landfilling separately from decomposables, at costs that are essentially negligible. Truckloads of construction/demolition wastes, wood wastes and like (broken paving, etc. etc.) are generally readily identifiable or can be required to self-identify. They can be guided at the landfill gate to "inert fill" areas. If biologically inert materials accidentally go to the fill face receiving decomposable waste they can be diverted by fill personnel to the appropriate areas receiving inerts. Members of the public are generally cooperative when asked to place furniture, large appliances and the like into the same inert waste areas. (the same cooperation is now received in appropriately dealing with hazardous wastes) On this basis of Box 5 the reduction in waste placed to undergo controlled landfilling would be about $20 \%$. The reduction in incremental controlled landfilling cost might be slightly less than proportional because of scaling effects but--without getting into any detailed calculations--should conservatively be at least $15 \%$.

By controlled landfilling of decomposable materials only, as much as possible, it should be possible to reduce $\mathrm{CO}_{2}$ equivalent abatement costs by $15 \%$ or so, other factors being equal. This is a modest but helpful cost reduction.

The cost of $\mathrm{CO}_{2}$ abatement lies in the range of $\$ 1-5 /$ tonne for the base case. Some material which is non-decomposable, such as glass and plastic, is a fairly low fraction of total waste and mingled with decomposable waste to such degree that cost of its separation is much more costly than decomposables above. Its separation to save on gas control is cost-ineffective and probably out of the question. Recycling programs, implemented at costs of the order of $\$ 10-100 /$ ton total waste do routinely recover these but proceed on bases of desired material recovery and independently of any modest benefit associated with gas recovery.

\section{Effect of increased containment costs}

Controlled landfilling appears to reduce rather than increase risks to groundwater, by reducing and allowing earlier management of soluble pollutants. There are strong arguments on basic hydraulic principles that support the reduction of risk. However controlled landfilling is not as yet a technology with which regulators are familiar. Regulators may consider that increased base containment is necessary when liquids are added to landfills, at least until experience shows that there is no increased risk. The requirements are likely to be state or locality-specific. Increased containment would take the form of an added bottom liner layer. In many cases this extra bottom liner is required only for controlled landfilling. Hence its cost is attributable to controlled landfilling. This cost has been evaluated repeatedly and found quite high; for purposes of analysis it is estimated at $\$ 50,000 /$ acre or $\$ 500,000$ per module.

13 Observations by author at Yolo and Palo Alto landfill gates. Also discussions with several landfill operating staff.

Topical Report: Greenhouse Cost-effectiveness of Controlled Landfilling

Contract DE-AC26 98FT40422 Page 56 
Results of a discounted cash flow analysis of the costs of $\mathrm{CO}_{2}$ abatement is shown in Table 5. This calculation is straightforward along the same lines as analyses for $\mathrm{CO} 2$ abatement cost-effectiveness presented earlier. For the base case, since the up-front cost increases by $\$ 500,000$ i. e. is approximately doubled, the cost of $\mathrm{CO}_{2}$ abatement is also approximately doubled.

Table 5

Comparative costs of $\mathrm{CO}_{2}$ abatement for base case 1000 ton/day landfill: Single vs. double base liner.

Incremental $\mathrm{CO} 2$

abatement cost vs.

no controls, \$/tonne

$d=0 \% d=7 \% \quad d=15 \%$ APR

Costs for

single liner

Costs for

double liner $\begin{array}{lll}1.09 & 2.08 & 3.37\end{array}$

$1.84 \quad 3.66$

6.18
Incremental $\mathrm{CO} 2$

abatement cost

vs. NSPS \$/tonne

$d=0 \quad d=.07 \quad d=.15$

$\begin{array}{lll}1.77 & 3.08 & 5.01\end{array}$

$\begin{array}{lll}4.4 & 7.63 & 12.43\end{array}$

EVALUATION OF METHANE COST:

Controlled landfilling versus absence of controls

The first methane cost evaluation is for the case where controlled landfilling is compared to a reference landfill which has no controls at all. Discount rates (implied costs of funds in annual percentage rates) of $d=7 \%$ and $d=15 \%$ are again used. The cost of methane $\mathrm{Cm}(\$ /(1000$ cubic feet $=\mathrm{MCF})$ via controlled landfilling can be calculated from a discounted cash flow analysis in which 


\begin{tabular}{|c|c|}
\hline & \\
\hline capital cost $=\Sigma R m C m(1-d)^{t}$ & $-\sum 40,000 \mathrm{e}^{-\mathrm{dt}}$ \\
\hline $\begin{array}{l}t=3 \\
\text { discounted methane value }\end{array}$ & $\begin{array}{l}t=2 \\
\text { operating cost }\end{array}$ \\
\hline
\end{tabular}

or

capital cost $=\quad \begin{array}{lll}\operatorname{RmCm}(1-\mathrm{d})^{2}+\mathrm{Cm} \Sigma \operatorname{Rm}(1-\mathrm{d})^{\mathrm{t}} & \begin{array}{l}\mathrm{t}=7 \\ \mathrm{t}=3,1\end{array} \\ & \text { discounted methane values } & \begin{array}{l}\mathrm{t}=2,1 \\ \text { discounted operating cost }\end{array}\end{array}$

where

$\mathrm{Cm}=$ cost/value of methane (dollars/MCF)

$\mathrm{Rm}=$ recovery of methane (in year $t$ as used above)

As noted methane ( $4 \%$ of total yield potential at $t=2$ above) is initially recovered by bottom layer extraction. Its value is included in the discounted cash flow analysis of appendix 4. Note that operating costs cancel out and value of methane extracted from the bottom layer is realized at the end of year 2 (one year after completion of waste placement). Thereafter, $t=3$ above is simply the time from capital expenditure to realizing the first full year's methane recovery (by the zero order model) occurring two years after completion of filling. Recovery continues for five years to the end of recovery at $t=7$ years after capital expenditure (or 6 years after filling is complete). The starting point for operating costs, (second term above), is one year after filling is complete (Note that a term for earlier incremental labor during construction was already included in capital costs).

Appendix 4 details the present worth evaluation of the controlled and NSPS landfill methane recoveries at chosen discount rates. Appendix 4 also notes assumptions which have gone into the present worth evaluation. Substituting the numerical values into equation (9)

At $0 \%$ discount rate

Mean capital cost $=\$ 481,000=1,744,000 \mathrm{Cm}-\$ 240.000$

methane cost $/$ revenue requirement $=\$ 0.413 /(\mathrm{MCF}=\mathrm{mmBtu})$

at $7 \%$ discount rate

Topical Report: Greenhouse Cost-effectiveness of Controlled Landfilling Contract DE-AC26 98FT40422 Page 58 
Mean capital cost $=\$ 481,000=1,228,948 \mathrm{Cm}-\$ 174467$

methane cost $/$ revenue requirement $=\$ 0.533$

at $15 \%$ discount rate

Mean capital cost $=\$ 481,000=809,365 \mathrm{Cm}-\$ 120,002$

methane cost or revenue requirement $=\$ 0.743$

Results are summarized in table 6 As with the $\mathrm{CO}_{2}$ abatement costs, many cost items and categories may vary, and unknowns remain. Again uncertainties are such that actual costs may range between $30 \%$ less to $50 \%$ over the stated costs.

Table 6

Calculated gas costs for controlled landfilling:

Base case, 1000 TPD

Methane cost
vs. no controls,
$\$ /(\mathrm{MCF}=$ mmBtu $\cong \mathrm{Gj})$
$\mathrm{d}=0 \quad \mathrm{~d}=7 \%$ APR $\mathrm{d}=15 \%$ APR
$=\$ 0.413 \quad 0.533 \quad .742 / \mathrm{MCF}$

$=\$ 0.413 \quad 0.533 \quad .742 / \mathrm{MCF}$
Methane cost

vs. NSPS

\$MCF

$$
\begin{array}{ccc}
\mathrm{d}=0 & \mathrm{~d}=7 \% \text { APR } & d=15 \% \text { APR } \\
\text { \$ } 0.458 & 0.419 / \mathrm{MCF} & .578 / \mathrm{MCF}
\end{array}
$$

Incremental gas cost: controlled landfilling versus same landfill with NSPS controls

The second evaluation is a controlled landfill comparison to conventional recovery, i e, the NSPS landfill module. The expression from which the cost of gas can be derived is in this case

$$
\begin{aligned}
& { }_{0} \mathrm{t}=7 \quad \mathrm{t}=32 \\
& \begin{array}{cc}
\text { capital cost }= & 337600 \mathrm{Cm} \sum_{t=3,1}^{e}(1-\mathrm{d})^{\mathrm{t}}(932394)^{\mathrm{t}}-80569 \mathrm{Cm} \sum(1-\mathrm{d})^{\mathrm{t}}(932394)^{\mathrm{t}} \\
\text { present worth controlled } & \mathrm{t}=3,1 \\
\text { landfill methane } & \text { present worth of } \\
\text { NSPS landfill methane }
\end{array}
\end{aligned}
$$

The first term is the discounted value of the gas obtained from controlled landfilling; the second term, subtracted, is discounted value of gas that would be obtained over time with conventional landfilling. Both of these are calculated for the selected discount rates in

Topical Report: Greenhouse Cost-effectiveness of Controlled Landfilling Contract DE-AC26 98FT40422 Page 59 
appendix 4. This approach simply assigns incremental capital cost to differential (discounted) gas recovery to obtain a cost for the extra gas obtained from controlled landfilling. For this comparison controlled and NSPS landfill operating costs are assumed equal; i e operating costs cancel out and extra operating cost for the controlled landfill is absent. Note also that the year 2 methane recoveries (before controls start), not shown, are the same for the two landfills, canceling out. The capital cost is that from table 1, representing the controlled landfill cost increment over the conventional NSPS landfill. .

Solving equation (10) above using values from appendix 4

For $0 \%$ discount rate vs. NSPS landfill

Capital cost $=338,000=\quad \mathrm{Cm} \times(1744800-1007630)=737170$ and $\mathrm{Cm}=0.458$

Similarly, for $7 \%$ discount rate

Capital cost $=338,000=\mathrm{Cm} \times(1,228,948-423,480)=805468 \mathrm{Cm}$

And $\mathrm{Cm}=0.419$ )

For $15 \%$ discount rate

Capital cost $=338,000=\mathrm{Cm}(809365-224985)=584380$

and $\mathrm{Cm}=0.578$

These findings were presented at each discount rate in table 6

In reviewing the above and table 6 it may seem surprising that, within precision of analysis, the unit costs of obtaining gas are comparable for two cases (and show unusual variation with discount rate): The unit methane cost is similar whether controlled landfilling is applied to a landfill that would otherwise have no controls, or for marginal "extra" gas compared to the conventionally controlled NSPS landfill. In this analysis comparing the controlled with "conventional" NSPS landfill several factors contribute to low marginal gas cost, and variation:

1. The operating cost for a controlled landfill should be no greater (and is really probably less) than if a conventional system were operated. This is particularly true longer term.

2. The controlled landfill saves normal cost of conventional gas control. For the extra cost controlled landfilling poses, it provides much more gas, being both more efficient both in terms of generation yield and recovery of that gas which is generated: 
3. The controlled landfill recovers gas much sooner than conventional practice; with use of a discount factor, the value of its gas is discounted substantially less than is the gas recovery from the conventional NSPS system, which on average produces gas much later.

4. Greater methane recovery of the controlled landfill compared to the conventional comes at less cost because of economies of scale, there is less marginal cost per unit capacity or size increment for the larger blower, flare, piping and other equipment.

5. As discount rate rises, it first reduces the value of the more slowly generated NSPS landfill gas. A discount rates rise above $7 \%$ the controlled landfill gas present worth is also reduced; at the higher discount rate the differential (marginal gas recovery, discounted) is then lessened and the gas cost rises.

\section{METHANE COST SENSITIVITY ANALYSES}

The incremental costs per incremental unit gas were obtained above for controlled landfilling for a single "base case" landfill, at selected discount rates and against two reference standards. Analyses below examine gas cost sensitivity to important factors including waste depth, inflow, and preprocessing.

\section{Methane cost vs. inflow and waste depth}

The following will examine factors which vary with inflow and depth of landfilled waste and then how these are likely to influence costs. On balance increased depth improves cost-effectiveness, i.e. reduces costs in close proportion to the inverse of depth.

As noted above an increase in fill time could pose a problem, inasmuch as waste open to the atmosphere for longer times could emit more methane to the atmosphere during the longer fill intervals. However as noted earlier this problem is avoided if depth and inflow rate increase proportionally, i e depth doubles from 60 to 120 feet and inflow rate doubles from 1000 to 2000 tons/day. This will be the assumption here.

One issue arising with increased depth ${ }^{14}$ has been pointed out by an outside reviewer: Though fill and coverage time should remain identical, time required for moisture to permeate waste will increase. On this issue, the Yolo demonstration has been valuable in showing "high" waste permeability to moisture (provided there is appropriately porous intermediate "daily" cover). Though moisture was added at rates less than the maximum possible, moisture field capacity was attained in 9 weeks as indicated by both moisture sensors and outflow at $40+$ foot depth. This suggests liquid permeability at least, and almost certainly above, $4 \times 10-4 \mathrm{~cm} / \mathrm{sec}$. Any time increase to reach desired moisture should be minor (at most 3 months) and the liquid addition is likely to be sequenced into

14 By Raymond Huitric, District Engineer, Los Angeles Sanitation Districts

Topical Report: Greenhouse Cost-effectiveness of Controlled Landfilling Contract DE-AC26 98FT40422 Page 61 
sections in any event, that is added more slowly than the maximum rate possible, to achieve uniform methane generation over time. Thus the timing of gas generation is assumed unchanged.

With this set of assumptions, the gas generated is doubled. With the same set of assumptions for cost increases with scale and water costs, etc, as earlier, the capital cost changes in comparison to the "base case" are as was shown in Table 3.

For the doubled depth and inflow the cost vs. base case is calculated as with the base case landfill. The calculation is straightforward (detail is omitted); gas recovered is doubled and operating costs are unchanged. Results of the calculation are presented in Table 7

\section{Table 7}

\section{Controlled Landfill Gas Costs at 2000 TPD}

vs. no controls: capital cost $=\$ 560,000$
at $0 \%$ disc rate
at $7 \%$ disc rate
at $15 \%$ disc rate
$\mathrm{Cm}=\$ 0.163$
$\mathrm{Cm}=\$ 0.245$
$\mathrm{Cm}=\$ 0.373$
vs. NSPS controls: capital cost $=\$ 379,000$
at $0 \%$ disc rate
at $7 \%$ disc rate
at $15 \%$ disc rate
$\mathrm{Cm}=0.257$
$\mathrm{Cm}=0.235$
$\mathrm{Cm}=0.338$

In essence for this analysis of cost at doubled landfill size/depth, other factors being equal, cost of product methane is approximately halved. In general, providing enough other factors can be held constant, it would appear that gas cost, as well as greenhouse gas abatement cost, should essentially be inversely proportional to depth.

\section{Controlled landfilling of decomposable organics only}

As noted earlier, an option is to landfill the decomposable fraction only, insofar as this can be separated out within practical constraints. Many landfills in fact separate out material that is for practical purposes biologically inert. This is often done for convenience. The sole purpose in many cases is to avoid installation and future operating costs of gas control for inorganic components which do not generate gas. The inorganic constituents are then landfilled in a separate area.

Based on waste compositions from Tchobanoglous (see box 5 earlier) and with allowance for scaling (costs fall and rise with scale to exponents less than 1; here assumed 0.7 ) it can 
be judged that gas costs, as is the case with greenhouse gas abatement would fall by about $15 \%$

\section{Cost of other pretreatments--shredding and breaking bags}

Gas control and energy value is readily seen to have value of at most a few dollars a ton by energy standards which may be applied. Benefit of intensive pretreatments such as shredding, or even breaking open bags, is likely to be marginal. This is based on the fact that gas yields that best-fit in models seem close to the yields demonstrated in laboratory work with shredded waste under ideal conditions. (It seems likely that the landfill compacting process itself accomplishes a great deal of bag opening with sheepsfoot rollers, by mashing and in effect "stabbing" bags) If gas yield were to be increased by (say) $20 \%$ (from 3.6 to $4 \mathrm{MCF} /$ ton) at a "typical" shredding cost of $\$ \$ 20 /$ ton, the marginal gas $(0.4 \mathrm{MCF} /$ ton) would be obtained at a cost of around $\$ 50 / \mathrm{mmBtu}$ or over twentyfold its gross energy value at current market. Shredding (other than through landfill compacting) appears impractical from a cost effectiveness standpoint.

Another factor to be considered is that much non-decomposable material, such as glass and plastic, is commingled with decomposable waste to such degree that cost of its separation to save on gas control is also cost-ineffective, apparently out of the question. This issue was discussed above.

\section{Cost effects of "double" base liner}

Federal rules (40 CFR 258.40 [a] 2, which also guides state rules) require the same "composite" liner of geomembrane embedded in low permeability clay, regardless of whether landfilling is controlled or conventional. However some states, out of regulatory caution, are adopting a policy, at least for the time being, of requiring double lining ( 2 geomembranes embedded in clay) when liquid is added to landfills. The incremental cost of this extra layer of lining would be attributable to controlled landfilling and has been estimated by Yolo County Engineers ${ }^{15}$ at approximately $\$ 50,000$ per acre.

It is quite straightforward that per-module cost increases by $\$ 500,000$ with double membrane lining. Using the same DCF analyses earlier, the costs in Table 8 can be calculated for the "base case" without and then with the double liner. The double lining has a serious impact, roughly doubling the cost of methane depending on the case. Imposition of this regulatory requirement is likely to deter controlled landfill implementation.

\footnotetext{
15 It can be noted here that Yolo County's engineers have to date done full design of over 100 acres of landfill modules and have filled waste totaling an aggregated 4 million tons.
} 


\section{Table 8}

Calculated gas costs for controlled landfilling with double base geomembrane (see text) Cost vs. no controls
$\mathrm{d}=0$
$\mathrm{d}=7 \%$ APR
$d=15 \%$ APR

Mean methane cost

Mean methane cost Mean methane cost

$=\$ 0.745 /(\mathrm{MCF}=\mathrm{mmBtu})$

$$
=1.01 / \mathrm{MCF} \quad=1.467 / \mathrm{MCF}
$$

Marginal costs of extra gas vs. Conventional (NSPS) Landfilling

$$
d=0 \quad d=7 \% \text { APR } d=15 \% \text { APR }
$$

methane cost

methane cost

methane cost

$=\$ 1.167 /(\mathrm{MCF}=\mathrm{mmBtu})$

$=1.04 / \mathrm{MCF}$

$=.1 .434 / \mathrm{MCF}$

\section{OTHER ISSUES:}

\section{CARBON SEQUESTRATION}

The original proposal leading to this analysis noted that significant amounts of carbon would be sequestered by landfilling. This aspect was not emphasized earlier because any landfilling practice--controlled, NSPS or uncontrolled--will sequester rather similar amounts of carbon. However it is worth examining the approximate amount of carbon sequestered by landfills. The calculations are as follows:

1. The IPCC estimated carbon content of MSW (total of chemosynthetic and fossil) is about $20 \%$ (IPCC, 1995)

2. A methane yield of $1.8 \mathrm{ft} 3 / \mathrm{lb}$ has associated $\mathrm{CO}_{2}$ (at $55 \% \mathrm{CH} 4$ ) of about $1.47 \mathrm{ft} 3 / \mathrm{b}$.

The total gas carbon content is readily calculated as 4.13 gram mols $\mathrm{C}$ or about 49.5 grams. Carbon equal to about $11 \%$ of the waste mass is emitted and $9 \%$ remains. Reported waste compositional analyses very somewhat but judgment here is that about half this carbon is chemosynthetic (plastics, etc.) and is prevented from entering the 
atmosphere (which it otherwise would if the waste were incinerated--see below). The other half, probably about $4.5 \%$ of waste weight as carbon, is carbon removed photosynthetically from the atmosphere in forms such as wood, lignin, and other anaerobically non-decomposable biomass fractions.

On the basis of landfilling statistics provided earlier in this report, US landfills' sequestration of photosynthetically fixed carbon is the order of about 6 million tons/year (corresponding to atmospheric $\mathrm{CO}_{2}$ removal about 23 million tonnes/year.) The amount of carbon sequestered is only slightly affected in moving from "conventional" to controlled landfilling. In the long term sequestration does depend on the maintenance of containment to prevent landfilled carbon from being oxidized and re-emitted as $\mathrm{CO}_{2}$ to the atmosphere. In this respect controlled landfilling has advantages over the "aerobic bioreactor" landfills now being tested. (SWANA bioreactor landfill committee, 1998)

\section{GREENHOUSE COST-EFFECTIVENESS COMPARISON WITH INCINERATION}

In some US regions, incineration or "waste to energy" is an option. An interesting comparison can be carried out between controlled landfilling and incineration. A mass of waste can either be incinerated or undergo controlled landfilling. Incineration reduces fugitive methane emissions, as equivalent $\mathrm{CO}_{2}$, to zero. The $\mathrm{CO}_{2}$ and $\mathrm{CO}_{2}$ equivalent emissions, and offsets of controlled landfilling may be compared. This is done below. For greatest simplicity a discount rate of zero is used. The basis is 500,000 US tons of waste which is either landfilled by controlled landfilling, or incinerated in a waste-to-energy process. Key values are noted by lower-case letters in parentheses. Assumptions are

1. The waste carbon that would otherwise be sequestered ( $4.5 \%$ by weight) is instead all combusted and emitted. Going on the weight basis that was used above, the incremental per-module $\mathrm{CO}_{2}$ tonnage is calculated as (a) 82500 tons. (Note that only combusted carbon that would otherwise be sequestered, not all carbon, can be counted, after allowing for gaseous carbon from the controlled landfill that also enters the atmosphere)

2. The controlled landfill emits $\mathrm{CO}_{2}$ equivalent (b) 22400 tonnes of fugitive methane (see earlier text, i. e., discussion after equation (3))

3. The methane from controlled landfilling, if $80 \%$ is converted to electricity at 10,000 Btu/kWh offsets (c) 125568 tonnes $\mathrm{CO}_{2}$ per module (Appendix 2)

4. The incineration of all of a 500,000 ton module's waste at an efficiency of 16,000 $\mathrm{Btu} / \mathrm{kWh}$ and $10^{7} \mathrm{Btu} / \mathrm{ton}$ will spare emission of $312500 \mathrm{US}$ tons or (d) 281250 tonnes of $\mathrm{CO}_{2}$. 
The net greenhouse advantage in incinerating (still on a per-module, 500,000 US ton basis) is $(-\mathrm{a})+(\mathrm{b})-(\mathrm{c})+(\mathrm{d})$ or 95582 tonnes $\mathrm{CO}_{2} /$ module. This advantage is gained at a differential cost of incineration over landfilling, which, though variable by circumstance, is at least $\$ 50 /$ ton of waste managed, or $\$ 25 \mathrm{million} /$ module. This in turn translates to a cost, for the incremental $\mathrm{CO}_{2}$ abated, of over $\$ 260 /$ tonne $\mathrm{CO}_{2}$ or over $\$ 900$ tonne $\mathrm{CO}_{2}$ carbon abated. If incineration is compared to a situation of no controls, incineration abates a net of 758,000 tonnes $\mathrm{CO}_{2}$ equivalent at a very similar $\approx \$ 25$ million cost, still calculating out to $\$ 33 /$ tonne $\mathrm{CO}_{2}$ or $\$ 120$ /tonne $\mathrm{C}$. The $\mathrm{CO}_{2}$ abatement from incineration is attained at high cost by extant standards. Most of the net abatement $(80+\%)$ could be obtained at cost 1-2 orders of magnitude less by controlled landfilling.

It is noted that a different (higher) discount rate could change relative $\mathrm{CO}_{2}$ abatement cost by incineration somewhat (detail omitted), but the key problem remains the differential cost required to attain the added $\mathrm{CO}_{2}$ abatement. It is likely that incineration would be conducted on the usual basis, that landfill space is not available, independently of its merits in greenhouse gas abatement.

\section{SUMMARY AND CONCLUSIONS: CO2 ABATEMENT AND METHANE COSTS}

In overall summary, the costs of controlled landfilling for $\mathrm{CO}_{2}$ abatement or renewable energy appear very attractive by extant standards. The costs for greenhouse gas abatement (equivalent $\mathrm{CO}_{2}$ ) are attractive even when all incremental costs of controlled landfilling are assigned to abatement. If, alternatively, all incremental controlled landfilling costs are assigned to incremental recovered methane, the costs of recovered methane are reasonable. This is true whether comparison is to a situation wherein there is otherwise no methane control, or whether the calculation is in comparison to conventional controls mandated under law (which may be inefficient and have other problems).

A CO2 equivalent abatement cost of $\$ 1-5 /$ tonne (single liner) equates to a cost of $\$ 3$ $14 /$ tonne $\mathrm{CO}_{2}$ carbon abated. Such cost is still an order of magnitude below the costs estimated for other $\mathrm{CO}_{2}$ carbon reductions necessary to meet specified targets, as recently estimated by the U. S. Department of Energy's Energy Information Administration (Energy Information Administration, 1998, USDOE) Marginal carbon costs needed to go from the $(1990+24 \%=$ business as usual) to $1990+9 \%$ to (1990 no increase) as defined in that report are the approximate order of $\$ 100$ to $200 /$ tonne $\mathrm{C}$ depending on year examined.

The calculated base case methane costs of $\$ 0.45-\$ 0.75 / \mathrm{mmBtu}$ are the order of half or less the cost of natural gas (though, landfill methane has its own, significant drawbacks as an energy resource as discussed later) 
Clearly, the calculated "greenhouse cost effectiveness" of controlled landfilling methane abatement could vary with many factors. For an example, preceding assumptions for the conventionally controlled landfill can be shown to result in fugitive emissions which are about $35 \%$ of total generation ${ }^{16}$ as follows:

Interval

To beginning of controls (year 1 )

Years 3-32 (inclusive) at $75 \%$ capture year $33-\infty$

Fraction of total generation fugitive
Percent of total methane generation that is fugitive
$4.0 \%$
20.2
$\underline{11.3}$

If fugitive emissions for the NSPS landfill were to be halved by operational modifications ${ }^{17}$, it is readily seen that the incremental cost of abatement by controlled landfilling would approximately double. For the base case, the cost of carbon abatement would rise from \$3-14/tonne to \$6-28/tonne. Such cost is still an (approximate) order of magnitude below the costs estimated for other $\mathrm{CO}_{2}$ carbon reductions necessary to meet various targets, as recently estimated by the U. S. Department of Energy's Energy Information Administration (EIA, USDOE, 1998)

Increased energy revenue that might result from favorable treatments of renewable energy in restructuring would be extremely helpful. This is discussed later On the other hand, the imposition of additional containment requirements in the form of additional bottom liner poses significant additional costs. Both the barriers posed by added base liners, in terms of increasing costs, and the facilitating effect of added energy revenue from renewable energy incentives are factors that policymakers should consider.

Obviously, variation in $\mathrm{CO}_{2}$ abatement costs can be expected based on differing design options and unknowns Although halving fugitive emissions with conventional design would about double abatement and energy costs, doubling of landfill size with other things equal would halve them. Controlled landfilling appears to be a low-cost option for the US to meet a portion of its greenhouse gas commitments.

Regulatory and relevant policy issues are discussed next. The potential reduction for the US as a whole is discussed later.

16 without discount

17 Modifications toward more efficient recovery may have some significant expense 


\section{CURRENT REGULATIONS AND POLICY RELATING TO CONTROLLED}

LANDFILLS

Until recently, a continuing issue surrounding bioreactors in the solid waste and regulatory communities has concerned allowable supplements, i.e., what can be added to landfills, particularly liquid. The federal regulation governing allowable waste disposal in landfills is 40CFR258.28 which states in its most pertinent part,

\section{"Bulk or noncontainerized liquid waste may not be placed in MSWLF units unless}

(1) The waste is household waste other than septic waste, or

(2) The waste is leachate or gas condensate derived from the MSWLF..."

This existing code was nearly always interpreted--until about 1994-5--as barring liquid additions other than leachate or condensate to landfills. This interpretation was principally on the part of various states' regulatory agencies. This interpretation would essentially preclude any methane enhancement technique--other than what is widely known as "leachate recirculation". At the same time, material balances along with experience show that leachate recirculation in and of itself does not adequately enhance methane. Supplemental liquid is needed, particularly when membrane covers are in place as in the case of controlled landfilling.

In 1994 a senior EPA official responsible for oversight of landfilling pointed out how 40CFR258.28 (above) as written applied only to liquid wastes ${ }^{18}$ and not to liquid amendments to wastes. Water, when added to a landfill to support biological decomposition is clearly not a waste but an amendment. Other components such as waste or "gray" waters, as well as soluble nutrients, could also be categorized as amendments. Thus, in essence, water and other liquid amendments to landfills are not prohibited. This is consistent with the envisioned use of controlled landfilling as a tool to help address climate change as part of the Climate Change Action Plan (see next).

In October, 1993 the Administration released the Climate Change Action Plan (CCAP). CCAP Action Item 37 (of 50 items) was particularly important, and in essence envisioned controlled landfilling as a tool for addressing climate change. Its recommendations included

-A small scale demonstration of leachate recirculation and other techniques to enhance methane generation at an existing landfill site

18 Personal communications, Andrew Teplitzsky, USEPA, 1995. Also personal communications to SWANA landfill gas steering committee, 1995. 
-Creation of a joint State/Federal coordination program to facilitate siting/permitting of enhanced recovery landfills

-Expansion of RD\&D to optimize, and demonstrate the technology and establish environmental performance

-Demonstration of economic recovery from small landfills

-Modifying environmental performance standards and regulatory requirements to remove unnecessary barriers to enhanced recovery technology in landfills

In addition to support evidenced in these policy statements within the Climate Change Action Plan, federal support is implicit in long-standing USEPA sponsorship of bioreactor work. The general approach of this sponsored work has been to improve biological conditions to accelerate decomposition of solid waste. This EPA work has not focused particularly on methane control but rather, concentrated on waste stabilization and leachate pollutant reduction of interest. It does, however, importantly, evidence support for the concept of managing biological conditions in landfills through controlled liquid amendment additions. One representative compendium of recent work may be found in proceedings of the seminar publication "Landfill Bioreactor Design and Operation", proceedings of the EPA Symposium in Wilmington, Delaware, March 1995, containing 13 papers. Much other work has taken place over the past three decades.

Recognizing potential benefits from bioreactor landfills, and with impetus from several individual members, the Solid Waste Association of North America is now (late 1998) finalizing a White Paper, supporting bioreactor landfills. With input from IEM, this white paper points out their application for methane control. This white paper is expected to receive serious attention from the solid waste management community and its regulatory agencies.

Some overriding regulations on solid waste management are federal, as cited above. Otherwise, regulations can be state-specific as long as any state's regulations are consistent with federal requirements and are federally approved.

Controlled landfills are one version of what have been more generally termed "bioreactor" landfills, in which biological conditions are improved to hasten waste decomposition and stabilization. As part of the process of white paper development, the Solid Waste Association of North America is carrying out data collection, including surveys of US state regulatory agencies to determine their position on leachate recirculation and landfills as bioreactors (SWANA, Gou and Guzzone, 1997). Of 50 distributed surveys (one for each US State), 37 were returned. The following discussion of status is largely from the 
September 1998 White Paper draft (which may be found in Proceedings of the SWANA 3rd Landfill Symposium, July 1998):

The survey indicated that approximately $130 \mathrm{MSW}$ landfills were currently employing leachate recirculation. While over half (21) of the respondents cited specific state regulations, most state regulations closely followed federal rules.

With regard to bioreactor landfills, SWANA's survey found that fourteen states indicated that they either accepted bioreactor landfills, approval was pending, or they would consider a proposal. States favoring, considering or accepting landfill bioreactors include: Alabama, Alaska, Arkansas, Califomia, Colorado, Delaware, Florida, Iowa (one project pending) Michigan, Mississippi, Montana, New Jersey, New York and Washington State. Example bioreactor landfill activities include

California: For two years Yolo County has been operating the bioreactor demonstration cell, discussed above, as a controlled landfill. Yolo County is negotiating with concerned state agencies to operate the next 15-acre module as a controlled landfill. This is the only states' bioreactor to be operated as a controlled landfill as described in this report.

Delaware: The Delaware Solid Waste Authority (DSWA) has operated the major landfill (largest in the state) as a bioreactor.

Florida: The preliminary state budget plans to allocate over 3.2 million dollars to establish one or more bioreactor landfill operations.

Georgia: Two aerobic bioreactor landfill projects are operational one at the Live Oak Landfill in Atlanta, the other at Baker Road Landfill in Columbia County.

Iowa: The State of Iowa is supporting (500,000 grant) the Bluestem Solid Waste Authority with a bioreactor project near Marion

New York State: An anaerobic bioreactor operation is being carried out at the Mill Seat Landfill; a pretreatment aerobic bioreactor activity, although with minimal measurement of the sort desired here (gas recovery and emission, and indices of these) is operational at Elmira.

South Carolina: The State Research and Development and Demonstration Program is sponsoring an aerobic activity at the Aiken County landfill

Washington State: Washington State Administrative Code 173-351-200-(9) states "Operating criteria (Liquid restrictions) - "Bulk or non-containerized liquid waste may not be placed in MSWLF units unless. . . . . . . . ii the water is leachate or gas condensate derived from the MSWLF unit, or water added in a controlled fashion and necessary for

Topical Report: Greenhouse Cost-effectiveness of Controlled Landfilling Contract DE-AC26 98FT40422 Page 70 
enhancing decomposition of solid waste as approved during the permitting process of WAC 173-351-700, whether it is a new or existing MSLF or lateral expansion"

Twelve states indicated that they would not (at least at present) approve bioreactor landfills. Others gave no answer or indicated they were in the process of evaluating the technology. Those that did permit bioreactor management usually classified the practice under recirculation rather than a separate category (although it is noted here that bioreactors and recirculation landfills can be quite different). In many of the states lacking specific regulations regarding bioreactors, the practice had never been requested although the topic had been considered internally as possible permit modifications or alterations.

With respect to the above state activities, etc. "bioreactor" refers to the improvement of landfill conditions for biological reactions through liquid addition (and other means). It does not imply but certainly includes controlled landfilling as discussed here (only the California Yolo bioreactor is a "controlled landfill" as described earlier). The Washington State position and code is important as an example of the explicit code language needed to show that liquid (water) amendments additions have been considered by the regulatory body. Such positive code language should greatly facilitate controlled landfilling permitting and application.

In summary, the important thing is that approaches necessary to implement controlled landfilling are being accepted and encouraged in a number of states noted above. The regulatory situation is rather fluid, in part because of a lack of familiarity by many states' regulators with landfills as bioreactors. The important thing is the trend so far: For many states where control of biological conditions by liquid additions has been considered, state regulatory treatment has tended to be favorable. Greenhouse gas abatement is also a focus in some states (California, New England States) In general, this augurs well for controlled landfilling.

Aside from general regulatory acceptability of the controlled landfilling process itself, additional policy and regulatory issues deserve mention, which could affect the degree to which controlled landfilling is implemented. Three of these are

1. The restructuring of the electricity sector to greater competition and means for facilitation of landfill gas renewable energy within such restructuring

One relevant question which might be asked at this point is why-if controlled landfilling could be a significant energy resource--is it not being pursued more actively? The basic answer is that electric and other energy markets are not presently that rewarding, or even economical to pursue. Power costing $4+$ cents per $\mathrm{kWh}$ to generate even if gas is "free" will usually sell at less than generation costs without renewable energy incentives. Part of the problem is the nature and scale of landfill gas and conversion technologies. This is discussed more in Appendix 5

Topical Report: Greenhouse Cost-effectiveness of Controlled Landfilling Contract DE-AC26 98FT40422 Page 71 
On this topic, it is encouraging that a number of mechanisms to provide renewable energy incentives could benefit controlled landfilling because of its increased energy potential. One such mechanism is the renewables portfolio standard proposed by the administration.

2. The facilitation of greenhouse gas emission abatement via various incentives

The greenhouse gas abatement per se from landfill gas abatement presently goes almost wholly unrewarded. A variety of mechanisms are under consideration to help realize revenue from greenhouse gas abatement approaches. These include various credits and emissions offset trading, discussed more in appendix 5 .

(From the analyses of this report, mechanisms in both 1 . and 2 . above would be extremely cost effective tools for greenhouse gas abatement.)

3. The determination of whether additional landfill base lining is will be required by regulators. This extra base lining at substantial extra cost is likely to deter controlled landfilling to significant extents.

There are strong arguments on basic grounds that controlled landfills if anything, pose less threat to groundwater than conventional landfills. Discussions by a relevant SWANA committee are ongoing with an important California State Agency (Water Board) to develop the most rational and appropriate regulatory structure under which controlled landfilling can be practiced.

Developments with respect to all these issues are discussed in more detail in Appendix 5. 


\section{POTENTIAL MAGNITUDE OF GREENHOUSE GAS ABATEMENT FROM CONTROLLED LANDFILLING FOR THE UNITED STATES}

Controlled landfilling could both increase US landfill gas energy recovery, and significantly reduce US greenhouse gas emissions. Uncertainties are inherent in any analysis of benefits. Nonetheless educated estimates are possible regarding additional energy and greenhouse gas emission reduction that might result from controlled landfilling in the United States. Such estimates are developed below

The estimate of potential emission abatement here starts with a simple assumption: under the influence of a combination of drivers, controlled landfilling become an approach of choice for landfilling a large fraction, approximately $80 \%$ of US waste. Driving forces exist that, if actively pursued, should result in this use level. These include (a) renewable energy and landfill gas encouragement through monetary incentives (b) impetus from electricity generators and Public Utilities Commissions, as well as US utility actions to reduce greenhouse gas emissions and (c) Regulatory actions--including codes addressing both greenhouse gases and other pollutants such as air pollutants (as with New Source Performance Standards as well as the Climate Change Action Plan Action item 34) and (d) salable credits for emissions.

Potential electric generation and fugitive methane emissions judged likely under NSPS rules are shown in Box 6 . These provide a standard for comparison of the situation where controlled landfilling is widely applied, compared to "business as usual", with all waste conventionally landfilled and gas collected under NSPS rules. Waste placement in US landfills is assumed to be 160 million tons/year. A total of 104 million tons of waste (i.e. $65 \%$ of US waste) is assumed to be subject to control under NSPS rules.

In box 6, for landfills requiring NSPS controls by VOC/size criteria under the clean air act, the same assumed kinetics, gas yield, recovery, and fugitive emissions are used as earlier throughout this report. With these "best" modern procedures, under NSPS rules, $8 \%$ of total methane will be generated before extraction begins and/or final cover is applied, and $4 \%$ of this will be extracted. The next $80.7 \%$ of methane is generated during the "extraction phase" during the period up to 30 years postclosure while an extraction system is active. With no incentives, LFG is assumed extracted with $75 \%$ efficiency. The final $11.3 \%$ of methane is generated at low rates after 30 years or more, in the "tailing" phase and most escapes to the atmosphere. Altogether with no incentives and "business as usual" operation $34.5 \%$ of methane generated escapes from such landfills. (Note the estimate of $34.5 \%$ fugitive emission in a sample calculation earlier.) For the balance of US waste, having no controls, all methane is emitted to the atmosphere, 


\section{Box 6}

\section{Estimated future methane recovery electricity generation and equivalent $\mathrm{CO}_{2}$ abatement for US waste stream--likely under current NSPS rules}

Amount of US waste $=160$ million US tons/year

Fraction/amount of US waste with methane recovery ultimately mandated under NSPS: $65 \%$ of 160 million tons/year $=104$ million tons/year

Waste without controls $=(160-104)$ million tons $=56$ million tons

Default methane yield $=1.4 \mathrm{ft} 3 / \mathrm{lb} .(2.8 \mathrm{MCF}$ per U. S. ton $)$

Total methane generated (long-term steady state) $=2.912 \times 10^{8} \mathrm{MCF} / \mathrm{yr}$

Total methane recovered $=64.5 \% \times 2.912 \times 10^{11}=1.878 \times 10^{8} \mathrm{MCF} / \mathrm{year}$

Total electricity potential if $80 \%$ of methane is used for electricity generation at 10,000 $\mathrm{Btu}=10 \mathrm{MCF} / \mathrm{kWh}:=1715 \mathrm{MWe}$ (time average) or $15.03 \times 10^{6} \mathrm{MWh} /$ year

Total carbon offsets from electricity generation $=13.5 \times 10^{6}$ million tonnes $/$ year (at 0.9 tonne fossil $\mathrm{CO}_{2}$ /[delivered $\mathrm{MWh}$ ])

Total fugitive methane emissions $=0.345 \times 2800 \times 104$ million tons waste $+2800 \times 56$ million tons waste $=100464 \mathrm{MCF}+156800 \mathrm{MCF}=257264 \times 106 \mathrm{MCF}$

Total $\mathrm{CO}_{2}$ equivalents of fugitive methane emissions $=257264 \times 106 \mathrm{MCF} \times 0.4$ tonne $/ \mathrm{MCF}=102905 \mathrm{MCF}$

Greenhouse gas emission reductions and offsets that would result from application of controlled landfilling are derived in Box 7 . These assumptions also require discussion. The rather intricate rules governing landfill gas recovery were summarized earlier. The two situations considered are (1) Those landfills requiring NSPS controls by size and VOC emission criteria under the Federal Clean Air Act and (2) those landfills that would escape controls under present criteria, but for which a combination of energy incentives and other factors (regulatory control) would facilitate controlled landfilling, thus mitigating their emissions as well. It is assumed below that controlled landfilling is applied to the $65 \%$ of US waste (104 million US tons) that would otherwise have NSPS controls, and an additional 15\% (24 million tons of waste) that would otherwise have no controls. 
With controlled landfilling, yield rises (to 1.8 cubic feet per pound as stated earlier) and collection will become highly efficient. Here as earlier in this report it is assumed that the efficient collection is such that $3.488 \mathrm{MCF}$ are recovered out of a potential total of 3.6 $\mathrm{MCF} /$ ton. With respect to fugitive emissions, $30.5 \%$ more of generated methane that would be emitted if the landfill were conventional and under NSPS rules is instead collected. (This is because (a) there can be complete gas recovery once cover is installed and (b) "tailing" emissions after 30 years no longer occur since generation is completed much sooner.) Calculations in box 7 show that emissions of an additional 2.9 million tonnes ( 35.5 million tonnes +25.8 million tonnes) $/ 21$ of generated methane would be abated from landfills with these assumptions. Note that this 2.9 million tons of methane is additional, over and above the 3 million tonnes of generated methane that would be recovered under the CAA/NSPS. In other words, credit is not included for recovery that would occur anyway under new rules.

The landfills for which controls would be required, and for which controlled rather than conventional landfilling improves recovery efficiency are assumed to receive a total of 104 million tons of waste ( $65 \%$ of US total waste).

A second category of landfills includes both those below 2.5 million tons total design capacity, or those, even when total design capacity is over 2.5 million tons, will require no collection controls because of below threshold $(50 \mathrm{Mg})$ VOC emissions. Numerous such large "VOC-clean" landfills are now being documented with capacity up to 5 million tons or more (Walsh, 1997, Hill, 1996). Controlled landfilling would realize energy recovery and mitigate emissions with most of these "VOC-clean" sites. Even at less than 2.5 million tons landfill sizes, none having to control methane at all under the CAA/NSPS, there is still substantial potential. It must be recognized that each 1 million tons of waste represent about 30-35 megawatt-years of power generation potential by calculations herein. Thus controlled landfilling at smaller and "exempt" landfills would realize substantial benefit as well. For this latter category (both types of landfills discussed, controlled and uncontrolled) the recovery changes from zero (since not required under law) to $\approx 96 \%$. The landfills in this category that would otherwise be emitters are assumed to receive 24 million tons of waste (15\% of US waste. Note the waste in this and the earlier category totals $80 \%$ of US landfilled waste)

For present landfills the methane is assumed generated at 1.4 cubic feet per pound waste. With this generation value and earlier assumptions the $\mathrm{CO}_{2}$ equivalent emission abated is straightforwardly calculated as summarized in Box 7. The accepted value of methane's global warming potential by the Intergovernmental Panel on Climate Change (IPCC) is 21fold that of $\mathrm{CO}_{2}$ on a weight basis (100 year time horizon), from which the equivalent $\mathrm{CO}_{2}$ emission abatement from methane mitigation (not considering other factors) is also readily calculated as shown in the box. Assuming the energy use of the methane rises to $80 \%$, the long-term steady-state electricity generation potential is readily calculated at $\approx 4000 \mathrm{MWe}$.

Topical Report: Greenhouse Cost-effectiveness of Controlled Landfilling Contract DE-AC26 98FT40422 Page 75 
(Part of the electricity can alternately be other energy use, but any energy use displacing fossil fuel gives climate benefit close to that calculated for electricity)

\section{Fossil fuel displacement}

One issue that needs to be discussed is the assumed amount of fossil fuel displaced through use of landfill methane. The type of primary energy conserved depends on what would otherwise be used to generate electricity or heat--whether fossil energy (i. e. coal, oil, gas), or whether a renewable source such as wind or hydro--or whether nuclear is used by a utility. However a central factor is that hydroelectric and nuclear are normally used to fullest possible extents, and other renewables will be minor and often fully exploited as well (like wind) in the energy mix. Consequently supplemental or "swing" fuels--which are used to make up the total generation needed by the electricity or other energy application will be nearly all fossil (probably $95+\%$ ) These swing fuels are those whose use is reduced by biogas-based electricity generation. On this basis the fossil energy conserved through landfill gas fueled electricity generation has been assumed throughout this report at a representative fossil fuel heat rate of $10,000 \mathrm{Btu} / \mathrm{kWh}$.

The final factor in greenhouse gas abatement is which fossil $\mathrm{CO}_{2}$ is displaced ${ }^{19}$. With US generation divided as at present between natural gas and coal, fossil fuels' average hydrogen to carbon ratios approximate that of oil and fossil $\mathrm{CO}_{2}$ emission will be reduced by about 1 US ton $\mathrm{CO}_{2}(0.9$ tonnes) per $\mathrm{MWH}$ generated. This figure has likewise been used throughout this report. With this additional assumption the potential $\mathrm{CO}_{2}$ equivalent abatement is as shown in Box 7.

Altogether, the reduction in equivalent fossil $\mathrm{CO}_{2}$ emissions in the illustration is 80 million tons per year. Many assumptions could be varied and estimated $\mathrm{CO}_{2}$ equivalent reductions anywhere between 50 and 100 million tons/year. For example, in terms of sensitivity with assumptions above, each 10 million tons of US waste shifted from conventional NSPS control to controlled landfilling results in 4.6 million more tonnes of annual $\mathrm{CO}_{2}$ equivalent abatement. For waste without controls, controlled landfilling of each additional 10 million tons gives long-term benefit of 13.3 million tonnes $\mathrm{CO}_{2}$ equivalent annually.

In any event, major additional greenhouse gas mitigation benefit-at least many tens of millions of tonnes of equivalent $\mathrm{CO}_{2}$ abatement-can result from wide application of controlled landfilling.

19 (the "swing" fuel is nearly always fossil that is displaced by a renewable)

Topical Report: Greenhouse Cost-effectiveness of Controlled Landfilling

Contract DE-AC26 98FT40422 Page 76 


\section{Box 7}

\section{US greenhouse gas mitigation potential $\left(\mathrm{CO}_{2}\right.$ equivalents) with application of controlled landfilling:}

(See full text for further discussion)

$\mathrm{CO}_{2}$ equivalent emission reduction from controlled landfilling of 104 million tons $\mathrm{MSW}$ :

$(0.345-0.040=0.305$ fractional abatement increase $) \times 2.8 \mathrm{MCF} /$ ton $\times 104$ million tons $\mathrm{x}$ 0.4 tonnes $/ \mathrm{MCF}=35.5$ million tonnes

$+$

Methane emission reduction from 24 million tons of otherwise uncontrolled waste:

$1.0-0.04=0.96$ fractional abatement increase $\times 2.8 \mathrm{MCF} /$ ton $\times 24$ million tons $\times 0.4$ tonnes $\mathrm{CO}_{2} / \mathrm{MCF}=25.8$ million tonnes

$+$

Fossil $\mathrm{CO}_{2}$ offsets: $\mathrm{MWe}$ from controlled landfilling $=128$ million tons $\times 3.488 \mathrm{MCF} /$ ton $\mathrm{x}$ $0.1 \mathrm{MCF} / \mathrm{MWe}$ x $0.8 \mathrm{fractional}$ use x $1 / 8760 \mathrm{hr}$./year $=35.7 \mathrm{MWh} /$ year

net gain vs. NSPS control $=35.7$ million $\mathrm{MWh} /$ year $-15.03 \mathrm{MWh} /$ year or 20.67 million $M W h / y e a r$

$\mathrm{CO}_{2}$ offset from LFG energy use $=0.9 \times 20.67 \times 106 \mathrm{MW}$.year $=18.6$ million tonnes.

Total $\mathrm{CO}_{2}$ equivalent offsets (million tonnes/year) $=25.8+35.7+18.6=80.1$ million tonnes/year

\section{CONCLUSIONS}

The cost effectiveness of "controlled landfilling" has been examined for reducing emissions of methane, a potent greenhouse gas, from US solid waste landfills. Costs for greenhouse gas reduction for a "typical" base case 1000 TPD landfill appear quite attractive by extant standards, ranging from $\$ 1$ to $\$ 5 /$ tonne (metric ton) $\mathrm{CO}_{2}$. The marginal controlled 
landfilling cost per unit $\mathrm{CO}_{2}$ abatement is attractive whether the comparison basis is a landfill with no controls, or where the basis for comparison is a landfill where less-efficient conventional controls under the New Source Performance Standards are applied. For the former case, costs range from $\$ 1$ to $\$ 3 /$ tonne at discount rates of 0 to $15 \%$ APR. In the latter case in comparison to conventional controls, the marginal cost per marginal gas collected is $\$ 2$ to $5 /$ ton. These costs are conservatively derived in that all incremental costs of the controlled landfilling process were fully assigned to greenhouse gas abatement. These costs equate to roughly $\$ 3-14 /$ tonne $\mathrm{CO}_{2}$ carbon abated for the base case, an order of magnitude-or more--lower than marginal carbon abatement costs by most other means as summarized in recent references.

Significant landfill-to-landfill differences will exist in important variables which directly affect $\mathrm{CO}_{2}$ abatement costs. Trends in $\mathrm{CO}_{2}$ abatement cost include (a) cost falling roughly as the inverse of landfill depth and (b) costs roughly doubling if extra base lining containment is required as a condition of controlled landfilling as opposed to conventional landfill practice. Removal of easily separated inert materials can give modest cost benefits of roughly $10-20 \%$.

If differential costs of controlled landfilling are--instead--assigned to methane energy recovery, the marginal cost per unit extra methane recovered are reasonable, given landfill methane characteristics as an energy source. For the base case controlled landfill compared to the absence of controls, the marginal cost ranges from about $\$ 0.40 /(\mathrm{MCF}=$ $\mathrm{mmBtu} \cong \mathrm{Gj})$ to $0.75 /(\mathrm{MCF}=\mathrm{mmBtu})$. Compared to NSPS controls, the marginal cost of methane actually falls as incremental extra expenditure leads to much more rapid recovery of greater quantities of methane.

An intricate and changing regulatory and policy situation has been reviewed that relates to controlled landfilling in several ways. Although there are variations from state to state, a SWANA survey shows that state regulators are coming to accept bioreactor and controlled landfills as viable waste management options. Additional constraints, principally additional base lining, that will pose additional costs, are being required in some states.

In terms of policy, there is strong and explicit federal support in the Climate Change Action Plan for the use of controlled landfilling for addressing climate change. Other trends should aid implementation of controlled landfilling. These include present movement toward approaches, such as renewable portfolio standards, giving extra revenue necessary to maintain renewable energy uses including methane from controlled landfills in the present competitive energy market. There is movement toward greenhouse gas abatement credits, which could be of substantial help because of methane's greenhouse potency. Communications with regulators by the present author and others in SWANA are ongoing, in order that the most rational regulatory treatment of controlled landfilling can develop. 
The potential of greenhouse gas abatement through controlled landfilling has been examined for the US as a whole. An example calculation has shown the $\mathrm{CO}_{2}$ abatement potential to be about 80 million tons/year compared to "business as usual" without controlled landfilling. Given the uncertainties attending any such estimates, this simply indicates that abatement of somewhere between 50 and 100 million tonnes of $\mathrm{CO}_{2}$ per year is possible. This is very substantial abatement, amounting to about 1 to $2 \%$ of total US energy-related $\mathrm{CO}_{2}$ emissions, or about $5-10 \%$ of the fossil $\mathrm{CO}_{2}$ emissions from US coalfired power plants.

In final summary, controlled landfilling offers an attractive and cost effective mechanism for the United States to meet significant portions of its greenhouse gas emission reduction targets. Additional work to continue the field demonstration test, and initiate tests at increased scale, appears justified and is proposed in conjunction with this report.

\section{REFERENCES}

Ashare, E. D. L. Wise, and R L Wentworth. 1977 Fuel Gas Production from Animal Residue. Dynatech R/D Company. U. S. Department of Energy/NTIS

Augenstein D. C. and J. Pacey, 1991 Landfill Methane Models. Proceedings of SWANA 1991 Annual International Solid Waste Conference. Solid Waste Association of North America (SWANA) Silver Spring, MD.

Augenstein, D. R. Yazdani, R. Moore and K. Dahl. 1997 Yolo County Controlled Landfill Demonstration Project. Proceedings, 2d SWANA Landfill Symposium, pp. 3-39. SWANA, Silver Spring MD).

Augenstein, D., R. Yazdani, K. Dahl and R. Moore 1998 Yolo County Controlled landfill Demonstration. Proceedings, California Integrated Waste Management Board Symposium on Landfill Gas Assessment and Management.

Augenstein, D. 1992 The greenhouse effect and US Landfill Methane. Global Environmental Change, p. 311-328 1992

CARB (California Air Resources Board) 1990 SCM (Suggested Control Measure for Landfill Gas Emissions); California Air Resources Board; California Air Pollution Control Officers Association Technical Review Group. September

EMCON Associates 1982 Methane Generation and Recovery from Landfills. Ann Arbor Science, Ann Arbor Michigan). 
Energy Information Administration, U. S. Department of Energy, 1998 Impacts of the Kyoto Protocol on U. S. Energy Markets and Economic Activity. 1998 Report SR/OIAF/98-03. October)

W. D. Gauntlett. EPRI TR-101068. 1992. Survey of Landfill Gas Generation Potential: 2 MW Molten Carbonate Fuel Cell. Electric Power Research Institute Palo Alto, CA.)

Halvadakis, C. P., A. O. Robertson and J. Leckie. 1983 Landfill Methanogenesis: Literature Review and Critique. Stanford University Civil Engineering Report no, 271. Available from NTIS.

Hartz, K. E. , R. E. Klink and R. K. Ham 1982 Temperature Effects: Methane Generation by Landfill Samples. Journal of Environmental Engineering ASCE

Koerner, G, R., M. Koerner and J. P. Martin. 1993 Field Performance of Leachate Collection Systems and Design Implications. Proceedings of 31st Annual SWANA Conference, San Jose, CA.)

Kraemer, T. H. H. Herbig, and S. Cordery-Potter. 1993 Gas Collection Beneath a Geomembrane Final Cover System. Proceedings, 16th Annual Landfill Gas Symposium, SWANA, Silver Spring MD. also

Lee, G. F. and A. Jones 1990 Managed Fermentation and Leaching. Biocycle, pp 78-83. March

Leszkiewicz, J. and P. Macaulay 1995 Municipal Solid Waste Landfill Bioreactor Technology Closure and Post Closure. Proceedings, U. S. EPA Bioreactor Landfill Conference, Wilmington, DE. March

Peer, R. D. L. Epperson, D. L. Campbell and P. Von Brock 1992 Development of an Empirical Model for methane Emissions from Landfills. US EPA Office of Research and Development, Washington, D. C.

SRI International, 1991 Data Summary of Municipal Solid Waste Management Alternatives, USDOE National Renewable Energy Laboratory, Golden Colorado.

SWANA Bioreactor Landfill Committee. 1998. The Bioreactor Landfill: An Innovation in Solid Waste Management. Work in preparation. July 1998 draft publicly available in Proceedings, Third Annual Landfill Symposium. Solid Waste Association of North America (SWANA) Silver Spring, Maryland..

Tchobanoglous, G., H. Theisen and S. Vigil Integrated Solid Waste Management McGraw-Hill, New York 1993) 
U. S. EPA, 1993a. Opportunities to Reduce Anthropogenic Methane Emissions in the United States EPA 430-R-93-012

Vogt, W. G. and D. Augenstein. 1997 Comparison of Models for Predicting Landfill Methane Recovery. Final Report prepared by SCS Engineers and IEM, Inc. for the Solid Waste Association of North America (SWANA). Available from SWANA, Silver Spring, $\mathrm{MD}$

Walsh, J J 1997 NSPS Tier II Testing. Initial Results now Complete. Presentation at SWANA's 20th Annual Landfill Gas Symposium, SWANA, Silver Spring Maryland. Paper available from $\mathrm{J} J$ Walsh, SCS Engineers, Covington, $\mathrm{Ky}$.) 


\section{APPENDICES}

\section{Appendix 1}

Discounted value of $\mathrm{CO} 2$ emission from uncontrolled, NSPS and controlled landfills

\begin{tabular}{|c|c|c|c|c|c|c|c|c|c|}
\hline \multirow[t]{2}{*}{ Year } & \multicolumn{4}{|c|}{$\begin{array}{l}\text { landfill, no control } \\
\mathrm{CO} 2 \text { tonnes, given discounts }\end{array}$} & \multicolumn{3}{|c|}{ NSPS Landfill } & \multicolumn{2}{|c|}{$\begin{array}{l}\text { Controlled landfill } \\
\mathrm{CO} 2 \text { tonnes at discounts } \\
=07 d=0.15\end{array}$} \\
\hline & $d=0$ & $\mathrm{~d}=0.0$ & $\mathrm{~d}=0.15$ & $d=0$ & $d=0.07$ & $\mathrm{~d}=0.15$ & $5 \mathrm{~d}=0$ & & $=0.15$ \\
\hline 2 & 44800 & 38748 & 32368 & & 22400 & 19374 & 16184 & 22400 & $19374 \quad 16184$ \\
\hline 3 & 34830 & 28016 & 21391 & & 8708 & 7004 & 5348 & & negligible past \\
\hline 4 & 32476 & 24294 & 16953 & & 8119 & 6073 & 4238 & & year 1 \\
\hline 5 & 30280 & 21065 & 13435 & & 7570 & 5266 & 3359 & & (see text) \\
\hline 6 & 28233 & 18266 & 10648 & & 7058 & 4566 & 2855 & & \\
\hline 7 & 26324 & 15839 & 8439 & & 6581 & 3960 & 2110 & & \\
\hline 8 & 22855 & 11894 & 5293 & & 6136 & 3434 & 1672 & & \\
\hline 9 & 22855 & 11894 & 5293 & & 5721 & 2977 & 1325 & & \\
\hline 10 & 21388 & 10351 & 4211 & & 5335 & 2582 & 1050 & & \\
\hline 11 & 19896 & 8955 & 3329 & & 4974 & 2239 & 832 & & \\
\hline 12 & 18550 & 7765 & 2639 & & 4638 & 1941 & 660 & & \\
\hline 13 & 17296 & 6733 & 2091 & & 4324 & 1683 & 523 & & \\
\hline 14 & 16127 & 5389 & 1657 & & 4032 & 1460 & 414 & & \\
\hline 15 & 15036 & 5062 & 1313 & & 3759 & 1266 & 328 & & \\
\hline 16 & 14020 & 4390 & 1041 & & 3505 & 1098 & 260 & & \\
\hline 17 & 13072 & 3807 & 825 & & 3268 & 952 & 206 & & \\
\hline 18 & 12188 & 3301 & 654 & & 3047 & 825 & 163 & & \\
\hline 19 & 11394 & 2869 & 520 & & 2841 & 716 & 130 & & \\
\hline 20 & 10596 & 2482 & 411 & & 2649 & 620 & 103 & & \\
\hline 21 & 9880 & 2152 & 326 & & 2470 & 538 & 81 & & \\
\hline 22 & 9212 & 1866 & 258 & & 2303 & 467 & 64 & & \\
\hline 23 & 8389 & 1580 & 200 & & 2147 & 405 & 51 & & \\
\hline 24 & 8008 & 1403 & 128 & & 1867 & 304 & 32 & & \\
\hline 26 & 6492 & 1055 & 102 & & 1741 & 264 & 25 & & \\
\hline 27 & 6492 & 915 & 81 & s & 1623 & 229 & 20 & & \\
\hline 28 & 6053 & 793 & 64 & & 1513 & 198 & 16 & & \\
\hline 29 & 5643 & 688 & 51 & & 1411 & 172 & 13 & & \\
\hline 30 & 5262 & 597 & 40 & & 1315 & 149 & 10 & & \\
\hline 31 & 4906 & 517 & 32 & & 1227 & 129 & 8 & & \\
\hline 32 & 4574 & 449 & 25 & & 1144 & 112 & 6 & & \\
\hline subtot 4 & 96576 & 246642 & 135375 & 135518 & 71354 & 42127 & & & \\
\hline past 32 & 63424 & $\underline{3262}$ & $\underline{115}$ & & 16921 & 814 & $\underline{28}$ & & \\
\hline Tot. & 560000 & 249904 & 135490 & 152439 & 72168 & 42155 & & & \\
\hline CLF & 537600 & 227268 & 119756 & 130039 & 52794 & 25971 & & & \\
\hline
\end{tabular}

Topical Report: Greenhouse Cost-effectiveness of Controlled Landfilling Contract DE-AC26 98FT40422 Page 82 


\section{Appendix 2}

Discounted value analysis of $\mathrm{CO} 2$ offsets $^{*}$ : controlled and NSPS landfills

$\mathrm{CO} 2$ offset present value, tonnes Controlled Landfill

at given discount rates

\begin{tabular}{|c|c|c|c|}
\hline Year & $d=0$ & \multicolumn{2}{|c|}{$d=7 \% d=15 \%$} \\
\hline 2 & 4032 & 3487 & 2913 \\
\hline 3 & 24307 & 20030 & 15755 \\
\hline 4 & 24307 & 18675 & 13561 \\
\hline 5 & 24307 & 17412 & 11672 \\
\hline 6 & 24307 & 16235 & 10046 \\
\hline 7 & 24307 & 15140 & 8647 \\
\hline 8 & $\overline{125568}$ & $\overline{88482}$ & $\overline{58275}$ \\
\hline 9 & & & \\
\hline 10 & & & \\
\hline 11 & & & \\
\hline 12 & & & \\
\hline 13 & & & \\
\hline 14 & & & \\
\hline 15 & & & \\
\hline 16 & & & \\
\hline 17 & & & \\
\hline 18 & & & \\
\hline 19 & & & \\
\hline 20 & & & \\
\hline 21 & & & \\
\hline 22 & & & \\
\hline 23 & & & \\
\hline 24 & & & \\
\hline 25 & & & \\
\hline 26 & & & \\
\hline 27 & & & \\
\hline 28 & & & \\
\hline 29 & & & \\
\hline 30 & & & \\
\hline 31 & & & \\
\hline 32 & & & \\
\hline
\end{tabular}

$\mathrm{CO} 2$ offset present value tonnes, NSPS landfill at given discount rates $\mathrm{d}$

$d=0 \quad d=7 \% \quad d=15 \%$

$\begin{array}{lll}4032 & 3487 & 2913.1\end{array}$

$\begin{array}{lll}4702.1 & 3782.2 & 2887.7\end{array}$

$\begin{array}{llll}4384.2 & 3274.6 & 2288.6\end{array}$

$\begin{array}{cccc}4087.8 & 2843.8 & 1813.8\end{array}$

$\begin{array}{llll}3811.5 & 2466.0 & 1437.5\end{array}$

$\begin{array}{lll}3553.8 & 2138.3 & 1139.3\end{array}$

$\begin{array}{lll}3313.5 & 1854.2 & 902.9\end{array}$

$\begin{array}{llll}3089.5 & 1607.8 & 715.6\end{array}$

$\begin{array}{lll}2880.6 & 1394.6 & 567.1\end{array}$

$\begin{array}{lll}2685.9 & 1208.9 & 449.5\end{array}$

$\begin{array}{lll}2504.3 & 1048.3 & 356.2\end{array}$

$\begin{array}{lll}2335.0 & 909.0 & 282.3\end{array}$

$\begin{array}{lll}2177.1 & 788.2 & 223.7\end{array}$

$\begin{array}{lll}2030.0 & 683.5 & 177.3\end{array}$

$\begin{array}{lll}1892.7 & 592.7 & 140.5\end{array}$

$\begin{array}{lll}1764.8 & 513.9 & 111.4\end{array}$

$\begin{array}{lll}1645.4 & 445.6 & 88.3\end{array}$

$\begin{array}{lll}1534.2 & 386.4 & 70.0\end{array}$

$\begin{array}{lll}1430.5 & 335 & 55.4\end{array}$

$\begin{array}{lll}1333.8 & 290.6 & 43.9\end{array}$

$\begin{array}{lll}1243.6 & 251.9 & 34.8\end{array}$

$\begin{array}{lll}1159.5 & 218.5 & 27.6\end{array}$

$1081.1 \quad 189.4 \quad 21.9$

$\begin{array}{lll}1008.0 & 164.3 & 17.3\end{array}$

$939.9 \quad 142.4,13.7$

$876.3 \quad 123.5 \quad 10.9$

$\begin{array}{lll}817.1 & 107.1 & 8.6\end{array}$

$\begin{array}{lll}761.9 & 92.9 & 6.8\end{array}$

$\begin{array}{lll}710.3 & 80.5 & 5.4\end{array}$

$\begin{array}{lll}662.3 & 69.8 & 4.3\end{array}$

$\underline{617.6 \quad 60.6 \quad \underline{3.4}}$

$6 5 0 6 6 . 3 \quad 3 \longdiv { 1 5 5 6 . 6 } \quad 1 6 8 1 8 . 8$

controlled landfill

"adrantage" $\quad d=0 \quad d=7 \% d=15 \%$

$\begin{array}{llll}\text { vs. no controls } & 125568 & 88482 & 58275\end{array}$

vs. NSPS landfill $\quad 60502 \quad 56926 \quad 41456$

*At $80 \%$ energy use and $\mathrm{CO} 2$ displacement ratio in text

Topical Report: Greenhouse Cost-effectiveness of Controlled Landfilling Contract DE-AC26 98FT40422 Page 83 


\section{Appendix 3}

Calculation of present worth (debit) of controlled landfill operating cost--see text

$\begin{array}{llll}\text { year } & \begin{array}{l}\mathrm{d}=\text { discount rate }=0 \\ \text { (no discount) }\end{array} & \mathrm{d}=7 \% \text { APR } & \mathrm{d}=15 \% \mathrm{APR} \\ 2 & \$ 40,000 & \$ 34,596 & \$ 28,900 \\ 3 & \$ 40,000 & \$ 32,174 & \$ 24,565 \\ 4 & \$ 40,000 & \$ 29,922 & \$ 20,880 \\ 5 & \$ 40,000 & \$ 27,827 & \$ 17,748 \\ 6 & \$ 40,000 & \$ 25,880 & \$ 15,086 \\ 7 & \$ 40,000 & \$ 24,068 & \$ 12,823 \\ \text { TOTAL } \$ & \$ 240,000 & \$ 174,467 & \$ 120,002\end{array}$




\section{Appendix 4}

Present Worth of Methane from Controlled and NSPS Landfills

Discounted Methane Recovery, MCF from NSPS Landfill

$\begin{array}{lrrr}\text { t, years } \mathrm{d}=0 & \mathrm{~d}=7 \% \text { APR } & \mathrm{d}=15 \% \\ 2 & 42000 & 36326 & 30345 \\ 3 & 65308 & 52531 & 40107 \\ 4 & 60893 & 45551 & 31785 \\ 5 & 56776 & 39498 & 26692 \\ 6 & 52937 & 34250 & 19965 \\ 7 & 49358 & 29699 & 15823 \\ 8 & 46021 & 25753 & 12541 \\ 9 & 42911 & 22331 & 9939 \\ 10 & 40010 & 19364 & 7876 \\ 11 & 37304 & 16791 & 6242 \\ 12 & 34783 & 14560 & 4948 \\ 13 & 32431 & 12625 & 3921 \\ 14 & 30238 & 10948 & 3107 \\ 15 & 28194 & 9493 & 2463 \\ 16 & 26288 & 8232 & 1952 \\ 17 & 24511 & 7138 & 1547 \\ 18 & 22854 & 6190 & 1226 \\ 19 & 21309 & 5367 & 972 \\ 20 & 19868 & 4654 & 770 \\ 21 & 18525 & 4035 & 610 \\ 22 & 17272 & 3500 & 484 \\ 23 & 16105 & 3035 & 383 \\ 24 & 15016 & 2631 & 101 \\ 25 & 14001 & 2281 & 241 \\ 26 & 13054 & 1979 & 191 \\ 27 & 12172 & 1715 & 151 \\ 28 & 11349 & 1487 & 120 \\ 29 & 10582 & 1290 & 95 \\ 30 & 9866 & 1118 & 75 \\ 31 & 9200 & 970 & 60 \\ 32 & 8577 & 841 & 47 \\ \text { Total } & 1,007,630 & 423480 & 224985\end{array}$

Discounted Methane Recovery MCF from Controlled Landfill

$\begin{array}{rrr}\mathrm{d}=0 & \mathrm{~d}=7 \% \text { APR } & \mathrm{d}=15 \% \\ 56000 & 48434 & 40460 \\ 337600 & 271550 & 207329 \\ 337600 & 252542 & 176229 \\ 337600 & 234864 & 149795 \\ 337600 & 218424 & 127325 \\ \underline{337600} & \underline{203134} & \underline{108227} \\ 1,744,000 & 1,228,948 & 809,365\end{array}$

Notes to Appendix 4 
1. Total methane generation potential of conventional and NSPS landfill is 500,000 tons $\times 2.8$ $\mathrm{MCF} /$ ton $=1,400,000 \mathrm{MCF}$. Of this methane, $4 \%$ or $56,000 \mathrm{MCF}$ is collected (from base layer) before controls start. (Another $4 \%$ is fugitive, escaping to the atmosphere)

2. The balance of methane, $92 \% \times 1,400,000=1,288,000 \mathrm{MCF}$ is generated in year 3 and thereafter by a first order model $\mathrm{Gm}=\mathrm{k}_{1} \mathrm{e}^{-\mathrm{k}_{2} \mathrm{t}}$. This generation begins in year 3 in which generation is $87077 \mathrm{MCF}$. Any generation in year $\mathrm{t}$ is given by $\mathrm{Gm}=107425(.932394)^{\mathrm{t}}$

3. Recovery of methane Rm from the NSPS landfill in year $t$ is $75 \%$ of $\mathrm{Gm}$ or $80569(.932394)^{t}$ The total recovery from the NSPS landfill is

$$
\mathbf{t}=32
$$

$80569 \sum(932394)^{t}$

$$
\mathrm{t}=3,1
$$

4. Total generation potential of the controlled landfill is 3.6 MCF/ton. After generation during setup (112,000MCF as with the NSPS; $50 \%$ or 56,000 MCF recovered) the remaining potential of $1688000 \mathrm{MCF}$ is recovered at $337600 \mathrm{MCF} /$ year in years 3 through 7 inclusive.

5. Value of methane is realized at the end of year $t$. Present worth is summed in the table of appendix 2 .

END APPENDLX 4 


\section{Appendix 5.}

\section{Additional controlled landfilling regulatory/ policy issues: Renewables treatments in restructuring, greenhouse emission credits, and incremental containment}

To preface this appendix, the widely publicized "landfill shortage" of the early 1990's has disappeared. There is a current surplus of capacity. This has resulted in falling landfill gate fees. It has, importantly, lessened the value of some controlled landfill benefits such as the increased air space which can come from decomposing more waste more rapidly. At the same time landfill operators need to receive incremental revenue to justify controlled landfilling's incremental cost. The developing situations in all of these areas merit discussion.

\section{Landfill Gas Energy uses and Electricity Restructuring}

\section{Effects of energy revenue}

Although landfill gas is used for energy at over $150 \mathrm{U}$. S. sites, a number of drawbacks limit its use. These include (a) levels of contaminants, (b) in the past, unpredictability of gas energy recovery. Additional problems include (c) since more than very small amounts of storage are impractical, it must be used as it is generated. (d) Electric generation, which can make use of landfill gas as it is generated, occurs at scales which are much smaller (1-10MWe) than typify other generating technologies. (e) There are additional barriers in terms of emission limits. particularly that of NOx from internal combustion engines which are otherwise highly attractive.

Current energy markets, particularly with increased competition in electricity restructuring (70+ percent of landfill gas that is used for energy use is used to fuel electricity generation) are not generally favorable. It is estimated that much (over half) of recovered landfill gas, even when recovery is compelled by clean air act rules, and gas is thus "free", goes unused ${ }^{20}$. Altogether, at sites where more than $1 \mathrm{MWe}$ could be generated, only about ' $10-15 \%$ of total US landfill gas that is generated is used. (estimates from EPRI, 1993, EPA, 1993 and Augenstein et. al., 1994)

All of these problems can be overcome and fractional use increased if there is sufficient energy revenue. The situation is discussed further in references including Augenstein, 1997 (Augenstein, D. 1997 Economics, Externalities and Landfill Gas Energy. Proceedings, Sixth International Landfill Symposium, Sardinia, Italy. October)

20 Personal communications, S. A. Thorneloe and J. Pacey. Also Augenstein, D. 1997 Economics, Externalities and Landfill gas energy. Proceedings, Sixth Annual Landfill Gas Symposium, Sardinia. Italy. 
The implicit assumption in greenhouse gas abatement analyses of this report is that there will be significant energy use of the gas. However in view of costs, income from energy values of the recovered gas may net out to near zero. For this reason no revenue from energy was assumed in estimating cost of greenhouse gas abatement.

Although this is often the case it need not necessarily be so. Nearly all (99+\%) of landfill gas derives from photosynthetically fixed material (paper, food wastes etc.). Landfill gas is, thus, renewable energy. Various programs have been applied in the past or present or else proposed to foster renewable energy and there is significant hope in this area.. For example the administration-supported renewable electricity portfolio standard, in one version or another, could lead to several percent of electricity being generated from renewable resources within the next decade.

The "market clearing" price premium to ensure desired use of other renewables, principally wind and wood, in a competitive market, are considered to lie in the range of $1-4$ cents/kWh for electricity depending on renewable, site, and other factors. Each 1 cent per $\mathrm{kWh}$ works out to about $\$ 1.00$ more revenue available per MCF or mmBtu. A large part of extra revenue could be available to support controlled landfilling. Note also that there are several ways in which methane revenue can be enhanced including direct sale price premium paid by utilities [portfolio standard and voluntary "green" programs], and tax credits. Problems such as California's inadequate financing $(0.2 \mathrm{cents} / \mathrm{kWh})$ must be circumvented by careful attention to details of any proposed restructuring.

\section{Emissions Abatement Credits}

Monetary rewards for greenhouse gas reduction could help advance the implementation of controlled landfilling As an example of potential benefit, a credit for equivalent fossil $\mathrm{CO}_{2}$ abatement of $\$ 5 /$ tonne ( $\$ 14 /$ tonne fossil $\mathrm{CO}_{2}$ carbon) would provide enough benefit to propel controlled landfilling for all of the base case 1000TPD options. However despite present movement toward international agreements to limit greenhouse gas there is at present in the US no assurance of "cash in hand" for any such reduction.

Although monetary benefits for reductions are not yet in hand, a number of factors are positive and improving. The United States is now proposing an emissions trading program which will presumably result in at least some value for greenhouse emissions abatement. A large number of major corporate entities including some participants that are surprising (American Electric Power, General Motors, duPont) are recognizing greenhouse gas issues and proposing actions (though not always the same ones). Other important entities supporting greenhouse gas abatement include the Edison Electric Institute (EEI) on behalf of investor-owned utilities; the Electric Power Research Institute, EPRI is also active in research. 
The federal 1605 (b) voluntary reporting program on greenhouse gas reductions provides standard which are major steps in the right direction toward facilitating controlled landfilling. In essence, electric utilities or other landfill gas energy users can claim and bank greenhouse gas abatement credit for the landfill gas emissions prevented by energy use. With the 1605 (b) program, credits usually accrue even if gas recovery and abatement is compelled under regulations. Presumably, "banked" credits will have some value. The credits may already have value for regulated utilities which have been directed to make efforts to reduce greenhouse gases. Certain landfill gas energy companies are already banking and keeping credits.

It is also noteworthy that other entities are promoting approaches promising monetary benefits from greenhouse gas abatement and renewable energy use. These include NARUC, the National Association of Regulatory Utility Commissioners which is favoring support of renewably generated electricity. STAPPA/ALAPCO, the parent organization of State Air Pollution Prevention Associations and Association of Local Air Pollution Control Organizations ${ }^{21}$ is highly influential in state air pollution control, and is now drafting a paper on their own proposals for credits for greenhouse gas reduction.

In short, a number of entities including non-governmental and private corporations are working toward one or another approach for credits for greenhouse gas abatement. This should ultimately help to realize such credits. The technology will need to be ready when credits are ready.

3. Cost of additional base geomembrane lining/containment--is the extra containment needed?

Another issue central to controlled landfilling is regulatory--the requirement in some states or areas for additional base lining as a differential requirement for "bioreactor" including controlled, landfills.

The cost of double base lining is such as to approximately double the cost of controlled landfilling, as seen in Tables 5 and 8 . This cost has been enough to pose a deterrent to almost every operator who might otherwise consider the practice. At the same time there appear to be good arguments against need for double lining. With increasing experience and ongoing analysis several points can now be made in favor of a uniform lining standard (no differential) for controlled landfilling compared to conventional Subtitle D practice:

1. Liquid additions can be limited and controlled to give levels (weight fractions moisture) and also drainage rates which have typified lined landfills in the past (under $75 \mathrm{~cm} /$ year

21 The NARUC position statement to Congress is available on their website; Information on STAPPA/ALAPCO

Topical Report: Greenhouse Cost-effectiveness of Controlled Landfilling Contract DE-AC26 98FT40422 Page 89 
superficial liquid velocity in the successful demonstration. This flux is comparable to or less than the flux of ambient rainfall ).

2. Both from hydraulic considerations and improved design, present liquid management should minimize hazards at liquid addition levels and rates shown highly effective for methane enhancement. The federal limit of $30 \mathrm{~cm}$ (1 foot) to liquid head over the base of the landfill should be easily met with current drainage layers already

3. Pollutant loads diminish faster in leachate draining from controlled/bioreactor landfills. This is well-established from abundant scientific work. Getting rid of pollutants earlier should reduce risks.

4. Leachate will almost invariably be present to saturate base clay in both conventional and controlled landfills. The leachate saturating clay contributes most of the net liquid head. Thus, the net liquid head is very similar for both cases. The basic hydraulic argument is that, should base geomembrane break develop. any groundwater pollution threat is proportional to (net liquid head) $x$ (pollutant load) Pollutant drops in greater ratio than any possible head increase, based on dilution alone.

4. Leachate and condensate recirculation are already permitted in landfills having standard lining (federal code 40CFR258.28).

On the basis of 1-4 above, there does not seem to be any basis on which to judge that conventional landfills, which may pose more threat longer term, need less lining than controlled landfills. In essence, there should be no lining requirement differential on the basis of relative risk.

These points were developed by the present author and others, and discussed with the California Water Resources Board, a key agency (whose lead other states often follow), on November 12, 1998 in Sacramento. Two other members of a SWANA liaison committee formed to deal with this topic, John Pacey of EMCON and Ramin Yazdani of Yolo County also took part. Such effort to inform regulators will be critical in addition to technical effort, to develop process acceptance. 